UNIVERSIDADE DE SÃO PAULO

INSTITUTO DE QUÍMICA DE SÃO CARLOS

RODRIGO ROSSI DE ARAÚJO

Degradação de metilparabeno e propilparabeno pelo processo foto-Fenton solar 


\section{Degradação de metilparabeno e propilparabeno pelo processo foto-Fenton solar}

\section{Versão Original}

Dissertação apresentada ao Instituto de Química de São Carlos da Universidade de São Paulo para a obtenção do título de Mestre em Ciências

Área de Concentração: Química Analítica e Inorgânica

Orientador: Prof. Dr. Eduardo Bessa Azevedo 
Sic et simpliciter, Omnia fert Aetas. 


\section{AGRADECIMENTOS}

Agradeço primeiramente à minha família, aos meus pais Silvana e Walter, que me apoiaram desde os tempos que eu aprontava nas escolinhas quando criança até a conclusão do meu Mestrado; não foi uma jornada fácil, eu também não facilitei muitas coisas, porém serei eternamente grato por tudo que vocês me forneceram, todo suporte material e emocional, sempre depositando confiança em mim e na minha capacidade e sendo uma espécie de "pilar" para o meu sucesso.

À minha namorada, Daniela, por estar comigo em todos os momentos, me apoiando direta ou indiretamente da forma que fosse e da maneira que dava, independentemente da situação ou da gravidade do problema. Assim como meus pais, foi meu segundo "pilar” aqui em São Carlos, me aturando todo esse tempo.

Agradeço ao Prof. Dr. Eduardo Bessa Azevedo, por toda orientação, paciência, ajuda e conhecimento compartilhado, essenciais para meu crescimento pessoal e profissional no período que se estendeu o meu Mestrado.

Aos meus queridos amigos Valdinho, Doug, Tabaco, Papoula e Rafa, principalmente por terem me dado conselhos apropriados nos momentos que eu precisava, e também simplesmente por estarem aí no dia a dia, seja para conversar ou dar umas risadas e fazer nossa rotina ser mais leve.

Aos meus companheiros de laboratório Maykel, Dorado, Appa, Vanessa, Letícia, Rafa, Pininho e Ana pela companhia e por estarem sempre dispostos a ajudar quando fosse necessário.

À Prof. Dra. Eny Maria Vieira pela disponibilização do cromatógrafo para uso no meu trabalho, e a todos os alunos e técnicos do Grupo de Química Analítica Aplicada a Medicamentos e a Ecossistemas Aquáticos (IQSC/USP).

Aos professores, alunos e técnicos do Grupo de Cromatografia (CROMA) do Instituto de Química de São Carlos, pela disponibilização da centrífuga e também pela amizade.

$\mathrm{E}$, finalmente, ao $\mathrm{CNPq}$, pelo auxílio financeiro. 


\section{RESUMO}

Neste trabalho, utilizou-se um Processo Oxidativo Avançado (POA) para a degradação de uma solução aquosa contendo uma mistura de metilparabeno e propilparabeno (50 $\mu \mathrm{g} \mathrm{L}^{-1}$ cada). O processo estudado foi o foto-Fenton solar, em um reator do tipo CPC operado no modo batelada com reciclo total. As condições operacionais foram otimizadas por meio da Metodologia de Superfície de Resposta (MSR), sendo elas: 771,6 $\mu \mathrm{g}$ $\mathrm{H}_{2} \mathrm{O}_{2} \mathrm{~L}^{-1}, 65,3 \mu \mathrm{g} \mathrm{Fe}^{3+} \mathrm{L}^{-1}$ e vazão $0,9 \mathrm{~L} \mathrm{~min}^{-1}$. $\mathrm{O} \mathrm{pH}$ foi fixado em 2,5. A determinação das concentrações dos analitos foi realizada por Cromatografia Líquida de Alta Eficiência acoplada a um Detector de Arranjo de Diodos (CLAE-DAD), tendo sido monitorado o comprimento de onda $258 \mathrm{~nm}$. Utilizou-se como técnica extratora e de pré-concentração a Microextração Líquido-Líquido Dispersiva (MELLD), sendo o $n$-octanol o solvente extrator e a acetona o solvente dispersivo. Avaliou-se a cinética de degradação do processo otimizado (em triplicata), obtendo-se uma degradação $>99 \%$ em 50 min. As constantes de taxa (em função da dose de energia, unidades $\mathrm{m}^{2} \mathrm{~kW}^{-1}$ ) foram 1,2 $\pm 0,034\left(\mathrm{R}^{2}\right.$ $=0,987)$ e $1,1 \pm 0,042\left(\mathrm{R}^{2}=0,979\right)$ para o metilparabeno e o propilparabeno, respectivamente. O efluente do reator mostrou-se biologicamente inativo, tendo sido testadas sua ecotoxicidade (Lactuca sativa) e sua atividade antimicrobiana (Escherichia coli).

PALAVRAS-CHAVE: foto-Fenton, degradação, metilparabeno, propilparabeno, reator CPC. 


\begin{abstract}
In this work, an Advanced Oxidation Process (AOP) was used for the degradation of aqueous methylparaben and propylparaben $\left(50 \mu \mathrm{g} \mathrm{L} \mathrm{L}^{-1}\right.$ each). The studied process was the solar photo-Fenton reaction, using a CPC-type reactor, which was operated in batch mode with total recycle. The experimental conditions were optimized using the Response Surface Methodology (RSM) and the obtained results were: $771.6 \mu \mathrm{g} \mathrm{H}_{2} \mathrm{O}_{2} \mathrm{~L}^{-1}, 65.3 \mu \mathrm{g}$ $\mathrm{Fe}^{3+} \mathrm{L}^{-1}$, and flow rate $0.9 \mathrm{~L} \mathrm{~min}^{-1}$. The solution $\mathrm{pH}$ was set at 2.5 . The analytes concentration was determined by High Performance Liquid Chromatography coupled to a Diode-Array Detector (HPLC-DAD), monitoring the $258 \mathrm{~nm}$ wavelength. The Dispersive Liquid-Liquid Extraction was used as a pre-concentration and extraction technique before injection, whereas $n$-octanol was the extraction solvent and acetone was the dispersive one. The optimized degradation process kinetics was assessed (triplicate) and more than $99 \%$ degradation was obtained after $50 \mathrm{~min}$. The rate constants (normalized by the energy dose, $\mathrm{m}^{2} \mathrm{~kW}^{-1}$ units) were $1.2 \pm 0.034\left(\mathrm{R}^{2}=0.987\right)$ and $1.1 \pm 0.042\left(\mathrm{R}^{2}=\right.$ 0.979 ) for methylparaben and propylparaben, respectively. The reactor effluent was biologically inactive, regarding its ecotoxicity (Lactuca sativa) and antimicrobial activity (Escherichia coli).
\end{abstract}

KEYWORDS: photo-Fenton, degradation, methylparaben, propylparaben, CPC reactor. 


\section{ÍNDICE DE FIGURAS}

FIGURA 1 - ESTRUTURA GERAL DOS PARABENOS

FIGURA 2 - FONTES E ROTAS DE EXPOSIÇÃO HUMANA AOS PARABENOS NO MEIO AMBIENTE COM AS RESPECTIVAS CONCENTRAÇÕES MÁXIMAS E O TIPO DE PARABENO. .5

FIGURA 3 - VARIAÇÃO DAS ESPÉCIES DE FERRO COM O PH. 10

FIGURA 4 - TIPOS DE REATORES SOLARES: A) NÃO CONCENTRADOR; B) CONCENTRADOR (PTC - PARABOLIC THROUGH CONCENTRATOR); E C) CPC (COMPOUND PARABOLIC CONCENTRATOR)...

FIGURA 5 - NÍvEIS E DISTRIBUIÇÃo ESPACIAL DE UM PLANEJAMENTO $2^{2}$ COM VARIÁVEIS A) REAIS E B) CODIFICADAS.

FIGURA 6 - EXEMPLO DE UM CAMINHO NO SENTIDO DA MÁXIMA INCLINAÇÃO..........................................15

FIGURA 7 - NÍVEIS DE UM PLANEJAMENTO COMPOSTO CENTRAL COM DOIS FATORES..................................16

FIGURA 8 - FlUXOGRAMA COM AS TÉCNICAS DE PREPARO DE AMOSTRA E ANÁLISE PARA OS PARABENOS. 22

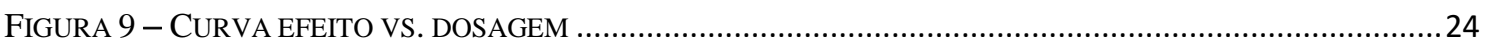

FIGURA 10 - REATOR CPC: A) VISTAS ORTOGRÁFICAS (DIMENSÕES EM CM) E B) FOTOS. .............................28

FIGURA 11 - ESPECTRO DA TRANSMISSÃO DE LUZ NO VIDRO BOROSSILICATO. ............................................29

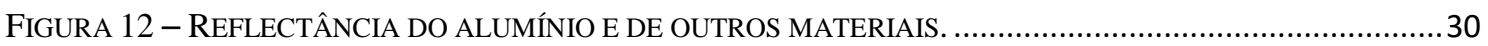

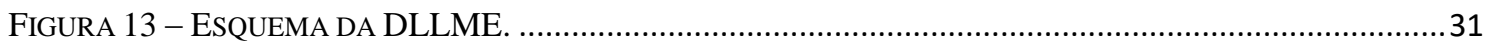

FIGURA 14 - REATOR LED: A) VISTAS ORTOGRÁFICAS (DIMENSÕES EM CM) E B) FOTOS. .............................. 35

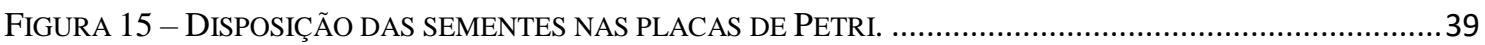

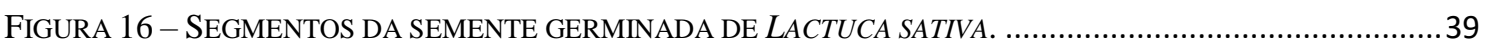

FigURA 17 - GRÁFICOS DE PARETO PARA (A) METILPARABENO E (B) PROPILPARABENO.............................. 43

FigurA 18 - GRÁFICOS DA SUPERFícIE DE RESPOSTA PARA (A, C, E) METILPARABENO E (B, C, F)

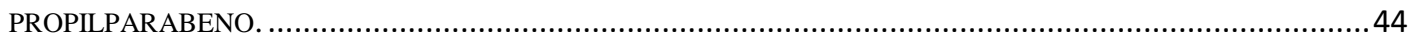

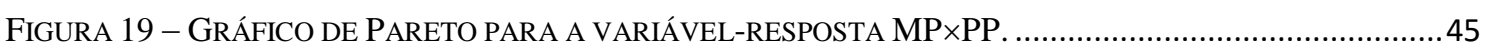

FIGURA 20 - GRÁFICOS DE SUPERFÍCIE DE RESPOSTA PARA A VARIÁVEL-RESPOSTA MP×PP........................46

FIGURA 21 - RESULTADOS DO CMI: — METILPARABENO E • PROPILPARABENO. .........................................49

FigURA 22 - GRÁFICOS DE PARETO DO CCD (PARCELA FATORIAL) PARA: (A) METILPARABENO E (B)

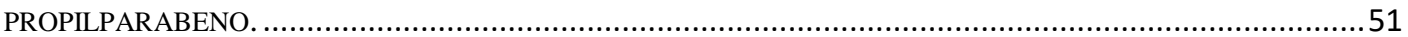

FIGURA 23 - GRÁFICOS DE SUPERFíCIE DE RESPOSTA E DE CONTORNO PARA A VARIÁVEL-RESPOSTA MP×

PP OBTIDOS A PARTIR DO PLANEJAMENTO COMPOSTO CENTRAL. ....................................................53

FIGURA 24 - GRÁFICO DE PARETO PARA MP*PP DO PLANEJAMENTO COMPOSTO CENTRAL (COMPLETO). . 54

FIGURA 25 - DISPERSÃO RESIDUAL DOS PONTOS COM RELAÇÃO AO PREVISTO PELO MODELO. .....................55

FiguRA 26 - CinÉTICA DE DEGRADAÇÃo PARA: (A) METILPARABENO E (B) PROPILPARABENO.

EXPERIMENTOS REALIZADOS EM TRIPLICATA 


\section{ÍNDICE DE TABELAS}

TABELA 1 - PRINCIPAIS PROPRIEDADES FÍSICO-QUÍMICAS DOS PARABENOS

TABELA 2 - CONCENTRAÇÕES DE PARABENOS DETERMINADA NA ENTRADA E NA SAÍDA DE ETE NA LITERATURA. LEGENDA: ND - NÃO DETECTADO, NQ - NÃO QUANTIFICADO. .....................................

TABELA 3 - TIPOS DE SISTEMAS E COMPOSTOS UTILIZADOS NOS POA............................................................

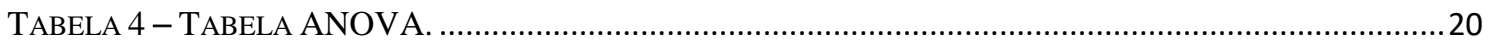

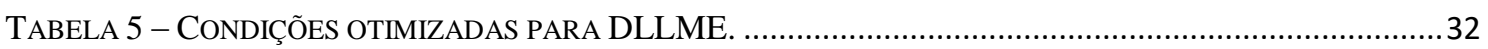

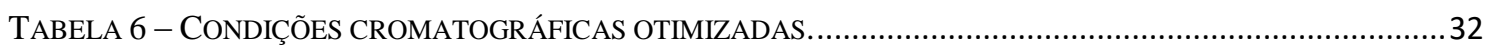

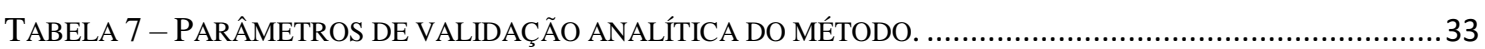

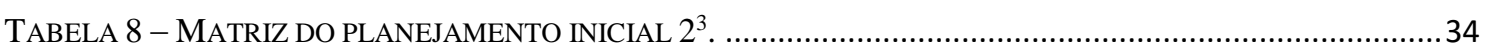

TABELA 9 - RESULTADOS NORMALIZADOS DO PLANEJAMENTO INICIAL $2^{3}$ COM DUPLICATAS......................41

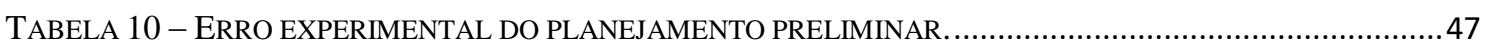

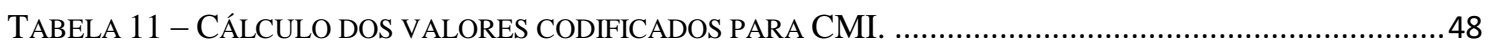

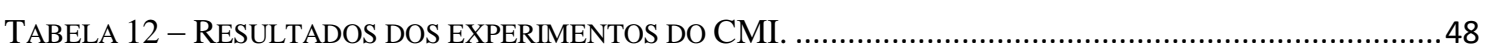

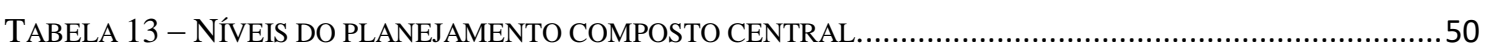

TABELA 14 - RESULTADOS DO PLANEJAMENTO COMPOSTO CENTRAL (PARCELA FATORIAL). .......................50

TABELA 15 - RESULTADO DO PLANEJAMENTO COMPOSTO CENTRAL (PARCELA AXIAL)...............................52

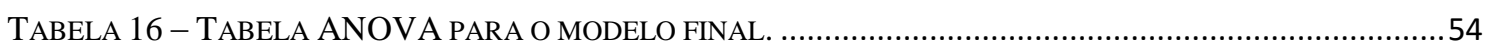

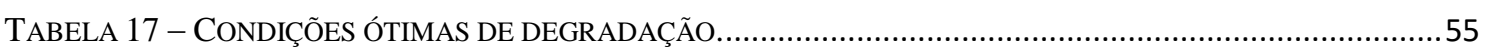

TABELA 18 - CONSTANTES CINÉTICAS E COEFICIENTES DE DETERMINAÇÃO_.................................................56

TABELA 19 - COMPARAÇÃO DOS RESULTADOS OBTIDOS COM OUTROS DA LITERATURA................................58 


\section{LISTA DE ABREVIATURAS E SIGLAS}

ANOVA - Analysis of Variance, análise de variância;

BHI - Brain Heart Infusion;

CCD - Central composite design, planejamento composto central;

CMI - Caminho de máxima inclinação;

CPC - Compound Parabolic Concentrator, coletor parabólico composto;

DAD - Diode array detector, detector de arranjo de diodos;

DDT - Diclorodifeniltricloroetano;

DLLME - Liquid-liquid microphase extraction, micro extração líquido-líquido dispersiva;

EPA - United States Environmental Protection Agency, Agência de Proteção Ambiental dos Estados Unidos;

ER - Extraction recovery, recuperação da extração;

ETE - Estação de tratamento de esgoto;

HPLC - High-performance liquid cromatography, cromatografia líquida de alta eficiência;

IG - Índice de germinação;

IUPAC - International Union of Pure and Applied Chemistry, União Internacional de Química Pura e Aplicada;

LC - Liquid Cromatography, Cromatografia líquida;

LOD - Limit of detection, limite de detecção;

LOQ - Limit of quantification, limite de quantificação;

MP - Metilparabeno;

MQ - Média quadrática;

OECD - Organization of Economic Co-operation and Development, Organização de Cooperação e Desenvolvimento Econômico;

PBS - Phosphate-buffered saline, tampão salino de fosfato;

PCB - Polychlorinated biphenyl, bifenil policlorado; 
POA - Processos oxidativos avançados;

PP - Propilparabeno;

PTC - Parabolic Through Concentrator, coletor concentrador;

RSD - Relative standard deviation, desvio padrão relativo;

RSM - Response Surface Methodology, metodologia de superfície de resposta;

SQ - Soma quadrática;

TCDD - Tetraclorodibenzo-p-dioxina;

UFC - Unidades formadoras de colônia;

UV - Ultravioleta. 


\section{SUMÁRIO}

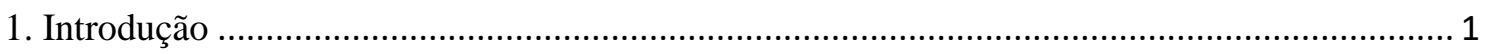

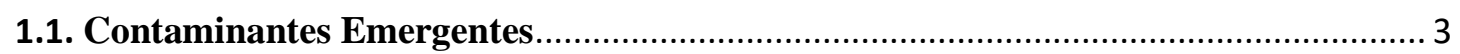

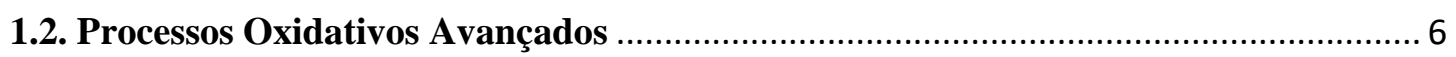

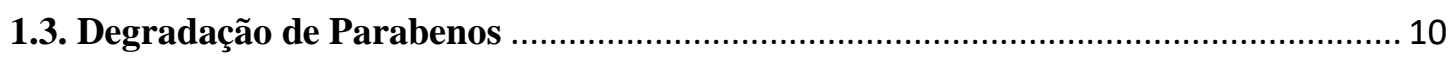

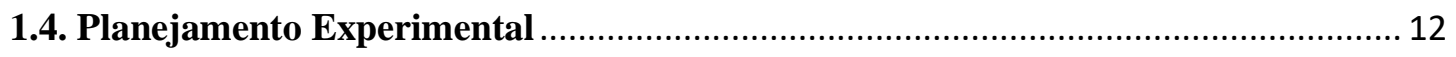

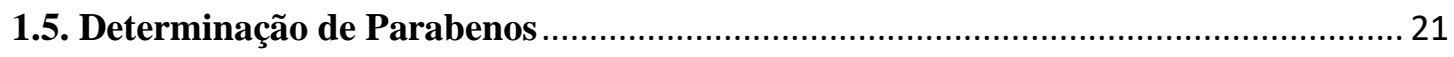

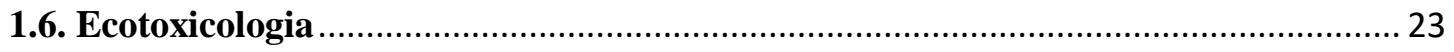

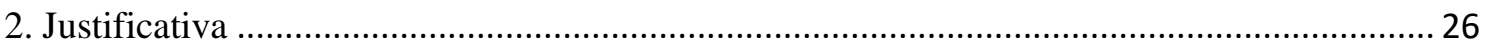

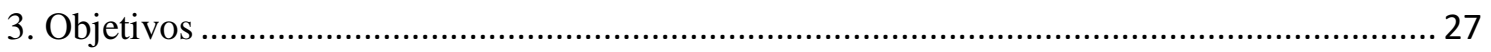

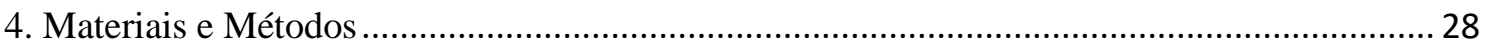

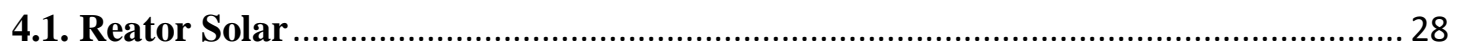

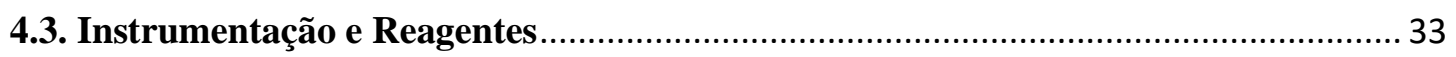

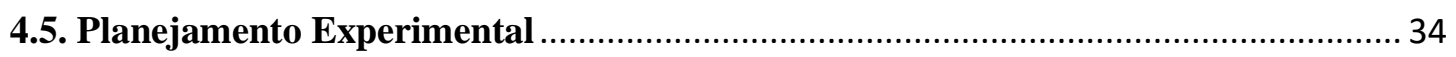

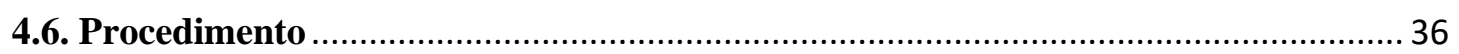

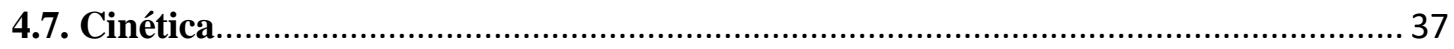

4.8. Ensaio de Ecotoxicidade com Lactuca Sativa ............................................................. 38

4.9. Ensaio de atividade antimicrobiana com Escherichia coli ....................................... 40

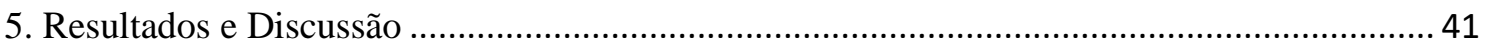

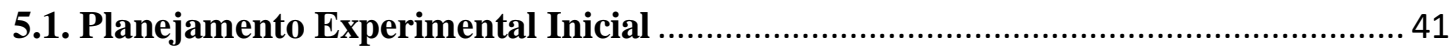

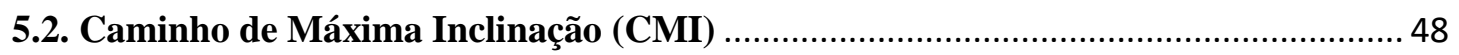

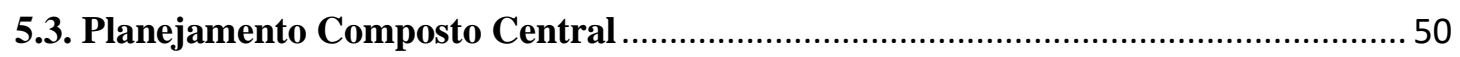

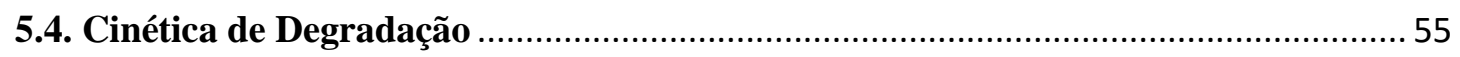

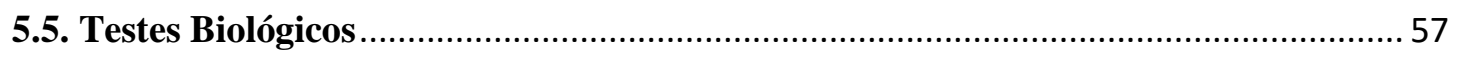

5.6. Comparação com outros trabalhos da literatura ………............................................ 57

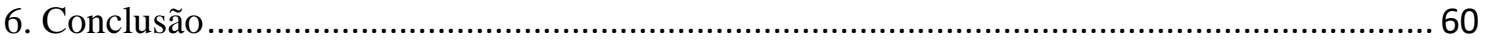

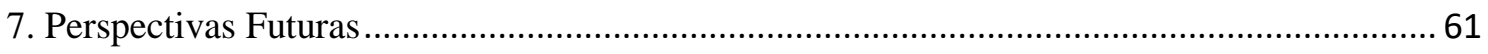

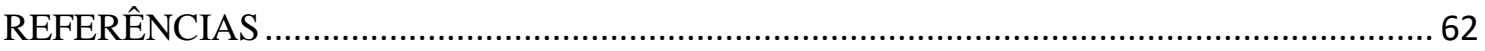




\section{Introdução}

Os parabenos são ésteres derivados do ácido $p$-hidroxibenzoico e são bem conhecidos por suas propriedades antimicrobianas e antifúngicas (DAUCHY et al., 2015). Por esse motivo, são utilizados amplamente como conservantes em uma série de produtos sintéticos diferentes, desde fármacos a alimentos (como aditivos) e cosméticos. Apenas nos cosméticos são utilizados em mais de 22.000 produtos, com concentrações de até $0,4 \%$ para cada tipo de parabeno (ou $0,8 \%$ se forem utilizados em combinações) (ANDERSEN, 2008).

Os parabenos atuam principalmente contra bactérias, mofos e leveduras, não possuindo efeito contra vírus, esporos (bactérias) e príons; portanto, são usados concomitantemente a outros conservantes para melhores resultados. Seu efeito biológico mais usual é o de inibição do transporte através de membranas e de funções mitocondriais (SONI; CARABIN; BURDOCK, 2002).

A estrutura geral dos parabenos é ilustrada na Figura 1. O radical $\mathrm{R}$ varia de acordo com o tipo de parabeno. Os radicais mais utilizados são: metila, etila, propila, butila, isobutila, isopropila e benzila.

Figura 1 - Estrutura geral dos parabenos.

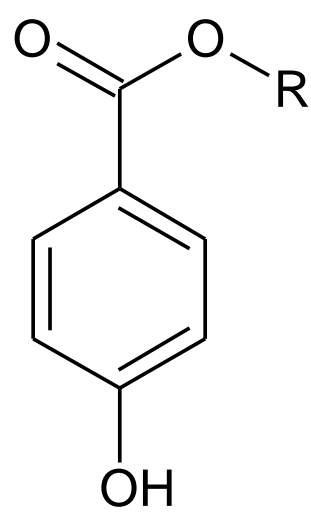

Fonte: Autoria própria.

Os parabenos são considerados como "conservantes ideais", pois possuem um amplo espectro de atividade antimicrobiana, são estáveis em uma grande faixa de $\mathrm{pH}$, 
possuem baixa toxicidade e baixo custo (BLEDZKA; GROMADZINSKA; WASOWICZ, 2014).

Eles são sintetizados a partir da esterificação do ácido $p$-hidroxibenzoico com o álcool desejado, na presença de um catalisador. Podem também ser encontrados no meio ambiente por organismos que os sintetizam, como algumas espécies de bactérias e plantas (DAUCHY et al., 2015).

Suas propriedades são inteiramente dependentes do tipo de substituinte. Os parâmetros mais importantes influenciados pelo tamanho da cadeia R são: a atividade antimicrobiana, a solubilidade em água, o ponto de ebulição, o ponto de fusão, o coeficiente de partição octanol-água e a constante de ionização ácida.

Na Tabela 1 são listadas algumas características físico-químicas dos principais parabenos (e do ácido $p$-hidroxibenzoico).

Tabela 1 - Principais propriedades físico-químicas dos parabenos.

\begin{tabular}{|c|c|c|c|c|c|c|}
\hline \multirow{2}{*}{$\begin{array}{l}\text { Proprieda- } \\
\text { des }\end{array}$} & \multirow{2}{*}{$\begin{array}{c}\text { Ácido } \\
p \text {-hidroxiben- } \\
\text { zoico } \\
\end{array}$} & \multicolumn{5}{|c|}{ Parabenos } \\
\hline & & Metil & Etil & Propil & Butil & Benzil \\
\hline $\begin{array}{l}\text { Massa mo- } \\
\text { lar }\left(\mathrm{g} \mathrm{mol}^{-1}\right)\end{array}$ & 138 & 152 & 166 & 180 & 194 & 228 \\
\hline P.F. $\left({ }^{\circ} \mathbf{C}\right)$ & 214 & 131 & 117 & 97 & 68,5 & 110 \\
\hline P.E. $\left({ }^{\circ} \mathbf{C}\right)$ & 298 & 275 & 297,5 & 285,1 & 300,3 & - \\
\hline $\begin{array}{l}\text { Pressão de } \\
\text { vapor (Pa) }\end{array}$ & - & 0,114 & 0,012 & 0,041 & 0,033 & - \\
\hline $\begin{array}{c}\text { Solubilidade } \\
\text { em água a } \\
25^{\circ} \mathbf{C} \\
\left(\mathbf{m g ~ L}^{-1}\right)\end{array}$ & 5.000 & 2.500 & 885 & 500 & 207 & 160 \\
\hline Log Kow & 1,58 & 1,96 & 2,47 & 3,04 & 3,57 & 3,27 \\
\hline pKa & 2,70 & 8,17 & 8,22 & 8,35 & 8,37 & 8,50 \\
\hline
\end{tabular}

Fonte: Adaptação de DAUCHY et al., 2015, p. 1.

De forma geral, observa-se que, quando há um aumento no tamanho da cadeia, há uma diminuição na solubilidade do parabeno em água, juntamente com um aumento no coeficiente de partição octanol-água (ou seja, a polaridade do composto diminui e ele se torna mais hidrofóbico). O ponto de ebulição dos parabenos são bastante próximos e o pKa está entre 8,17 (metil) e 8,50 (butil). A $25^{\circ} \mathrm{C}$, em sua forma pura, os parabenos apresentam-se como pequenos cristais incolores ou pó cristalino. São insípidos, inodoros 
e higroscópicos. O metil e o propilparabeno são estáveis em meio ácido e próximo à neutralidade, além de serem resistentes à hidrólise (SONI; CARABIN; BURDOCK, 2005).

A atividade antimicrobiana dos parabenos aumenta quando a cadeia do radical $\mathrm{R}$ também aumenta, porém, sua solubilidade diminui. Como o crescimento microbiano geralmente ocorre na fase aquosa, para que ocorra a atividade inibitória dos parabenos, é necessário que estejam dissolvidos em água. Logo, mesmo que os parabenos de cadeia maior sejam mais ativos em neutralizar o crescimento microbiano, os parabenos mais utilizados comercialmente são os de cadeia menor, como o metilparabeno e o propilparabeno, por serem mais solúveis em água (ROUTLEDGE et al., 1998; SONI et al., 2002).

\subsection{Contaminantes Emergentes}

Os parabenos são rapidamente absorvidos no trato gastrointestinal, metabolizados e degradados em seus derivados mais simples, como ácido $p$-hidroxibenzoico, glicina e ácido glucorônico, dentre outros conjugados, sendo então eliminados parcialmente pela urina nas primeiras horas após a ingestão. Em geral, são compostos de toxicidade muito baixa e pouco nocivos ao organismo humano (SONI; CARABIN; BURDOCK, 2005).

Porém, Darbre et al. (2004) publicaram uma pesquisa na qual relataram a presença de parabenos em tumores de mama humanos. Esta publicação colocou a segurança e a confiabilidade que se havia depositado até então nos parabenos em cheque, dando origem a uma série de pesquisas sobre os efeitos dessas substâncias no organismo humano.

O efeito mais importante, destacado na literatura, é a ação dos parabenos como interferentes endócrinos leves, substâncias que alteram a ação endógena de hormônios, além de modificar a síntese, o metabolismo e o transporte de hormônios em geral. Embora, inicialmente, se acreditasse que esses interferentes endócrinos atuassem competindo com os hormônios na ligação aos receptores nucleares (estrogênio, androgênio, tireoidal, progesterona e retinoidal), sabe-se agora que o mecanismo envolvido é mais complexo, aumentando ou diminuindo, a produção de esteroides endógenos e a síntese de receptores (BLEDZKA; GROMADZINSKA; WASOWICZ, 2014). 
Os seres humanos estão expostos aos parabenos por diversas fontes, desde a ingestão de alimentos e fármacos que contenham o conservante, à aplicação de produtos de uso pessoal, como cosméticos, diretamente na pele. Entre outras fontes, podem-se citar o consumo d'água e a exposição pelo contato com água ou ar. A Figura 2 ilustra algumas das possibilidades e rotas que os parabenos podem percorrer até serem absorvidos, eliminados e degradados, além de suas respectivas concentrações máximas encontradas na literatura (BLEDZKA; GROMADZINSKA; WASOWICZ, 2014).

Muitos estudos e revisões foram realizados para se estimar a quantidade total, diária e média de parabenos ingeridos por um ser humano adulto, de $60 \mathrm{~kg}$, por todas as fontes ilustradas na Figura 2. Os valores estimados são bem diferentes de acordo com cada autor. No entanto, houve consenso em relação à ordem de magnitude: miligramas por dia.

Soni et al. (2005), por exemplo, estimam que a ingestão total de parabenos é de aproximadamente $76,0 \mathrm{mg} \mathrm{dia}{ }^{-1}$ ou $1,3 \mathrm{mg} \mathrm{kg}^{-1} \mathrm{dia}^{-1}$ para um indivíduo de $60 \mathrm{~kg}$. Essa estimativa considera a exposição (pela ingestão de alimentos) a aproximadamente 1,0 $\mathrm{mg} \mathrm{dia}^{-1}$; por cosméticos, a 50,0 $\mathrm{mg} \mathrm{dia}{ }^{-1}$ e por fármacos, a 25,0 $\mathrm{mg} \mathrm{dia}{ }^{-1}$.

As estações de tratamento de esgoto (ETE) são bastante eficientes na remoção de parabenos, como mostrados na Figura 2. Os esgotos chegam às estações com valores de até 79,6 $\mu \mathrm{g} \mathrm{L}^{-1}$ de parabenos (Tabela 2). Nas ETE, principalmente nas de tratamento anaeróbio, essa concentração cai bruscamente durante o primeiro estágio do processo de degradação, e sua concentração continua a cair pelo resto do tratamento. A eficiência média da remoção dos parabenos nas ETE é de 96,1 - 99,9\%. Embora seja uma boa eficiência, concentrações tão altas (para contaminantes emergentes) quanto $0,4 \mu \mathrm{g} \mathrm{\textrm {L } ^ { - 1 }}$ ainda podem ser detectadas nos efluentes de ETE. Além disso, no caso das de tratamento anaeróbio, o lodo proveniente do processo de degradação pode conter de $0-0,4 \%$ da concentração inicial dos parabenos (GMUREK et al., 2015). A Tabela 2 mostra alguns estudos realizados e as concentrações detectadas de parabenos em cada um deles (JONKERS et al., 2009). 
Figura 2 - Fontes e rotas de exposição humana aos parabenos no meio ambiente com as respectivas concentrações máximas e o tipo de parabeno.

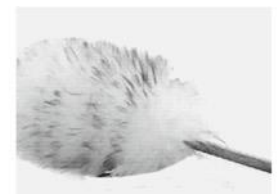

Poeira comum

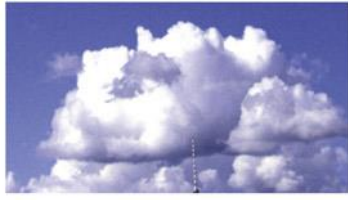

Ar

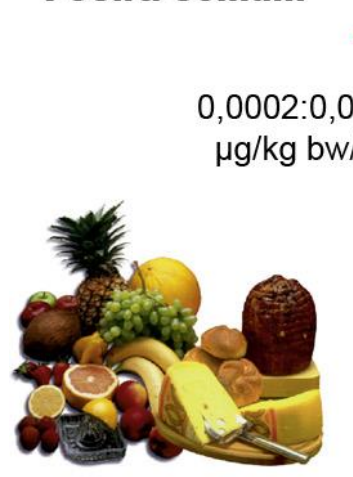

Alimentos $2,53 \mu \mathrm{g} / \mathrm{g} \mathrm{fw}$ (total PB)

\section{Água para consumo}

1:13

$\mu \mathrm{g} / \mathrm{kg}$ bw/day

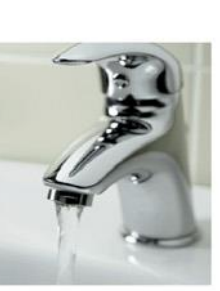

Estação de coleta de água

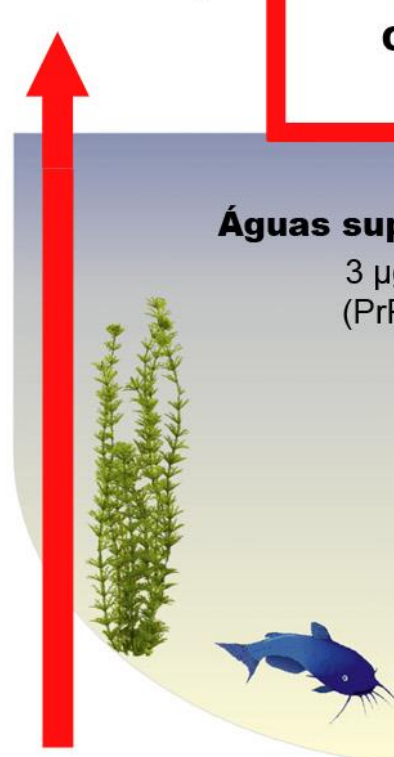

Águas subterrâneas

\section{| 0,000547:0,0138} $\mu \mathrm{g} / \mathrm{kg}$ bw/day
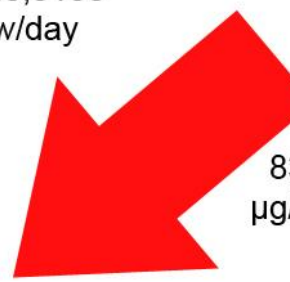

$833-2400$ $\mu \mathrm{g} / \mathrm{kg}$ bw/day

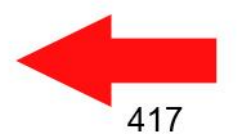

$\mu \mathrm{g} / \mathrm{kg}$ bw/day

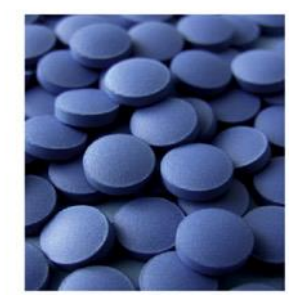

Produtos farmacêuticos

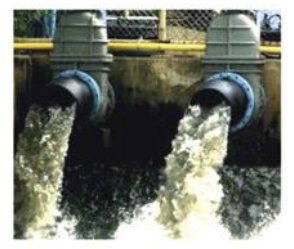

Estação de tratamento de esgoto (ETE) $3,83 \mu \mathrm{g} / \mathrm{L}$

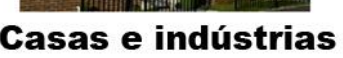

Efluente (MePB)

\section{Afluente}

$79,6 \mu \mathrm{g} / \mathrm{L}$
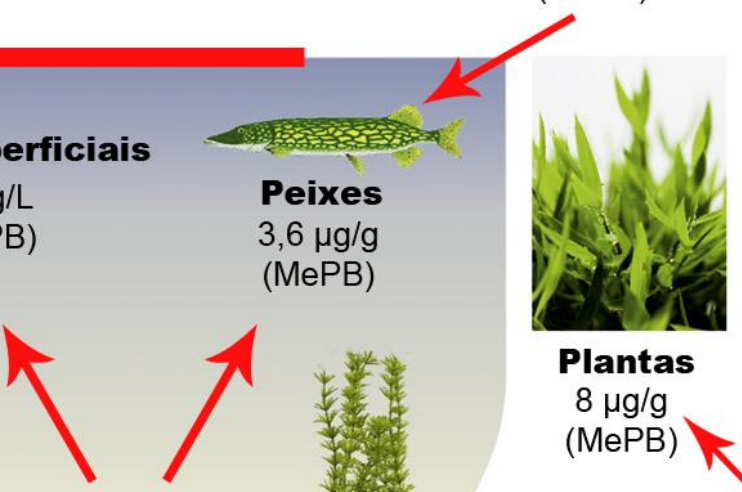

\section{Sedimento}

$0,377 \mu \mathrm{g} / \mathrm{g} \mathrm{dw}$ (BuPB)
Plantas

$8 \mu \mathrm{g} / \mathrm{g}$

(MePB)

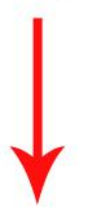

\section{Lodo}

$0,202 \mu \mathrm{g} / \mathrm{g} \mathrm{dw}$ (MePB)

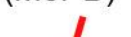

Produtos de uso pessoal

$8000 \mu \mathrm{g} / \mathrm{g}(0,8 \%)$ (total PB) 
Tabela 2 - Concentrações de parabenos determinada na entrada e na saída de ETE na literatura. Legenda: ND - Não detectado, NQ - Não quantificado.

\begin{tabular}{|c|c|c|c|c|c|c|c|}
\hline \multirow{2}{*}{ Tipo } & \multirow{2}{*}{$\begin{array}{l}\text { Região de amostragem e } \\
n^{\circ} \text { de ETE }\end{array}$} & \multicolumn{5}{|c|}{ Concentrações $\left(\mu \mathrm{g} \mathrm{L}^{-1}\right)$} & \multirow{2}{*}{ Referências } \\
\hline & & $\mathrm{MePB}$ & EtPB & PrPB & $\mathrm{BuPB}$ & $\mathrm{BePB}$ & \\
\hline Saída & Suécia - 3 & ND- 0,3 & $<0,1-0,2$ & $<0,1-0,3$ & - & ND-1,0 & Paxeus (1996) \\
\hline Entrada & Ontario, Canada -8 & $0,1-1,47$ & $0,02-0,27$ & $0,2-2,43$ & $0,02-0,26$ & - & Lee et al. (2005) \\
\hline Saída & Ontario, Canada -8 & $0,02-0,03$ & $<0,01$ & $<0,01-0,04$ & $<0,01$ & - & Lee et al. (2005) \\
\hline Entrada & Califórnia, USA - 1 & $12,5-79,6$ & - & - & - & - & $\begin{array}{l}\text { Loraine e Petti- } \\
\text { grove (2006) }\end{array}$ \\
\hline Saída & Califórnia, USA - 1 & ND-3,83 & - & - & - & - & $\begin{array}{l}\text { Loraine e Petti- } \\
\text { grove (2006) }\end{array}$ \\
\hline Entrada & Espanha - 1 & $0,43-2,92$ & $0,05-0,21$ & $0,23-0,81$ & $0,02-0,08$ & - & $\begin{array}{c}\text { Canosa et al. } \\
\text { (2006) }\end{array}$ \\
\hline Saída & Espanha - 1 & ND & ND & ND & ND & ND & $\begin{array}{c}\text { Canosa et al. } \\
(2006\end{array}$ \\
\hline Entrada & Galícia, Espanha - 2 & $1,92-5,13$ & $0,45-0,55$ & $1,15-1,30$ & $0,15-0,18$ & NQ & $\begin{array}{c}\text { González-Mariño } \\
\text { et al. (2009) }\end{array}$ \\
\hline Saída & Galícia, Espanha - 2 & NQ-0,001 & NQ & NQ & $\begin{array}{l}\text { NQ- } \\
0,004\end{array}$ & NQ & $\begin{array}{c}\text { González-Mariño } \\
\text { et al. (2009) }\end{array}$ \\
\hline Entrada & Suíça (nordeste) - 7 & $0,065-9,88$ & $\begin{array}{c}0,002- \\
0,72\end{array}$ & $0,043-1,54$ & $\begin{array}{c}0,0097- \\
0,864\end{array}$ & $\begin{array}{l}<0,002 \\
-0,004\end{array}$ & $\begin{array}{l}\text { Jonkers et al. } \\
\text { (2009) }\end{array}$ \\
\hline Saída & Suíça (nordeste) - 7 & $0,04-0,423$ & $\begin{array}{c}<0,0003- \\
0,017\end{array}$ & $\begin{array}{c}<0,0005- \\
0,028\end{array}$ & $\begin{array}{c}0,0002- \\
0,012\end{array}$ & $\begin{array}{l}0,0002 \\
-0,016\end{array}$ & $\begin{array}{c}\text { Jonkers et al. } \\
\text { (2009) }\end{array}$ \\
\hline Saída & Rio de Aveiro, Portugal - 3 & $0,013-0,031$ & $\begin{array}{c}<0,0003- \\
0,0066\end{array}$ & $\begin{array}{c}<0,0005- \\
0,021\end{array}$ & $\begin{array}{c}0,0002- \\
0,0039\end{array}$ & $<0,002$ & $\begin{array}{l}\text { Jonkers et al. } \\
(2010)\end{array}$ \\
\hline Entrada & Espanha (noroeste) - 3 & $0,29-10,0$ & $0,25-1,6$ & $0,52-2,8$ & $\begin{array}{c}0,039- \\
0,27\end{array}$ & - & $\begin{array}{c}\text { González-Mariño } \\
\text { et al. (2011) }\end{array}$ \\
\hline Saída & Espanha (noroeste) -3 & $0,006-0,05$ & $\begin{array}{c}\text { ND- } \\
0,0098\end{array}$ & ND-0,021 & ND & - & $\begin{array}{c}\text { González-Mariño } \\
\text { et al. (2011) }\end{array}$ \\
\hline Entrada & Pacífico Central, Japão - 1 & $1,4-2,4$ & $\begin{array}{c}0,052- \\
0,057\end{array}$ & $2,2-2,6$ & $0,37-0,45$ & - & $\begin{array}{l}\text { Terasaki et.al } \\
\text { (2012) }\end{array}$ \\
\hline
\end{tabular}

Fonte: Adaptação de BLEDZKA, D.; GROMADZINSKA, J.; WASOWICZ, W., 2014, p. 27).

\subsection{Processos Oxidativos Avançados}

Diante dos problemas identificados em relação aos parabenos, e sabendo que as estações de tratamento não conseguem eliminá-los por completo, os Processos Oxidativos Avançados (POA) surgem como alternativa para a eliminação dessa classe de compostos, 
pois são processos eficientes, de baixo custo, simples e não necessitam de pós-tratamento na maioria dos casos (GMUREK et al., 2015; MOTA, 2010).

De forma simplificada, os POA utilizam a geração in situ de radicais fortemente oxidantes (mais comumente o radical hidroxila, ${ }^{\circ} \mathrm{OH}$ ) para oxidar compostos (poluentes) orgânicos a derivados mais simples (e potencialmente menos tóxicos), $\mathrm{CO}_{2}$ e $\mathrm{H}_{2} \mathrm{O}$. Os meios para gerar esse radical são variáveis e caracterizam os diferentes processos. Os radicais hidroxila possuem potencial de redução de $2,80 \mathrm{~V}$, menor apenas que o do flúor, de 3,03 V (em relação ao Eletrodo Padrão de Hidrogênio, EPH). São processos pouco seletivos, podendo degradar inúmeras classes de contaminantes orgânicos de uma só vez, e limpos do ponto de vista ambiental (HUANG; DONG; TANG, 1993).

Os radicais hidroxila podem ser gerados por meio de reações entre oxidantes fortes, como o ozônio $\left(\mathrm{O}_{3}\right)$ e o peróxido de hidrogênio $\left(\mathrm{H}_{2} \mathrm{O}_{2}\right)$, e semicondutores como o óxido de zinco $(\mathrm{ZnO})$ e dióxido de titânio $\left(\mathrm{TiO}_{2}\right)$, com ou sem a presença de radiação ultravioleta (UV). Os processos também variam de acordo com a presença de catalisadores sólidos, sendo estes denominados heterogêneos, enquanto que os sem catalisadores são denominados de homogêneos. A Tabela 3 ilustra alguns tipos de POA conhecidos (TEIXEIRA; JARDIM, 2004).

Tabela 3 - Tipos de sistemas e compostos utilizados nos POA.

\begin{tabular}{|c|c|}
\hline \multirow{7}{*}{ Sistemas Homogêneos } & $\begin{array}{c}\text { Com Irradiação } \\
\mathrm{O}_{3} / \mathrm{UV}\end{array}$ \\
\hline & $\mathrm{H}_{2} \mathrm{O}_{2} / \mathrm{UV}$ \\
\hline & $\mathrm{H}_{2} \mathrm{O}_{2} / \mathrm{UV} / \mathrm{O}_{3}$ \\
\hline & $\mathrm{UV} / \mathrm{Fe}^{2+} / \mathrm{H}_{2} \mathrm{O}_{2}$ \\
\hline & Sem irradiação \\
\hline & $\mathrm{O}_{3} / \mathrm{H}_{2} \mathrm{O}_{2}$ \\
\hline & $\mathrm{H}_{2} \mathrm{O}_{2} / \mathrm{Fe}^{2+}$ (Fenton) \\
\hline \multirow{5}{*}{ Sistemas Heterogêneos } & Com irradiação \\
\hline & $\mathrm{TiO}_{2} / \mathrm{O}_{2} / \mathrm{UV}$ \\
\hline & $\mathrm{TiO}_{2} / \mathrm{H}_{2} \mathrm{O}_{2} / \mathrm{UV}$ \\
\hline & Sem irradiação \\
\hline & Eletro-Fenton \\
\hline
\end{tabular}

Fonte: Adaptação de HUANG, C. P.; DONG, C.; TANG, Z., 1993, p. 361. 
Um dos processos mais utilizados é o processo foto-Fenton, que utiliza a radiação ultravioleta, $\mathrm{H}_{2} \mathrm{O}_{2}$ e $\mathrm{Fe}^{3+}$.

A reação de Fenton, de forma geral, é a reação de formação do radical hidroxila a partir da decomposição de $\mathrm{H}_{2} \mathrm{O}_{2}$, catalisada por $\mathrm{Fe}^{2+}$ em meio ácido, como mostrado na Equação 1 (LUCAS; PERES, 2006).

$$
\mathrm{Fe}^{2+}+\mathrm{H}_{2} \mathrm{O}_{2} \rightarrow \mathrm{Fe}^{3+}+\mathrm{OH}^{-}+\mathrm{OH}^{\bullet}
$$

$\mathrm{Na}$ ausência de um substrato, o radical hidroxila reage novamente com um íon ferroso (Equação 2) (GÜERE, 2014).

$$
\mathrm{Fe}^{2+}+\mathrm{OH}^{\bullet} \rightarrow \mathrm{Fe}^{3+}+\mathrm{OH}^{-}
$$

O íon férrico, subproduto das Equações (1) e (2), pode reagir novamente com o peróxido de hidrogênio ou superóxido $\left(\mathrm{O}_{2}^{-\bullet}\right)$, regenerando o íon ferroso (Equações 3 e 4) (KOMMINENI et al., 2015).

$$
\begin{gathered}
\mathrm{Fe}^{3+}+\mathrm{H}_{2} \mathrm{O}_{2} \rightarrow \mathrm{Fe}^{2+}+\cdot \mathrm{O}_{2}^{-}+2 \mathrm{H}^{+} \\
\mathrm{Fe}^{3+}+\cdot \mathrm{O}_{2}^{-} \rightarrow \mathrm{Fe}^{2+}+\mathrm{O}_{2}
\end{gathered}
$$

Assim, forma-se um ciclo catalítico que dá continuidade à reação de Fenton, até que o peróxido seja totalmente consumido.

Na presença de substratos orgânicos, estes são rapidamente degradados pelo radical hidroxila, por mecanismos que variam de acordo com a estrutura do substrato.

Para hidrocarbonetos alifáticos $(\mathrm{RH})$, as reações normalmente ocorrem através da abstração de um átomo de hidrogênio, como mostrado pelas Equações 5, 6 e 7 (MARTINS, 2011).

$$
\begin{aligned}
& R H+\mathrm{OH}^{\bullet} \rightarrow \mathrm{R}^{\bullet}+\mathrm{H}_{2} \mathrm{O} \\
& \mathrm{R}^{\bullet}+\mathrm{Fe}^{3+} \rightarrow \mathrm{R}^{+}+\mathrm{Fe}^{2+} \\
& \mathrm{R}^{+}+\mathrm{H}_{2} \mathrm{O} \rightarrow \mathrm{ROH}+\mathrm{H}^{+}
\end{aligned}
$$


Para hidrocarbonetos insaturados $(\mathrm{R}=\mathrm{R})$ ou aromáticos, onde há ligações do tipo $\pi$, as reações normalmente ocorrem, primeiramente, por meio de uma adição eletrofílica, como mostrado pelas Equações 8 e 9 (NOGUEIRA et al., 2007).

$$
\begin{gathered}
R=R+\mathrm{OH}^{\bullet} \rightarrow \mathrm{R}^{\bullet}-\mathrm{ROH} \\
\mathrm{R}^{\bullet}-\mathrm{ROH}+\mathrm{H}_{2} \mathrm{O} \rightarrow \mathrm{RH}-\mathrm{ROH}+\mathrm{OH}^{\bullet}
\end{gathered}
$$

De acordo com GAO et al. (2014), estes são os dois mecanismos pelos quais os parabenos reagem com o radical hidroxila, sendo que o mais favorecido termodinamicamente é o de adição eletrofílica.

Um cuidado que se deve tomar, durante a execução das reações de Fenton, é a escolha da concentração de peróxido de hidrogênio. Se adicionado em excesso, o peróxido pode atuar como um sequestrante de radicais hidroxila, para a formação do radical hidroperoxila $\left(\mathrm{HO}_{2}{ }^{\bullet}\right)$, que possui menor potencial de redução $(+1,42 \mathrm{~V})$ do que o radical hidroxila, diminuindo a velocidade da reação e, consequentemente, da degradação, como mostrado pela Equação 10 (PIGNATELLO; OLIVEROS; MACKAY, 2006).

$$
\mathrm{OH}^{\bullet}+\mathrm{H}_{2} \mathrm{O}_{2} \rightarrow \mathrm{H}_{2} \mathrm{O}+\mathrm{HO}_{2}^{\bullet}
$$

Para o processo foto-Fenton, há a necessidade de radiação ultravioleta $(h v)$, e a reação primária passa a ser a apresentada nas Equações 11 e 12 (MELO et al., 2009).

$$
\begin{gathered}
\mathrm{Fe}(\mathrm{OH})^{2+}+h v \rightarrow \mathrm{Fe}^{2+}+\mathrm{OH}^{\bullet} \\
\mathrm{Fe}^{3+}+\mathrm{H}_{2} \mathrm{O}+\mathrm{hv} \rightarrow \mathrm{Fe}^{2+}+\mathrm{OH}^{\bullet}+\mathrm{H}^{+}
\end{gathered}
$$

A degradação pelo processo foto-Fenton é mais acelerada do que a do Fenton convencional, pois há a regeneração de $\mathrm{Fe}^{2+}$ e a produção de radicais hidroxila por reações secundárias (Equações 13 e 14) (GÜERE, 2014).

$$
\begin{gathered}
\mathrm{Fe}^{3+}+\mathrm{H}_{2} \mathrm{O}+\mathrm{hv} \rightarrow \mathrm{Fe}^{2+}+\mathrm{OH}^{\bullet}+\mathrm{H}^{+} \\
\mathrm{H}_{2} \mathrm{O}_{2}+h v \rightarrow 2 \mathrm{OH}^{\bullet}
\end{gathered}
$$

Tanto a reação de Fenton como a de foto-Fenton são dependentes do pH do meio reacional, devido à presença dos íons ferro em solução. Como mostrado pelo diagrama 
de especiação do ferro na Figura 3, o pH ótimo para a reação ocorrer é 2,5 pois, em valores de $\mathrm{pH}$ maiores que 2,5 tem-se a formação de oxi-hidróxidos de ferro(III) amorfos, que podem precipitar lentamente. Assim como para valores de $\mathrm{pH}$ menores do que 2,5, o íon hidrônio $\left(\mathrm{H}_{3} \mathrm{O}^{+}\right)$pode sequestrar radicais hidroxila, o que leva a uma diminuição na eficiência da reação. Portanto, deve-se tomar o cuidado para que o meio reacional da degradação tenha pH entre 2,5 e 3,0 (MELO et al., 2009).

Figura 3 - Variação das espécies de ferro com o pH.

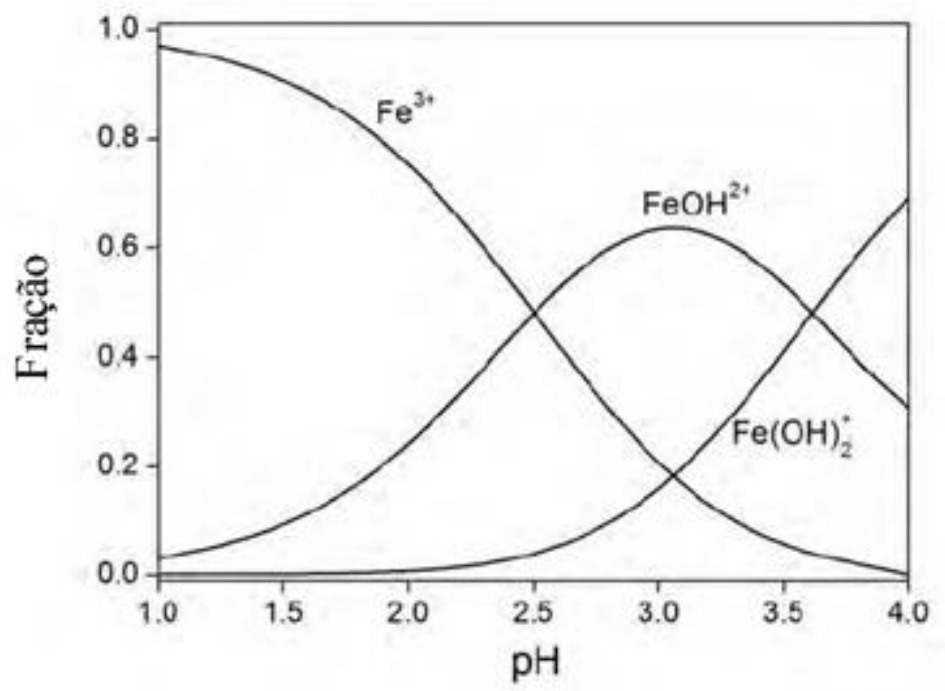

Fonte: Adaptação de MACHULEK, A. et al., 2012, p. 275.

\subsection{Degradação de Parabenos}

Para a degradação dos compostos pelo processo foto-Fenton, diversos tipos de reatores podem ser empregados. Reatores fotoquímicos com lâmpadas que simulam o espectro emitido pela luz do Sol ou lâmpadas monocromáticas são os tipos mais comumente usados.

No caso dos reatores solares, foco deste estudo, existem três tipos básicos: os concentradores (PTC - Parabolic Through Concentrator), os não concentradores e os parabólicos compostos (CPC - Compound Parabolic Concentrator). Os dois primeiros são coletores do tipo térmico e fotoquímico, respectivamente. Como o processo fotoFenton engloba ambas as etapas (fotoquímica e térmica), os parabólicos compostos são 
uma melhor alternativa, pois são intermediários e não possuem as desvantagens dos outros tipos. (MALATO et al., 2009).

As vantagens dos reatores CPC incluem seu baixo custo e bom aproveitamento da radiação incidente, pois possuem uma eficiência óptica de até 80\% (GAOS et al., 2015) e suas superfícies são moldadas em formato de involuta, como mostrado na Figura 4c, o que implica numa absorção da radiação solar tanto direta quanto difusa (BIRD; HULSTROM; LEWIS, 1983).

Figura 4 - Tipos de reatores solares: a) não concentrador; b) concentrador (PTC - Parabolic Through Concentrator); e c) CPC (Compound Parabolic Concentrator)

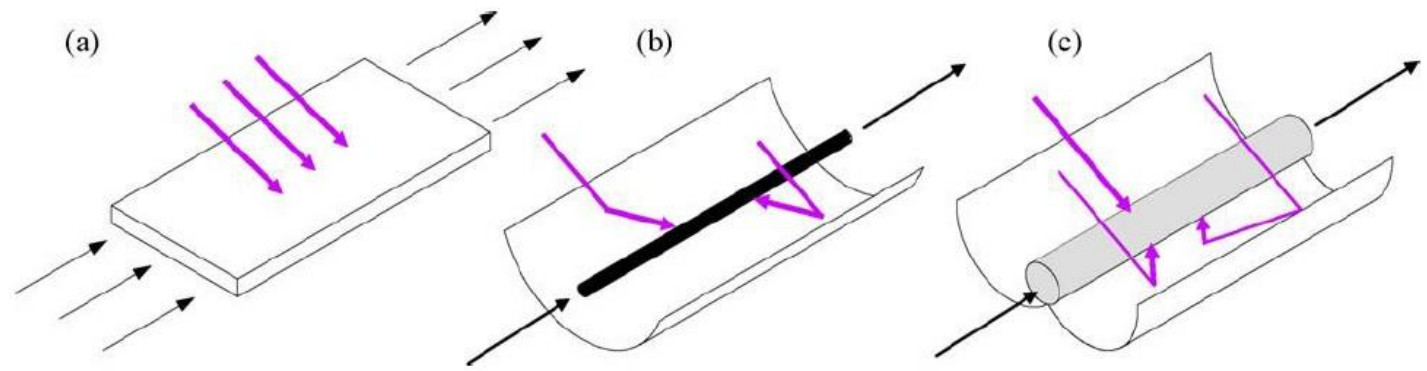

Fonte: MALATO, S.; FERNÁNDEZ-IBÁÑEZ, P.; MALDONADO, M. I.; BLANCO, J.; GERNJAK, W., 2009, p. 1.

Embora existam muitos estudos na literatura utilizando o processo foto-Fenton, os trabalhos que incorporam diretamente a luz do Sol nos processos de degradação são em número reduzido. Além disso, há diversas condições e parâmetros que variam de um trabalho para outro, o que leva à necessidade de se otimizar o processo.

Por exemplo, Zúñiga-Benitez et al. (2015) utilizaram um sistema com lâmpada de Xenônio, e obtiveram degradações de $99 \%$ para $1 \mathrm{mg} \mathrm{L}^{-1}$ de metilparabeno em 120 min de experimento, utilizando $21 \mathrm{mg} \mathrm{L}^{-1}$ e $155,4 \mathrm{mg} \mathrm{L}^{-1}$ para as concentrações de ferro(II) e peróxido de hidrogênio, respectivamente. Já Lucas e Peres (2015) trabalharam com um foto-reator UV com emissão fixada em $254 \mathrm{~nm}$ e obtiveram $63 \%$ de degradação para concentrações de 180 220 mg L ${ }^{-1}$ de metilparabeno e propilparabeno em $180 \mathrm{~min}$, utilizando concentrações de $200 \mathrm{mg} \mathrm{L}^{-1}$ para o peróxido de hidrogênio e $21,7 \mathrm{mg} \mathrm{L}^{-1}$ para o ferro (II). 


\subsection{Planejamento Experimental}

O planejamento experimental é uma ferramenta essencial para se estudar apropriadamente o efeito de um conjunto de fatores sobre uma variável-resposta de interesse, pois sua metodologia permite uma extração máxima de informação de um número menor (ou reduzido) de experimentos. Além disso, essas técnicas de planejamento empíricas auxiliam na determinação das variáveis significativas, assim como seus efeitos e a presença ou não de interações entre elas (BARROS NETO; SCARMINIO; BRUNS, 2007).

Em estudos de otimização, costuma-se empregar a metodologia de superfície de resposta (RSM, do inglês Response Surface Methodology). Nela são utilizadas diversas matrizes de ensaios (planejamentos fatoriais), variando-se os fatores simultaneamente até se alcançar o ponto de melhor resposta do experimento (DEJAEGHER; HEYDEN, 2011).

A RSM possui duas etapas distintas: modelagem e deslocamento, que são aplicadas diversas vezes com objetivo de se alcançar uma região ótima. A etapa de modelagem consiste na aplicação de planejamentos fatorais completos e ou fracionados e no ajuste de modelos simples (lineares ou quadráticos) à resposta obtida. Já o deslocamento trata-se da trajetória percorrida em um modelo ao longo de um caminho de máximo de inclinação, buscando sempre as melhores respostas (mais pronunciadas) até se atingir a região ótima (BARROS NETO; SCARMINIO; BRUNS, 2007).

Os planejamentos fatoriais consistem em analisar um conjunto de fatores (variáveis independentes) em níveis (valores) diferentes, de acordo com a resposta obtida. Em termos matemáticos, o planejamento fatorial pode ser traduzido como $b^{k}$, onde $b$ e $k$ correspondem aos níveis e fatores estudados, respectivamente. No modelo mais simples, por exemplo, pode-se estudar a influência de dois fatores em dois níveis diferentes; ou seja, um planejamento $2^{2}$ com 4 experimentos distintos, como mostrado na Figura 5.

Os níveis para cada fator são codificados em uma escala adimensional que corresponde a sua localização no espaço experimental, sendo (+1) para o nível superior (maior valor absoluto) e (-1) para o nível inferior (menor valor absoluto). Para traduzir os valores codificados para a escala tradicional, pode-se usar a fórmula da Equação 15, na qual 
$b_{i}$ é o nível do fator $i$ codificado; $B_{i}$ é o nível do fator $i$ original; $\bar{B}_{l}$ é o valor médio entre os níveis; e $\frac{A}{2}$ é a metade da variação entre os níveis (BEZERRA et al., 2008).

Figura 5 - Níveis e distribuição espacial de um planejamento $2^{2}$ com variáveis a) reais e b) codificadas.

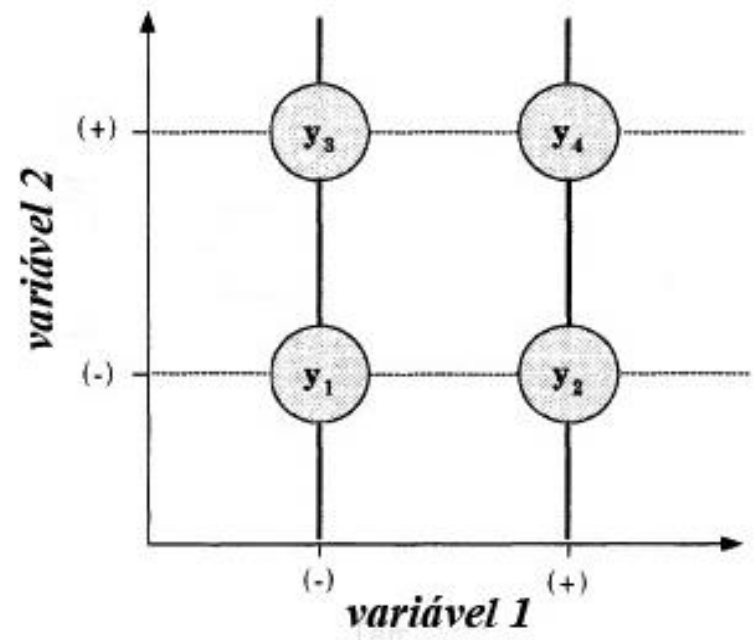

a)

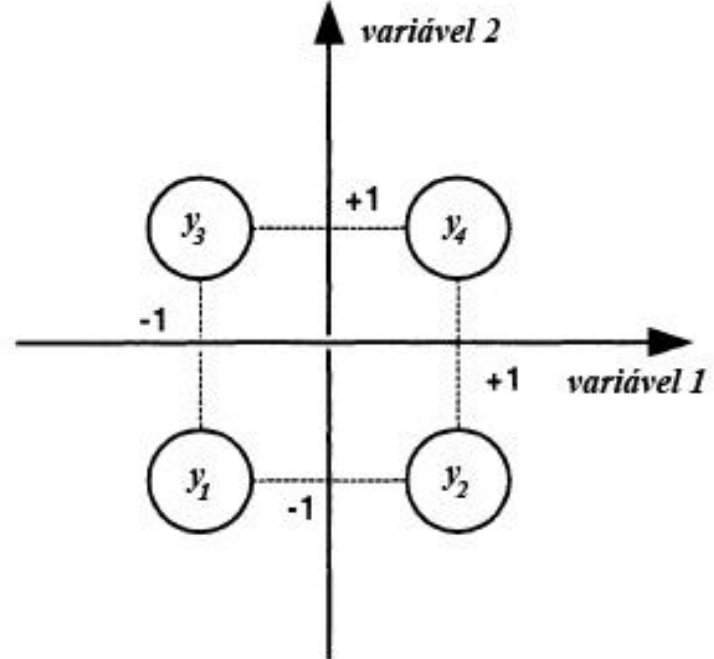

b)

Fonte: Adaptação de BARROS NETO; SCARMINIO; BRUNS, 2007.

$$
b_{i}=\frac{B_{i}-\overline{B_{l}}}{\frac{A}{2}}
$$

Os planejamentos $2^{\mathrm{k}}$ são muito comuns e são amplamente utilizados em triagens e estudos preliminares por sua simplicidade; mas, com o tempo, podem ser transformados em planejamentos mais sofisticados que conseguem descrever melhor a relação fator $\times$ resposta (BARROS NETO; SCARMINIO; BRUNS, 2007). É importante ressaltar que esses experimentos devem ser realizados, inicialmente, em duplicatas, para que seja possível estimar o erro experimental e de forma aleatória, pois dessa maneira minimizam-se as chances de se obterem dados errados de uma mesma réplica experimental ou de uma combinação em particular de dados, o que contribui para uma melhor qualidade das informações estatísticas coletadas e confere maior confiabilidade aos resultados (BRASIL et al., 2007). 
Após os experimentos terem sido realizados, a modelagem dos dados é feita através de uma regressão linear e os resultados são avaliados plotando-se gráficos de superfície entre os fatores, em um plano bidimensional representativo do comportamento da variável-resposta dentro da faixa estudada. Os modelos iniciais gerados podem ser descritos em funções lineares sem interações, do tipo exemplificado pela Equação 16, de três fatores diferentes, onde $b_{0}, b_{1}, b_{2}$ e $b_{3}$ são os coeficientes estimadores do modelo e $x_{1}, x_{2}$ e $x_{3}$ são os valores dos fatores codificados.

$$
\hat{y}=b_{0}+b_{1} x_{1}+b_{2} x_{2}+b_{3} x_{3}
$$

Também é possível analisar a significância de cada fator por meio de um diagrama de Pareto. O diagrama de Pareto é um gráfico de colunas que dispõe em ordem de maior importância, ou significância, os fatores do sistema experimental; ordenando-os e seus efeitos em uma sequência de "urgência", ou em outras palavras, relevância ao sistema, na faixa estudada. Também apresenta uma linha que determina o limite de confiança dos dados experimentais e valores negativos e positivos que indicam, respectivamente, os efeitos que causam modificações negativas e positivas na variável resposta, caso haja uma alteração positiva ao determinado fator (BARROS NETO; SCARMINIO; BRUNS, 2007).

Concluindo essa etapa, caso os fatores e os níveis escolhidos tenham sido adequados, as respostas obtidas normalmente indicam uma direção na qual prosseguir a fim de se atingir o objetivo inicialmente estabelecido, um caminho de "deslocamento" para a região de ótimo. Para prosseguir-se nesse sentido, toma-se como referência o fator de maior coeficiente em módulo (mais significativo) e determina-se um passo arbitrário, em unidades codificadas, no sentido do aumento de resposta, como mostrado na Figura 6. Os demais fatores são então calculados proporcionalmente a esse valor utilizado como referência, por meio da Equação 17, na qual $b_{i}$ e $b_{j}$ são os valores dos coeficientes da equação do modelo ajustado correspondentes, respectivamente, ao fator tomado como referência e ao fator sendo calculado; $x_{i}$ é o valor do passo dado, codificado, da variável de referência e $x_{j}$ é o valor, proporcional ao passo, do fator sendo calculado.

$$
\Delta x_{j}=\frac{b_{j}}{b_{i}} \Delta x_{i}
$$


Figura 6 - Exemplo de um caminho no sentido da máxima inclinação.

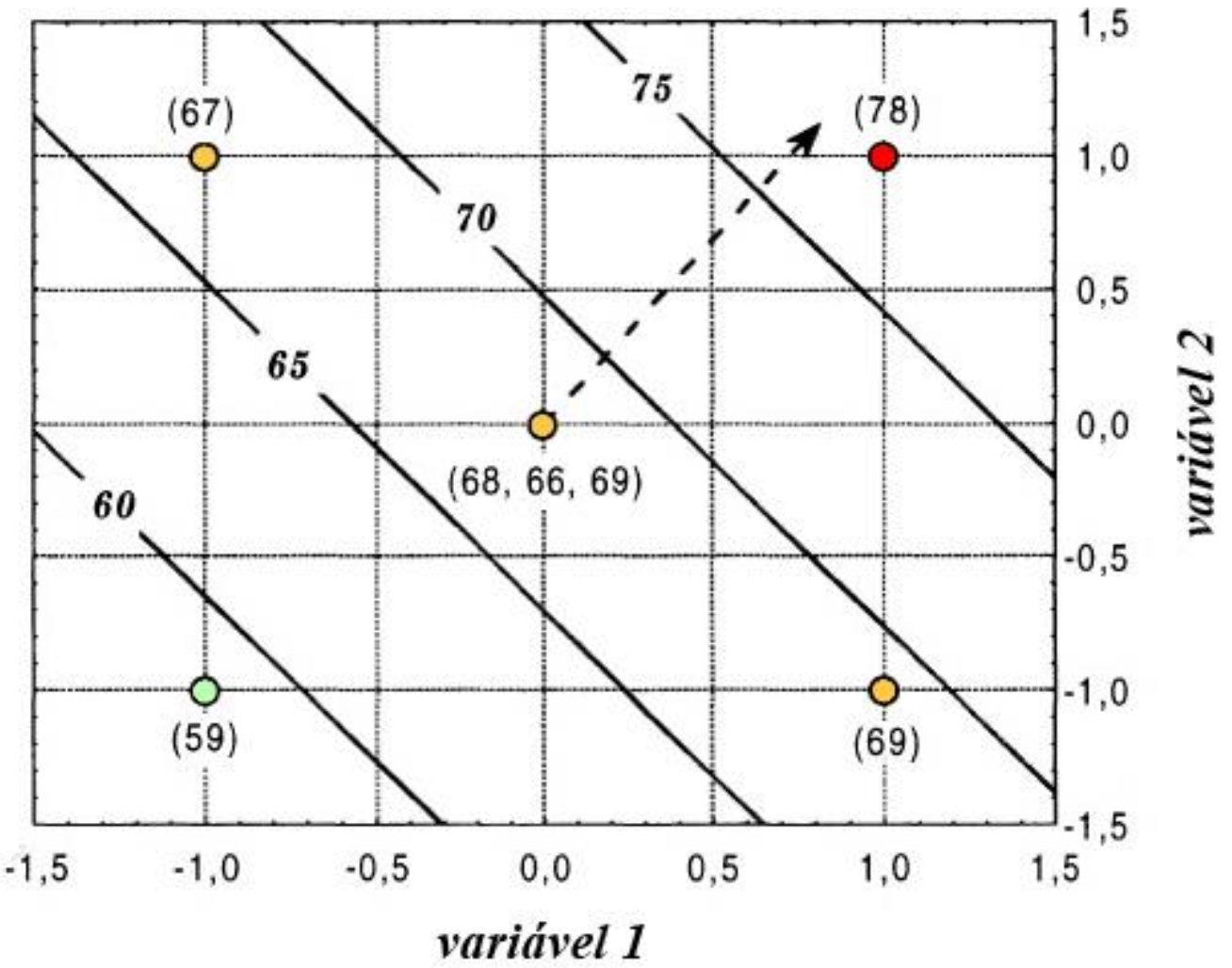

Fonte: Adaptação de BARROS NETO; SCARMINIO; BRUNS, 2007.

Estes novos experimentos são realizados, em passos cada vez maiores, até que se note uma diminuição ou aumento na resposta, dependendo do objetivo inicial, indicando que a região de máximo, ou de ótimo, foi atingida. Um novo planejamento é realizado em torno desse máximo local, com um número maior de níveis. O objetivo de se realizar um planejamento com mais de dois níveis é para se aumentar o número de graus de liberdade, verificar se há falta de ajuste no modelo e gerar uma função quadrática capaz de descrever a superfície de resposta de modo acurado, como mostrado, por exemplo, pela Equação 18, para 3 fatores (BARROS NETO; SCARMINIO; BRUNS, 2007).

$$
\hat{y}=b_{0}+b_{1} x_{1}+b_{2} x_{2}+b_{3} x_{3}+b_{4} x_{1}^{2}+b_{5} x_{2}^{2}+b_{6} x_{3}^{2}+b_{7} x_{1} x_{2}+b_{8} x_{1} x_{3}+b_{9} x_{2} x_{3}
$$

Existem diversos tipos de planejamentos que atendem a esse requisito, como os fatoriais de três ou mais níveis, Box-Behnken, Doehlert etc. Porém, os mais comuns são os compostos centrais para se avaliar curvaturas na superfície de resposta (BEZERRA et 
al., 2008). O planejamento de composto central pode ser fracionado em três partes distintas, que podem ser feitas em dois planejamentos diferentes: parcela fatorial, parcela axial e ponto central, como mostrado na Figura 7 nas cores vermelha, preta e roxo, respectivamente.

Figura 7 - Níveis de um planejamento composto central com dois fatores.

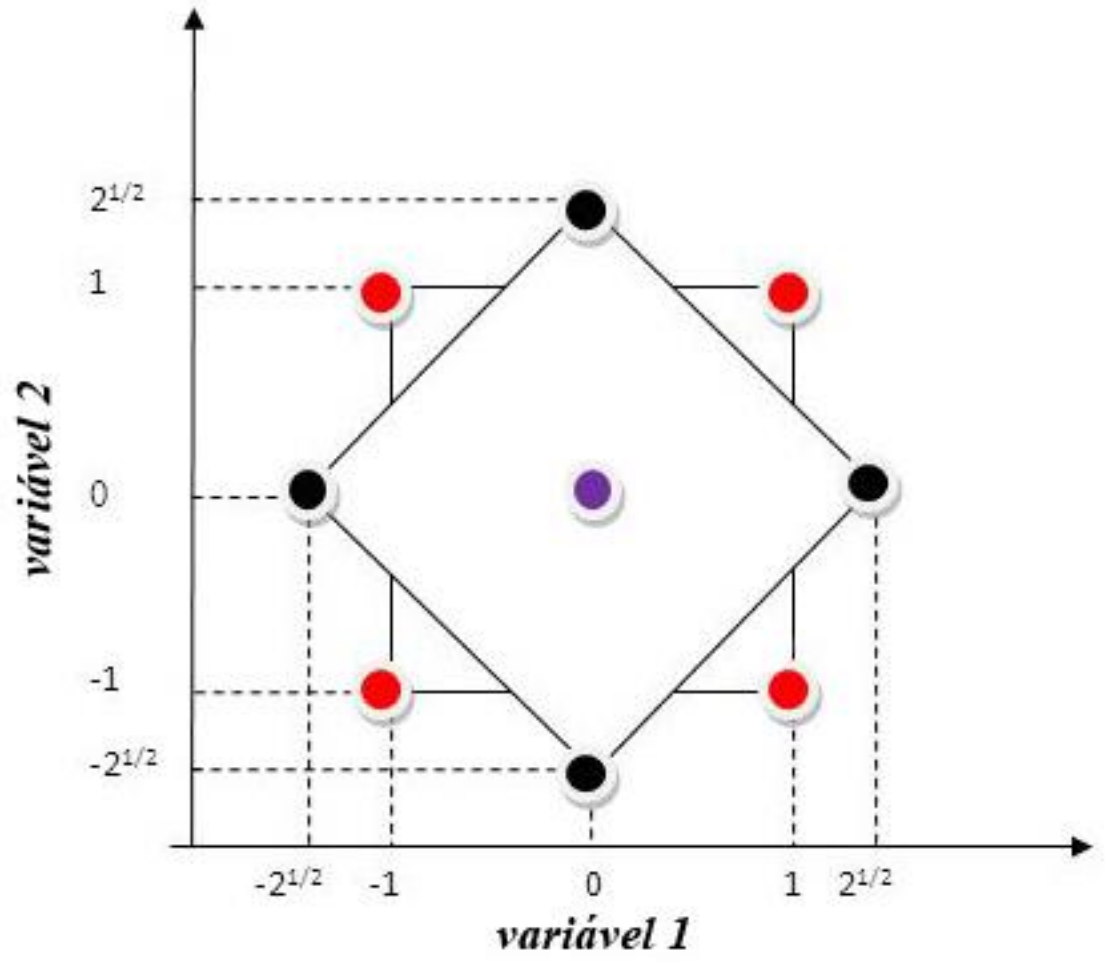

Fonte: Adaptação de BARROS NETO; SCARMINIO; BRUNS, 2007.

Note-se que a parcela axial corresponde a um giro de $45^{\circ}$ da parcela fatorial no gráfico da Figura 7 ou $\left(2^{k}\right)^{1 / 4}$ em valores codificados, onde $k$ é o número de fatores. Sabendo-se disso, é possível dividir o planejamento composto central em dois planejamentos fatoriais com ponto central, distintos. As réplicas são usadas para estimar o erro experimental, assim como a curvatura da superfície de resposta (BARROS NETO; SCARMINIO; BRUNS, 2007).

Para a determinação do ponto ótimo, deriva-se e iguala-se a zero a função da superfície de resposta, encontrando o máximo ou mínimo local e depois traduzindo seu valor utilizando a Equação 17. 
Por fim, é necessário se avaliar se o modelo proposto é significativo e está bem ajustado aos dados experimentais. Para isso, utiliza-se a Análise da Variância ou ANOVA (do inglês Analysis of Variance) (BARROS NETO; SCARMINIO; BRUNS, 2007).

De acordo com Barros Neto, Scarminio e Bruns (2007), a ANOVA baseia-se na decomposição algébrica do somatório dos desvios entre as respostas do sistema e sua média global $\left(y_{i}-\bar{y}\right)$, em duas somatórias distintas, e pode ser descrita quantitativamente pela Equação 19.

$$
\sum\left(y_{i}-\bar{y}\right)^{2}=\sum(\hat{y}-\bar{y})^{2}+\sum\left(y_{i}-\hat{y}\right)^{2}
$$

A primeira parcela corresponde à diferença entre as respostas previstas pelo modelo com relação à resposta média global observada $\left(\hat{y}_{i}-\bar{y}\right)$; e, a segunda, à diferença entre as respostas observadas com relação às respostas previstas pelo modelo $\left(y_{i}-\hat{y}_{i}\right)$.

Para maior praticidade, os termos da Equação 19 são também chamados de Soma Quadrática Total ( $\left.\mathrm{SQ}_{\mathrm{T}}\right)$, Soma Quadrática da Regressão $\left(\mathrm{SQ}_{\mathrm{R}}\right)$ e Soma Quadrática Residual $\left(\mathrm{SQ}_{\mathrm{r}}\right)$, respectivamente (Equação 20).

$$
S Q_{T}=S Q_{R}+S Q_{r}
$$

Num modelo bem ajustado, em termos quantitativos, espera-se que a Somatória Residual tenha um valor pequeno. Um resíduo pequeno implica que os valores previstos pelo modelo são mais próximos aos desvios observados na prática, configurando um bom ajuste. É possível descrever essa relação de forma mais clara pelo coeficiente de determinação, ou $\mathrm{R}^{2}$, que corresponde à razão entre a Soma Quadrática da Regressão e a Soma Quadrática Total, como mostrado na Equação 21 (NAGELKERKE, 1991).

$$
R^{2}=\frac{S Q_{R}}{S Q_{T}}=\frac{\sum(\hat{y}-\bar{y})^{2}}{\sum\left(y_{i}-\bar{y}\right)^{2}}
$$


Em uma situação ideal, onde não há resíduos e todos os pontos do sistema coincidem com os do modelo, $\mathrm{SQ}_{\mathrm{R}}=\mathrm{SQ}_{\mathrm{T}}$ e $\mathrm{R}^{2}=1$. Como não há sistemas ideais, assume-se que quanto maior o $\mathrm{R}^{2}$, mais bem ajustado está o modelo (NAGELKERKE, 1991).

Cada Soma Quadrática está associada a um certo número de graus de liberdade, que corresponde à quantidade necessária de valores independentes envolvendo as $n$ observações ou $p$ coeficientes do modelo, para se determiná-la (BARROS NETO; SCARMINIO; BRUNS, 2007). A razão entre a Soma Quadrática e seus graus de liberdade correspondentes, é chamada de Média Quadrática (MQ), como mostrado pelas Equações 22,23 e 24.

$$
\begin{gathered}
M Q_{T}=\frac{S Q_{T}}{n-1}=\frac{\sum\left(y_{i}-\bar{y}\right)^{2}}{n-1} \\
M Q_{R}=\frac{S Q_{R}}{p-1}=\frac{\sum(\hat{y}-\bar{y})^{2}}{p-1} \\
M Q_{r}=s^{2}=\frac{S Q_{r}}{n-p}=\frac{\sum\left(y_{i}-\hat{y}\right)^{2}}{n-p}
\end{gathered}
$$

Sabendo disso, pode-se verificar se a equação de regressão é estatisticamente significativa através de um teste $\mathrm{F}$, que determina se há relação entra a variável resposta $(\hat{y})$ e as variáveis de regressão ( $x_{p}$, para $p$ coeficientes). No teste $\mathrm{F}$, admitem-se duas hipóteses. A primeira é de que há relação entre as variáveis-resposta e de regressão e $b_{p} \neq 0$. A segunda hipótese é de que não há relação entre elas $\left(b_{p}=0\right)$ e a razão entre a Média Quadrática da Regressão e a Média Quadrática Residual do modelo seguem uma distribuição F, como mostrado pela Equação 25 (SILVA, 2008).

$$
F_{p-1, n-p}=F_{\text {calculado }} \cong \frac{M Q_{R}}{M Q_{r}}
$$

Assim, pode-se testar esta última hipótese, também chamada de hipótese nula, substituindo-se os respectivos valores de $\mathrm{MQ}_{\mathrm{R}}$ e $\mathrm{MQ}_{\mathrm{r}}$ e comparando-se o valor obtido a

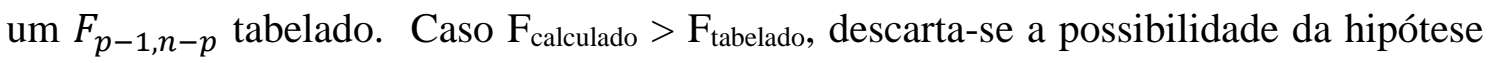
nula e pode-se afirmar que há uma relação entre as variáveis de regressão e a variável- 
resposta. Quanto maior o valor de $\mathrm{F}_{\text {calculado }}$ (maior $\mathrm{MQ}_{\mathrm{R}}$ e menor $\mathrm{MQ}_{\mathrm{r}}$ ), melhor esta relação e o modelo está bem ajustado (SILVA, 2008).

Um outro critério quantitativo que pode ser utilizado para julgar se o modelo é uma boa representação das observações ou não, é através da estimativa do erro do sistema, que só é possível caso haja réplicas em algum ponto no planejamento. Atribuindo um índice, $j$, às repetições, pode-se reescrever uma resposta genérica $y$, do experimento, por $y_{i j}$, onde $j$ e $i$ serão a $j$-ésima réplica para o $i$-ésimo ensaio distinto (BARROS NETO; SCARMINIO; BRUNS, 2007).

Assim, admitindo-se que hajam $m$ ensaios diferentes, o desvio residual $\left(\mathrm{SQ}_{\mathrm{r}}\right)$, pode ser reescrito e decomposto, semelhantemente ao desvio total ( $\mathrm{SQ}_{\mathrm{T}}$ ) anteriormente, em duas parcelas distintas, tal como mostrado, respectivamente, nas Equações 26 e 27.

$$
\begin{gathered}
S Q_{r}=\sum_{i}^{m}\left(S Q_{r}\right)_{i}=\sum_{i}^{m} \sum_{j}^{n_{i}}\left(y_{i j}-\hat{y}_{i}\right)^{2} \\
\sum_{i}^{m} \sum_{j}^{n_{i}}\left(y_{i j}-\hat{y}_{i}\right)^{2}=\sum_{i}^{m} \sum_{j}^{n_{i}}\left(y_{i j}-\bar{y}_{i}\right)^{2}+\sum_{i}^{m} \sum_{j}^{n_{i}}\left(\hat{y}_{i}-\bar{y}_{i}\right)^{2}
\end{gathered}
$$

A primeira parcela corresponde ao desvio de cada réplica de um ensaio distinto em relação à sua própria média, enquanto que a segunda parcela corresponde ao desvio de cada resposta prevista em relação à média das respostas observadas para o ensaio.

Em outras palavras, o primeiro somatório trata-se dos erros aleatórios, ou seja, dos erros associados à própria dispersão de dados no sistema e é chamado de Soma Quadrática devida ao Erro Puro ( $\mathrm{SQ}_{\mathrm{ep}}$ ), ou somente Erro Puro. Já o segundo somatório, no entanto, depende do modelo e é chamada de Soma Quadrática devida à Falta de Ajuste ( $\left.\mathrm{SQ}_{\mathrm{faj}}\right)$, ou apenas Falta de Ajuste (BARROS NETO; SCARMINIO; BRUNS, 2007).

Logo, a Equação 27 pode ser reescrita como na Equação 28.

$$
S Q_{r}=S Q_{e p}+S Q_{f a j}
$$

Se for retirada da somatória total a parcela correspondente aos erros aleatórios do sistema, e for dividida pela própria somatória, tem-se o valor máximo de explicação que 
o modelo ajustado pode fornecer à respeito das observações, ou $\mathrm{R}^{2}$ máx, como mostrado na Equação 29.

$$
R^{2} \text { max }=\frac{S Q_{T}-S Q_{e p}}{S Q_{T}}
$$

Cada novo termo da Soma Quadrática está relacionado a um número de graus de liberdade diferente e, consequentemente, a uma nova Média Quadrática. A Tabela 4 apresenta todas as relações descritas, e corresponde, enfim, à Tabela ANOVA usada para a avaliação do modelo no planejamento pela metodologia de superfície de resposta (SILVA, 2008).

Tabela 4 - Tabela ANOVA.

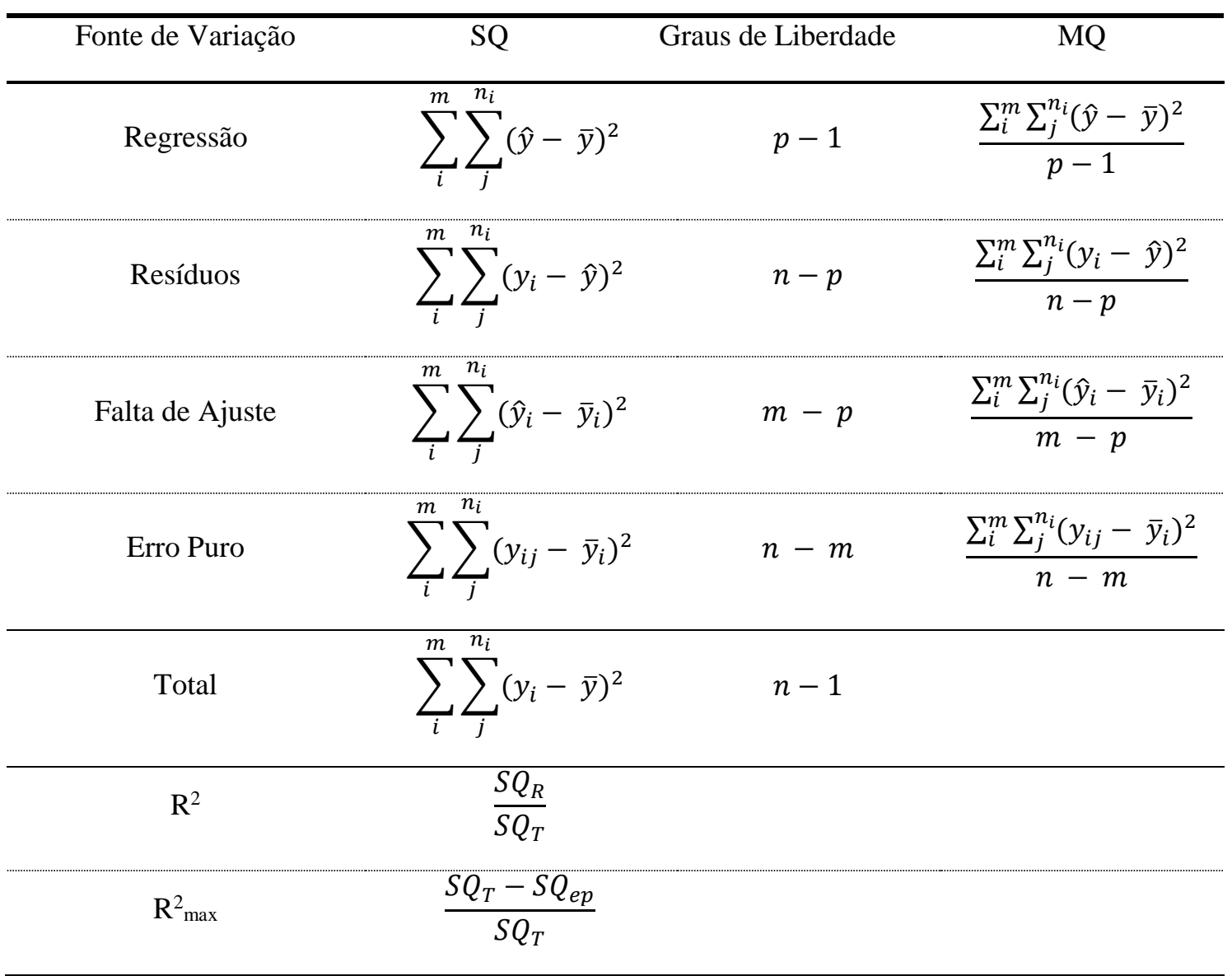

Fonte: Autoria própria. 
Vale ressaltar que, para o cálculo de $\mathrm{MQ}_{\mathrm{faj}}$, é necessário que se tenha mais ensaios $(m)$ do que fatores $(p)$ para que haja graus de liberdade suficientes para ser testada a falta de ajuste no modelo.

\subsection{Determinação de Parabenos}

Como ilustrado pela Figura 2, os parabenos podem ser encontrados nas mais diversas matrizes, seja constituindo alimentos ou produtos cosméticos, seja dissolvidos na água e distribuídos pelo ar e pelo solo. Também pela mesma Figura, e pela Tabela 2, pode-se assumir que, a grosso modo, os parabenos são encontrados em baixas concentrações nestes diferentes meios, com uma magnitude da ordem de nano ou microgramas por litro ou de nano ou microgramas por grama.

Portanto, para a escolha do método de determinação dos parabenos, deve-se levar em consideração se o método escolhido é adequado para o tipo de matriz e se ele é suficientemente sensitivo para identificar corretamente as baixas concentrações dos analitos na matriz.

A cromatografia é a técnica mais empregada para a determinação e separação dos parabenos, principalmente a cromatografia líquida (LC). Em alguns casos, porém, a LC pode não ser sensível o suficiente (dependendo do detector utilizado) para a detecção de concentrações muito baixas e matrizes complexas dificultam a separação completa dos analitos. Para contornar esses problemas, existem diversas técnicas de preparo de amostra. Elas são capazes de separar total ou parcialmente o analito de interesse dos diversos componentes de uma matriz e, em alguns casos, ainda permite concentrá-lo na solução final, de modo a ser detectado mais facilmente pelos equipamentos. Estes procedimentos facilitam a análise, pois são rápidos e simples e permitem que a análise seja realizada com grande precisão mesmo em equipamentos menos sofisticados (PIAO; CHEN; WANG, 2014).

Algumas das técnicas mais comuns de preparo de amostra para os parabenos são ilustradas no esquema da Figura 8. 
Figura 8 - Fluxograma com as técnicas de preparo de amostra e análise para os parabenos.

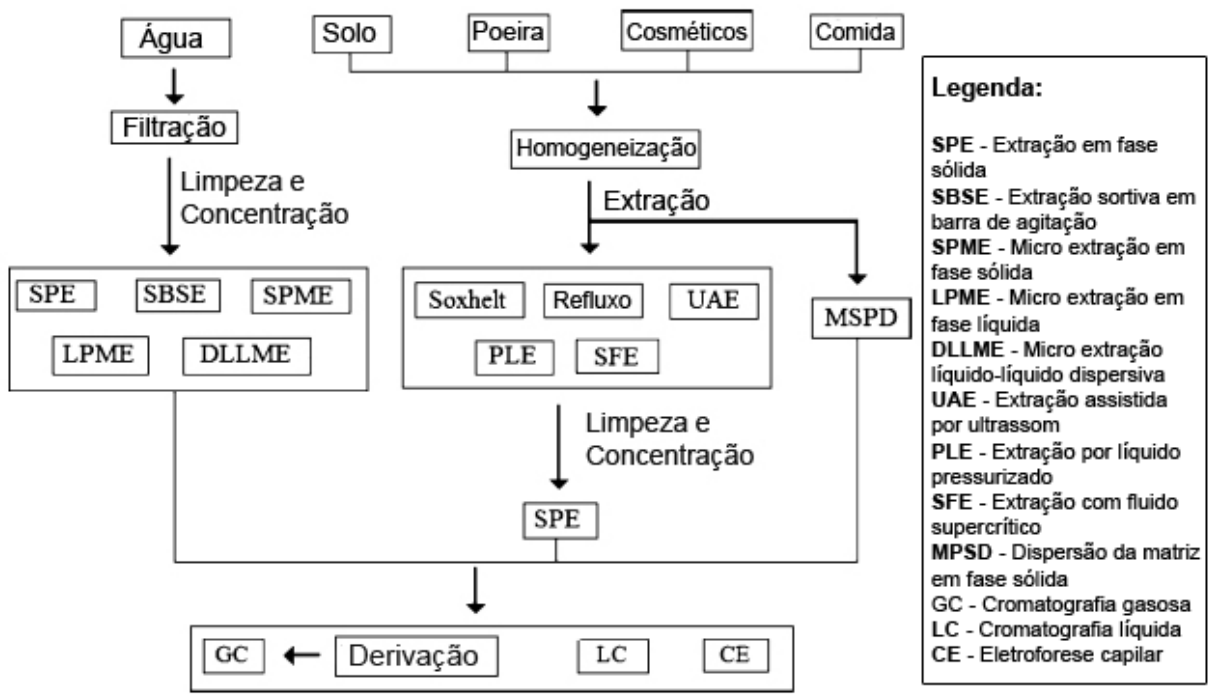

Fonte: Adaptação de PIAO, C.; CHEN, L.; WANG, Y., 2014, p. 141.

Entre os principais tipos de técnicas de preparo de amostra, ilustrados na Figura 8, destacam-se os adequados para matrizes líquidas: SPE, SPME, SBSE e DLLME, que empregam o princípio da distribuição do analito entre a fase aquosa e a fase extratora.

A micro extração líquido-líquido dispersiva (DLLME) é uma técnica rápida, de baixo custo e baixo consumo de solventes para extração e pré-concentração de analitos em amostras. Seu princípio baseia-se no uso de dois solventes: o primeiro (solvente extrator) é um solvente imiscível em água, no qual o analito deve possuir maior solubilidade; já o segundo (solvente dispersivo), deve ser parcialmente miscível, tanto em água como no solvente extrator, para permitir que haja uma grande área de interação entre a fase aquosa das amostras com a fase orgânica do solvente extrator. Além de permitir a extração do analito de interesse da matriz, a técnica também é um método de pré-concentração (GALINARO; PEREIRA; VIEIRA, 2015). 


\subsection{Ecotoxicologia}

A toxicologia pode ser definida como o ramo da ciência voltada para o estudo de agentes físicos e químicos, sintéticos ou naturais, que de alguma forma possam apresentar ou causar toxicidade aos organismos vivos (HODGSON, 2004). Já a ecotoxicologia envolve tanto conceitos de toxicologia quanto de ecologia, analisando-se a toxicidade não só para um único organismo, mas para uma população, bioma ou ecossistema. Embora a própria natureza possua mecanismos de eliminar agentes tóxicos, seja por processos bióticos ou abióticos, existem muitos compostos "persistentes" que resistem à degradação e permanecem um longo período de tempo no meio ambiente. Compostos orgânicos sintéticos como DDT (diclorodifeniltricloroetano), PCBs (bifenilpoliclorados) e TCDD (tetraclorodibenzo-p-dioxina) são alguns dos exemplos. Com o tempo estas substâncias podem sofrer bioacumulação na natureza e, subsequentemente nos organismos que ali vivem ou se alimentam, resultando em diversos problemas ambientais (LEIDY, 2004).

A medida da toxicidade de uma substância é complexa, pois varia de acordo com as propriedades da substância, com as características do organismo contaminado, a concentração (dosagem) ao qual o organismo foi exposto e também o tempo de exposição, fator que caracteriza se a toxicidade é de efeito agudo ou crônico (HODGSON, 2004).

A toxicidade aguda de uma substância caracteriza-se pelos efeitos por ela causada em um curto espaço de tempo, de até 14 dias após a administração de uma dose única ou de múltiplas exposições dentre as 24 horas iniciais. Já a toxicidade crônica é causada pela exposição contínua do organismo à uma substância, cujos efeitos são notados após um longo período de tempo (IUPAC, 1997).

Do ponto de vista quantitativo, estes efeitos são medidos em termos de $\mathrm{LD}_{50}, \mathrm{LC}_{50}$ ou $\mathrm{EC}_{50}$. As $\mathrm{LD}_{50}$ e ED50 correspondem à dosagem, enquanto que $\mathrm{LC}_{50}$ e $\mathrm{EC}_{50}$ correspondem à concentração, do material necessária para causar a mortalidade ( $\mathrm{LD}_{50}$ e $\left.\mathrm{LC}_{50}\right)$ ou algum outro efeito não definido $\left(\mathrm{ED}_{50}\right.$ e $\left.\mathrm{EC}_{50}\right)$ em $50 \%$ da população administrada; os dois primeiros termos são tratados de acordo com a dosagem da substância normalizada pelo peso do animal (ex., mg da substância $\mathrm{mg}^{-1}$ peso do animal), enquanto que os segundos termos tratam apenas da concentração do composto (ex., $\mathrm{mg} \mathrm{L}^{-1}$ em água) (LE BLANC, 2004). 
Estes parâmetros podem ser avaliados através de uma curva de dose/concentração pela resposta. A resposta é obtida através de experimentos no qual expõe-se um grupo de organismos à diversas concentrações ou dosagens da substância avaliada. Os resultados são plotados e normalmente a curva apresenta uma forma sigmoidal, como mostrado pela Figura 9 (LE BLANC, 2004).

Figura 9 - Curva efeito vs. dosagem

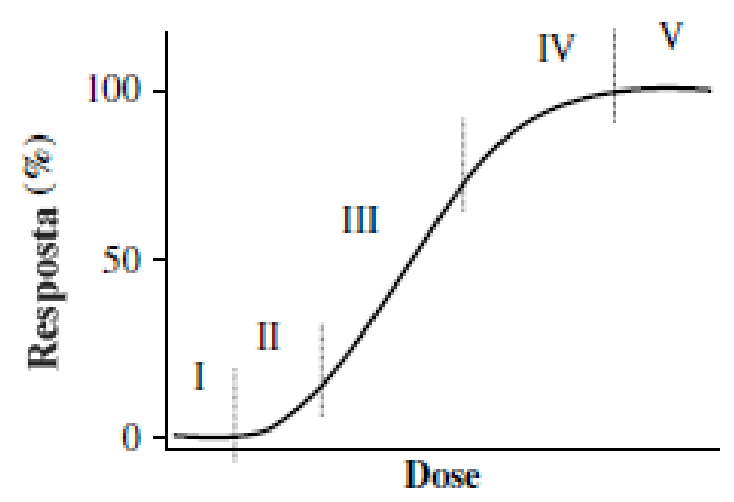

Fonte: Adaptação de LE BLANC, 2004.

Os segmentos I e II da curva correspondem à concentração ou dosagem do composto tóxico que não causou mortalidade aos organismos ou apenas aos mais susceptíveis, respectivamente. Os segmentos IV e V correspondem à concentração ou dosagem que causou a mortalidade dos organismos mais resistentes ou de todos os organismos, respectivamente. O segmento III, é o segmento de interesse, pois é a dosagem na qual a maior faixa $(50 \%)$ de indivíduos é afetada, e é a partir desta resposta que os parâmetros LD $\mathrm{LC}_{50}, \mathrm{ED}_{50}$ e $\mathrm{EC}_{50}$ são calculados (LE BLANC, 2004).

Estes testes podem ser realizados utilizando-se organismos animais, normalmente usando-se cobaias de espécies de ratos ou hamsters laboratoriais. Podem ser realizados também através de culturas de micro-organismos como Escherichia coli, Daphnia similis e Vibrio fischeri. Estes últimos são utilizados principalmente como parâmetro de qualidade de corpos aquáticos. E, por fim, há os testes com organismos vegetais como, por exemplo, sementes de Lactuca sativa (alface), no qual avalia-se o efeito letal, que corresponde a uma inibição de $50 \%$ da germinação das sementes, e o efeito subletal, indicado pelo crescimento da radícula e do hipocótilo. Nesse caso, embora não haja inibição da germinação das sementes, a plântula pode apresentar um alongamento ou diminuição no 
tamanho da radícula e do hipocótilo comparado ao controle (água pura) devido ao contaminante ou o efluente utilizado, este efeito é chamado de efeito subletal (CASTRO, 2013).

Todos os testes são regulados de acordo com parâmetros estabelecidos por órgãos ambientais, tais como a Agência de Proteção Ambiental dos Estados Unidos, a EPA (1996) e a Organização de Cooperação e Desenvolvimento Econômico OECD (2003) (BERTOLETTI, 2013). 


\section{Justificativa}

Os parabenos podem ser considerados como interferentes endócrinos leves e apresentam uma baixa atividade estrogênica. Embora, em grande parte, sejam metabolizados e excretados pelo organismo, o seu risco está na sua ampla aplicação e na gama diversificada de produtos que os contêm em sua fórmula, sendo que os mais utilizados são o metilparabeno e o propilparabeno, por possuírem boa atividade antimicrobiana, serem estáveis numa grande faixa de $\mathrm{pH}$ e serem solúveis em água. Isto implica numa exposição diária e excessiva dos seres humanos a estes preservantes, como visto na Figura 2.

As ETE conseguem degradar a maior parte dos parabenos presentes no esgoto; entretanto, como mostrado na Tabela 2, concentrações da ordem de $\mu \mathrm{g} \mathrm{L}^{-1}$ e ng L $\mathrm{L}^{-1}$ ainda são encontrados nos esgotos tratados.

Os POA são uma alternativa para a degradação desta classe de compostos, assim como muitos outros contaminantes, pois são processos razoavelmente simples e de baixo custo. Muitos trabalhos na literatura versam sobre a degradação dos parabenos por POA, porém, até onde se estendeu a pesquisa na base de dados, nenhum trabalho que utilizava luz solar ou um reator do tipo CPC foi encontrado. A maior parte dos estudos se limitam a utilizar um sistema de simulação com lâmpadas UV para as reações de foto-Fenton e de valores relativamente altos para a concentração inicial de parabenos, da ordem de $\mathrm{mg} \mathrm{L}^{-1}$.

Portanto, a utilização de um reator de maior escala e luz solar para a degradação dos compostos com concentrações mais próximas das quais são normalmente encontradas em efluentes foram os motivos que impeliram a realização deste estudo. 


\section{Objetivos}

- Otimizar a degradação do metilparabeno e do propilparabeno em água ultrapura por um POA (foto-Fenton), usando-se um reator CPC solar;

- Determinar as constantes de taxa de remoção;

- Avaliar a fitotoxicidade e a atividade antimicrobiana do efluente obtido. 


\section{Materiais e Métodos}

\subsection{Reator Solar}

Na Figura 10 é mostrado o reator solar CPC que foi utilizado. Na Figura 10a observa-se a vista ortográfica do reator e na Figura $10 \mathrm{~b}$ em fotos. Os tubos por onde passa a amostra a ser degradada são vistos em detalhe na Figura $10 b$.

Figura 10 - Reator CPC: a) vistas ortográficas (dimensões em $\mathrm{cm}$ ) e b) fotos.
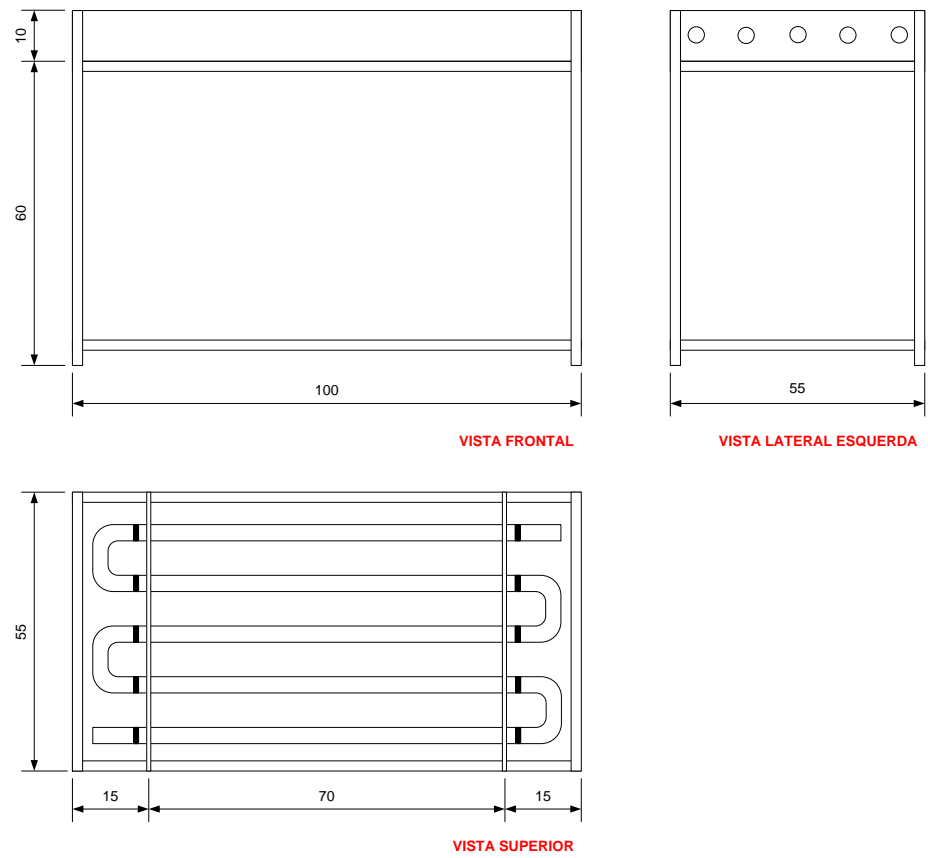

(a)
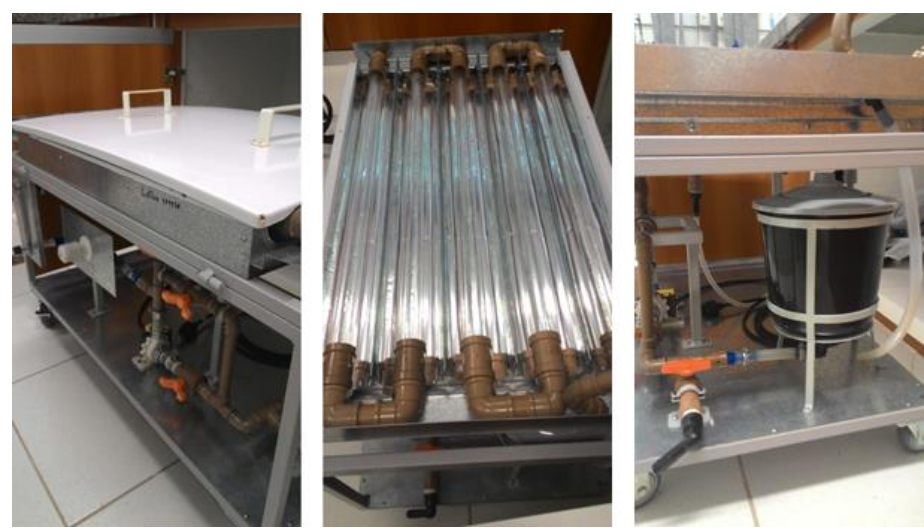

(b)

Fonte: Autoria própria. 
O reator é composto por cinco tubos feitos de vidro borossilicato (Schott-Duran ${ }^{\text {, }}$ tipo 3.3, diâmetro interno $28 \mathrm{~mm}$, comprimento $750 \mathrm{~mm}$, espessura 2,0 $\mathrm{mm}$ ) transparente à radiação solar incidente a partir de aproximadamente $280 \mathrm{~nm}$, como mostrado na Figura 11.

Figura 11 - Espectro da transmissão de luz no vidro borossilicato.

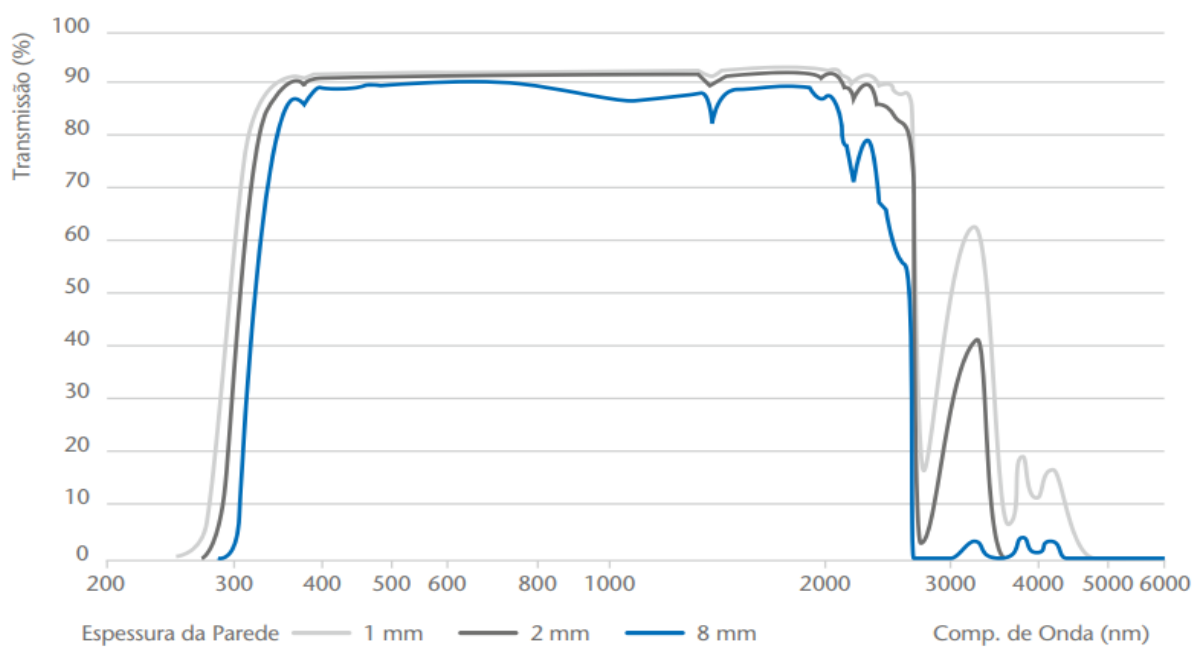

Fonte: Catálogo Schott "Tubos, Capilares e Hastes de Vidro de Borossilicato 3.3 Duran®”.

Os cinco tubos são ligados em série e as superfícies refletoras são moldadas por meio de chapas de alumínio polido que possuem uma boa refletância para comprimentos de onda de interesse entre 300-400 nm, das radiações UVA e UVB, que é a faixa onde o complexo de ferro das reações de foto-Fenton absorve, como mostrado pela Figura 12 (MOTA, 2010). A área iluminada total do reator CPC é de $0,33 \mathrm{~m}^{2}$. 
Figura 12 - Reflectância do alumínio e de outros materiais.

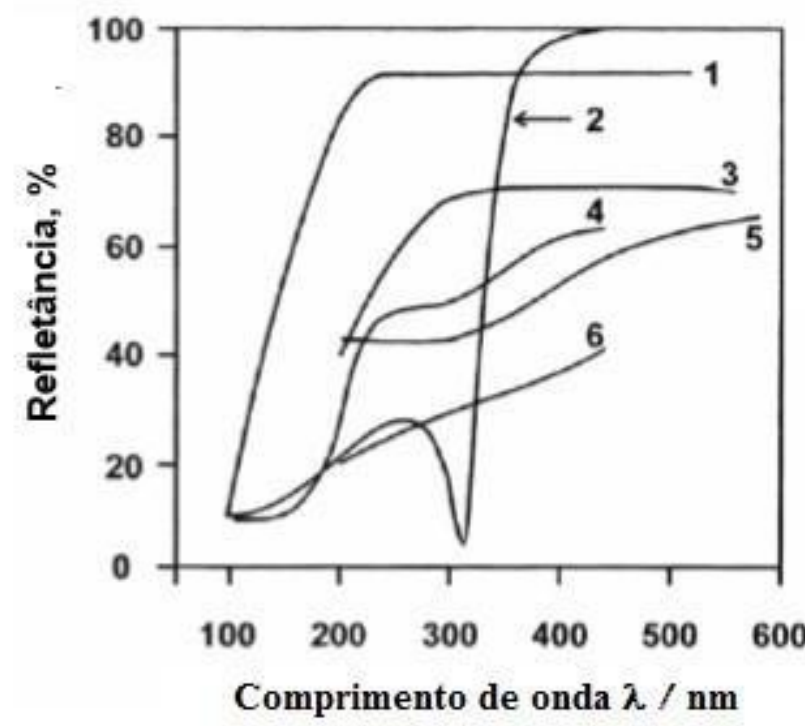

1. Alumínio

2. Prata

3. Cromo

4. Paládio

5. Níquel

6. Aço inoxidável

Fonte: MOTA, A. L. N., 2010, p. 11.

O reator possui uma bomba de recirculação que deve ser operada de forma afogada. O volume mínimo a ser utilizado no sistema e garantir seu funcionamento é de 4,5 L, sendo que o reservatório, localizado no plano abaixo da tubulação (Figura 10), possui capacidade máxima de 5,5 L. O controle da vazão foi feito por um rotâmetro, cuja vazão máxima era de 2,0 $\mathrm{L} \mathrm{min}^{-1}$.

A irradiância no reator foi medida por meio de um espectrorradiômetro StellarNet EPP2000C, com seu sensor de fibra óptica posicionado no mesmo plano do reator, garantindo assim a mesma incidência solar para ambos. Como a latitude da cidade de São Carlos é $22^{\circ} \mathrm{S}$, o reator CPC foi operado com essa inclinação e seus refletores direcionados para o norte, para maximizar a absorção de luz.

A quantidade de radiação solar que chega ao reator influencia diretamente a eficiência do processo foto-Fenton e varia de acordo com diversos fatores, como: a latitude do local, a época do ano e o clima no momento do experimento. Logo, a medição da intensidade da radiação solar em cada experimento é importante, pois permite que sejam normalizados e comparáveis mesmo tendo sido realizados em condições diferentes. 


\subsection{Extração e Quantificação}

A determinação dos parabenos em água foi feita por cromatografia líquida de alta eficiência com detector de arranjo de diodos (HPLC-DAD). Escolheu-se esta instrumentação, pois se utilizou uma mistura de parabenos (metil e propil) em solução aquosa. Como a concentração da amostra a ser degradada era baixa $\left(\mu \mathrm{g} \mathrm{L}^{-1}\right)$, foi necessário utilizar uma etapa de pré-concentração dos parabenos para assegurar uma boa análise cromatográfica. A técnica escolhida foi a microextração líquido-líquido dispersiva (DLLME).

De forma resumida, o procedimento da DLLME é mostrado pela Figura 13. A partir da amostra inicial em um tubo Falcon (1), injeta-se rapidamente, com uma seringa, uma mistura do solvente extrator com o solvente dispersivo dando origem a uma solução turva (2). Em seguida, agita-se a solução por meio de um agitador de tubos (vórtex) por uma quantidade de tempo determinada (3). Centrifuga-se então a amostra para a separação das fases (4). Coleta-se a fase orgânica com auxílio de uma microsseringa (por ser um volume pequeno, um pouco da fase aquosa também é coletada), transferindo-a para um primeiro inserto (5). No inserto, a separação entre a fase aquosa e a fase orgânica é mais evidente, permitindo a coleta somente da fase orgânica (6). Por fim, a fase orgânica é transferida para um inserto dentro de um "vial" contendo um segundo inserto (7), que será levado para a análise cromatográfica.

Figura 13 - Esquema da DLLME.

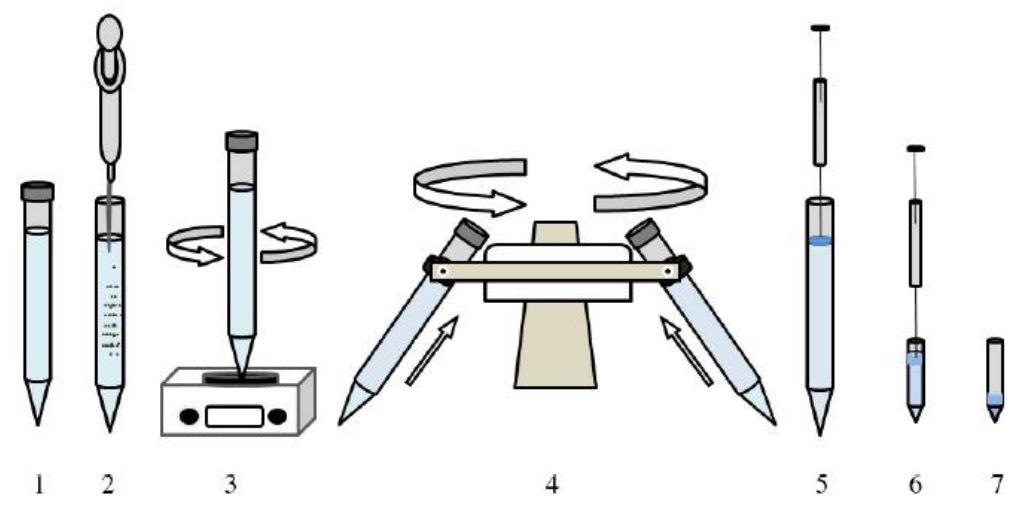

Fonte: Adaptação de GALINARO, C. A.; PEREIRA, F. M.; VIEIRA, E.M., 2015. 
Diversos parâmetros influenciam na eficiência da DLLME, como: pH e volume de amostra, volume e tipo dos solventes extratores e dispersivos, adição ou não de sal para o efeito salting out, tempo e velocidade de agitação etc. Portanto, para a obtenção de bons resultados, é necessário otimizá-los. Os parâmetros já otimizados para a extração dos parabenos em água foram obtidos de Galinaro, Pereira e Vieira. (2015) e são mostrados na Tabela 5.

Tabela 5 - Condições otimizadas para DLLME.

\begin{tabular}{lc}
\hline Solvente extrator & $n$-Octanol \\
\hline Solvente dispersivo & Acetona \\
\hline Volume de solvente extrator $(\mu \mathrm{L})$ & 100 \\
\hline Volume de solvente dispersivo $(\mathrm{mL})$ & 1 \\
\hline Volume de amostra $(\mathrm{mL})$ & 10 \\
\hline Massa de $\mathrm{NaCl}(\mathrm{g})$ & 1 \\
\hline pH da amostra & 6,0 \\
\hline Tempo de agitação (min) & 2 \\
\hline Tempo de centrifugação $(\min )$ & 5 \\
\hline Velocidade de centrifugação $(\mathrm{rpm})$ & 2.000 \\
\hline
\end{tabular}

De acordo com Galinaro, Pereira e Vieira (2015), as melhores condições cromatográficas para a determinação dos parabenos, a partir do método de extração anterior, estão resumidas na Tabela 6.

Tabela 6 - Condições cromatográficas otimizadas.

\begin{tabular}{|c|c|}
\hline Fase Estacionária & $\mathrm{C} 8$ \\
\hline Fase Móvel & Água (1\% HOAc):Metanol (35:65) \\
\hline Modo & Isocrático \\
\hline Temperatura $\left({ }^{\circ} \mathrm{C}\right)$ & 25 \\
\hline Volume de injeção $(\mu \mathrm{L})$ & 20 \\
\hline Tempo de corrida (min) & 9 \\
\hline Vazão $\left(\mathrm{mL} \min ^{-1}\right)$ & 1 \\
\hline Comprimento de onda monitorado (nm) & 258 \\
\hline
\end{tabular}

Os limites de detecção (LOD) e de quantificação (LOQ), a precisão (RSD - desvio padrão relativo) e exatidão (ER - recuperação da extração) do método proposto por Galinaro, Pereira e Vieira (2015) são mostrados na Tabela 7, separadamente, para os dois analitos estudados. 
Tabela 7 - Parâmetros de validação analítica do método.

\begin{tabular}{lcccc}
\hline & $\mathrm{LOD}\left(\mu \mathrm{g} \mathrm{L}^{-1}\right)$ & $\mathrm{LOQ}\left(\mu \mathrm{g} \mathrm{L}^{-1}\right)$ & $\mathrm{RSD}(\%)$ & $\mathrm{ER}(\%)$ \\
Metilparabeno & 0,8 & 2,4 & 8,3 & $30,3 \pm 3,9$ \\
\hline Propilparabeno & 0,5 & 1,3 & 6,7 & $68,0 \pm 7,6$ \\
\hline
\end{tabular}

Fonte: Adaptado de GALINARO, C. A.; PEREIRA, F. M.; VIEIRA, E.M., 2015, p. 2210.

Para confirmar a linearidade do método, obteve-se uma curva de calibração na faixa de trabalho do estudo, de $1-50\left(\mu \mathrm{g} \mathrm{L}^{-1}\right)$. Os coeficientes de determinação das duas retas estimadas foram $\mathrm{R}^{2}=0,998$ e 0,992 , para o metilparabeno e propilparabeno, respectivamente.

\subsection{Instrumentação e Reagentes}

Adicionalmente aos equipamentos já descritos, utilizou-se na análise uma coluna Luna C8 de $5 \mu \mathrm{m}(150 \times 4,6 \mathrm{~mm})$ da Phenomenex e um cromatógrafo série $1200 \mathrm{da}$ marca Agilent, acoplado a um Detector de Arranjo de Diodos (DAD), disponível no laboratório do Grupo de Química Analítica Aplicada a Medicamentos e a Ecossistemas (IQSC/USP).

Para a extração, utilizou-se um agitador (vórtex) da marca Norte Científica, modelo NA 3600, uma seringa de $3 \mathrm{~mL}$ (Arti Glass), uma microsseringa de $25 \mu \mathrm{L}$ (Hamilton) e uma centrífuga Rotina 380 Bench-Top da marca Hettich disponível no laboratório do Grupo de Cromatografia (CROMA) do Instituto de Química de São Carlos.

O metilparabeno (99\% de pureza, CAS 99-76-3), o propilparabeno (99\% de pureza, CAS 94-13-3) e o $n$-Octanol (99\% de pureza, CAS 111-87-5) foram obtidos da Sigma-Aldrich. O nitrato de ferro(III) nonahidratado (98,4\% de pureza, CAS 2018-01) foi obtido da J. T. Baker. Todos os reagentes foram usados sem tratamento prévio. Os valores de $\mathrm{pH}$ foram ajustados com soluções diluídas de $\mathrm{NaOH}$ e $\mathrm{H}_{2} \mathrm{SO}_{4}$, utilizando-se, para tal, um pHmetro Marconi PA 200. 


\subsection{Planejamento Experimental}

Inicialmente, estudaram-se as reações de foto-Fenton por meio de um planejamento fatorial completo $2^{3}$, com duplicatas, num total de 16 experimentos iniciais, executados de modo aleatório. Os experimentos foram realizados em duplicatas para se avaliar o erro experimental, antes de se prosseguir com o restante da metodologia. As variáveis independentes escolhidas foram: concentração de peróxido de hidrogênio $\left(\mu \mathrm{g} \mathrm{L}^{-1}\right)$, concentração de ferro(III) $\left(\mu \mathrm{g} \mathrm{L} \mathrm{L}^{-1}\right)$ e vazão $\left(\mathrm{L} \mathrm{min}^{-1}\right)$.

Como referência para a determinação dos valores que seriam usados nos níveis superior e inferior do planejamento, recorreu-se aos trabalhos publicados na literatura que tratavam da degradação dos parabenos pelos processos Fenton e foto-Fenton, assim como os resultados obtidos em experimentos prévios, conduzidos num reator fotoquímico modelo Multi-Fotons 320RA ${ }^{\mathrm{TM}}$ (Delpho Instruments ${ }^{\circledR}$ ), do próprio laboratório, mostrado na Figura 14.

Com este reator, obtiveram-se degradações médias de 89 e $97 \%$ em uma mistura total de $100 \mu \mathrm{g} \mathrm{L}^{-1}$ de metilparabeno e propilparabeno, respectivamente, utilizando-se 15 $\mathrm{mg} \mathrm{L}^{-1}$ de peróxido de hidrogênio e $1,5 \mathrm{mg} \mathrm{L}^{-1}$ de ferro(III) em $30 \mathrm{~min}$ de experimento.

No entanto, é importante ressaltar as diferenças entre o reator CPC deste trabalho e o reator LED do estudo prévio. A primeira diferença é a escala, pois o reator CPC trata um volume muito maior. A segunda, como o CPC foi operado no modo de batelada com reciclo total, é necessário otimizar-se um terceiro fator: a vazão. Por último, a irradiação no reator LED é monocromática $(365 \mathrm{~nm})$.

Portanto, com base nesses estudos, foram escolhidos os níveis dos fatores da matriz do planejamento (Tabela 8), codificados como -1 para o nível inferior e +1 para o nível superior.

Tabela 8 - Matriz do planejamento inicial $2^{3}$.

\begin{tabular}{lcc}
\hline \multirow{2}{*}{ Fatores } & \multicolumn{2}{c}{ Níveis } \\
\cline { 2 - 3 } & $\mathbf{( - 1 )}$ & $\mathbf{( + 1 )}$ \\
\hline $\mathrm{C}_{\mathrm{Fe}}{ }^{3+}\left(\mu \mathrm{g} \mathrm{L}^{-1}\right)$ & 50 & 60 \\
\hline $\mathrm{C}_{\mathrm{H} 2 \mathrm{O} 2}\left(\mu \mathrm{g} \mathrm{L}^{-1}\right)$ & 550 & 650 \\
\hline Vazão $\left(\mathrm{L} \mathrm{min}^{-1}\right)$ & 0,5 & 1,0 \\
\hline
\end{tabular}


Figura 14 - Reator LED: a) vistas ortográficas (dimensões em cm) e b) fotos.

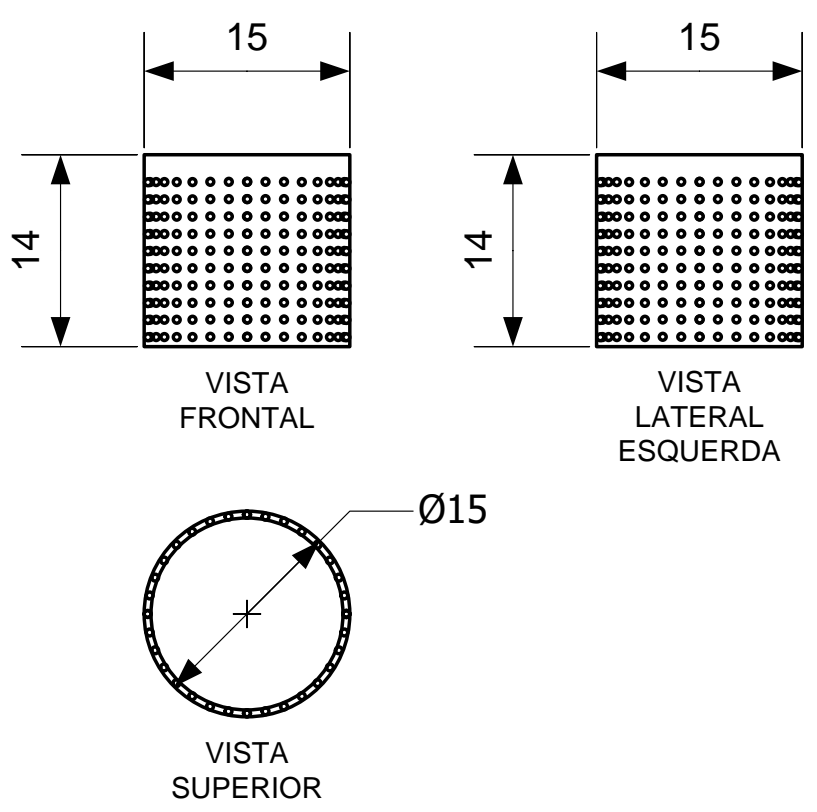

a)
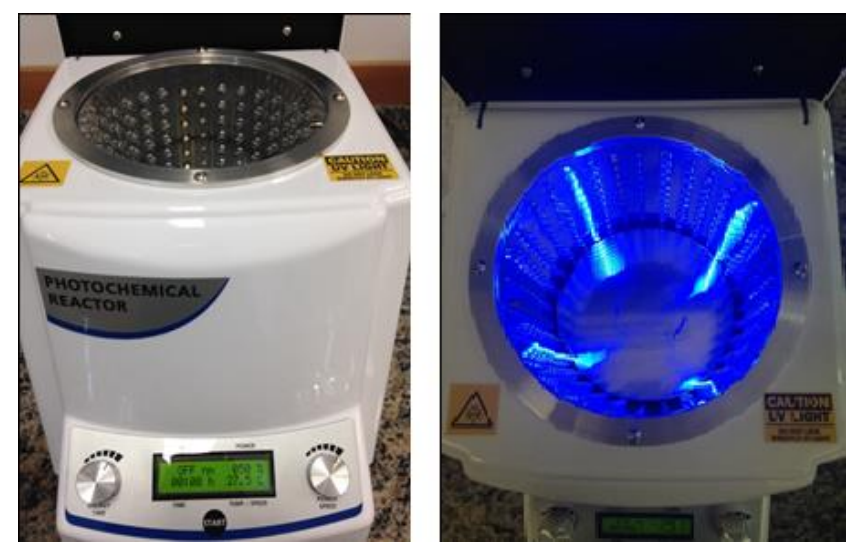

b)

Fonte: Autoria própria.

As 16 degradações foram feitas a partir das oito combinações possíveis do planejamento experimental, em duplicata.

A segunda etapa do método de superfícies de resposta foi então o caminho de máxima inclinação (CMI). Com base na melhor resposta obtida pelo primeiro planejamento, novos níveis foram criados e testados sequencialmente, no sentido do aumento da resposta, em busca de se atingir uma região de ótimo. 
Ao redor do ponto de máximo local determinado no CMI, foi executado um planejamento composto central com três fatores e novos níveis foram estabelecidos. Para cada fator, acrescentaram-se os níveis 0 (ponto central) e $\pm 1,682(\alpha)$ (BARROS NETO; SCARMINIO; BRUNS, 2007). Nesta terceira e última etapa, foram realizadas três réplicas no ponto central, a fim de se testar a falta de ajuste do modelo. No total, foram 17 experimentos realizados.

Para análise da qualidade do modelo final proposto, realizou-se uma ANOVA.

Todas as análises estatísticas dos planejamentos, desde gráficos, regressões, etc. foram feitas com o auxílio do software STATISTICA $10^{\circledR}$ (TIBCO).

\subsection{Procedimento}

A concentração inicial de parabenos para a degradação foi escolhida e fixada em $100 \mu \mathrm{g} \mathrm{L}^{-1}$, pois é uma concentração próxima das que costumam ser encontradas na entrada das ETE. Assim, além do desafio analítico, a concentração trabalhada foi próxima às encontradas no meio ambiente.

Os experimentos foram realizados em uma área externa do Laboratório de Desenvolvimento de Tecnologias Ambientais (LDTAmb) do Instituto de Química de São Carlos (IQSC/USP), entre às 10:00 e 13:00 horas durante o inverno e entre às 11:00 e 14:00 horas durante o verão, apenas nos dias em que o céu estava limpo ou com pouquíssimas nuvens. Este cuidado, além de aproveitar ao máximo a incidência solar no sítio experimental, confere uma maior uniformidade aos dados da irradiância total captada, pois o radiômetro utilizado não mede a radiação solar difusa incidente, apenas a direta; portanto, ao realizar os experimentos nesse horário, a radiação difusa que chega ao reator é minimizada.

Com o sistema montado (reator e espectrorradiômetro), completou-se o volume mínimo de 4,5 L do reservatório do reator CPC com a solução de parabenos em água, de concentração inicial especificada de $100 \mu \mathrm{g} \mathrm{L}^{-1}\left(50 \mu \mathrm{g} \mathrm{L}^{-1}\right.$ cada) e a solução de ferro(III) em sua respectiva concentração, ambas as soluções com o pH ajustado previamente em 
2,5. O reator foi então ligado e deixado em recirculação com a tampa fechada (no escuro) por cerca de 5 min a uma vazão de $1 \mathrm{~L} \mathrm{~min}^{-1}$. Em seguida, coletou-se a alíquota inicial do reator, ajustou-se a vazão para a vazão desejada, adicionou-se ao reservatório o respectivo volume desejado da solução de peróxido de hidrogênio e retirou-se a tampa do reator, expondo-o ao Sol e dando início ao experimento com duração total de 30 min.

Imediatamente após o término do experimento, coletou-se a alíquota final do reator e essa solução teve seu $\mathrm{pH}$ elevado para 10,0, a fim de promover a precipitação do ferro(III) e a degradação do peróxido em solução, cessando a reação. Em seguida, ela foi filtrada a vácuo com uma membrana de $0,45 \mu \mathrm{m}$ para a retirada dos oxi-hidróxidos de ferro(III) precipitados. Após a filtração, o pH de ambas as soluções (inicial e final) foi ajustado para 6,0 e as amostras foram armazenadas na geladeira antes da extração e análise.

Entre cada experimento, o reator CPC foi lavado com água corrente diversas vezes e esvaziado completamente, para evitar qualquer tipo de contaminação.

\subsection{Cinética}

Os experimentos da cinética foram realizados no ponto de condição ótima, definido pelo planejamento experimental. Foram estabelecidos nove tempos diferentes: 0 , 2,5, 5,0, 7,5, 10, 20, 30, 40 e 50 min para coleta de amostras, analisados em triplicata.

Como os parabenos absorvem na faixa de 250-260nm (com absorção máxima em $258 \mathrm{~nm}$ ) não foi necessário realizar-se um experimento para fotólise dos compostos à luz solar, uma vez que grande parte da radiação UVC (100-280 nm) é absorvida pelos gases na camada de ozônio $\left(\mathrm{O}_{3} / \mathrm{O}_{2}\right)$ e não chega à superfície terrestre e, além disso, os tubos de vidro utilizados no reator CPC são transparentes somente aos comprimentos de onda UVA (320-400 nm) e parte do UVB (280-320 nm), como mostrado na Figura 10. Também não houve necessidade de se realizarem experimentos para fotólise do peróxido de hidrogênio, pois segundo VANLOON e DUFFY (2010), o coeficiente de absorção molar do peróxido de hidrogênio é desprezível para comprimentos de onda acima de $300 \mathrm{~nm}$. 
Os gráficos da cinética e seus respectivos coeficientes foram obtidos com o auxílio do software ORIGIN ${ }^{\mathrm{TM}}\left(\right.$ OriginLab $\left.^{\circledR}\right)$.

\subsection{Ensaio de fitotoxicidade com Lactuca Sativa}

Avaliou-se a fitotoxicidade do produto de degradação do reator CPC com um teste de toxicidade aguda $(120 \mathrm{~h})$ com sementes de alface (Lactuca sativa) da variedade manteiga (também conhecida por "baba de verão"). Este ensaio é conhecido e amplamente utilizado por ser um método simples, de rápida resposta e de baixo custo para se avaliar a fitotoxicidade de uma amostra. Caso a amostra possua compostos tóxicos ao organismo-teste, os efeitos ficam visíveis na germinação (ou não) das sementes e no crescimento das plântulas durante os primeiros dias (VALENTIM; DEZOTTI, 2008).

Avaliou-se tanto a amostra inicial quanto a final, obtida após processo de degradação pelo reator CPC. Elas foram comparadas entre si e com o controle (água mineral).

O procedimento baseou-se na metodologia empregada por Ortega et al. (1996) e Rossi e Beltrami (1998), realizado no Laboratório de Desenvolvimento de Tecnologias Ambientais (LDTAmb.). Primeiramente, as sementes foram esterilizadas por imersão em uma solução $0,1 \%$ de hipoclorito de sódio, sob agitação magnética durante $30 \mathrm{~min}$. Em seguida, foram filtradas e lavadas por dez minutos com um mesmo volume de água mineral, em triplicata.

Dez sementes foram então colocadas sobre um papel de filtro embebido com 2 $\mathrm{mL}$ das soluções testadas dentro de uma placa de Petri. As diluições escolhidas, para as amostras inicial e final, foram de 10, 30, 50, 70 e 100\% de concentração da alíquota retirada do reator, todas feitas em quadruplicata. Água mineral com $\mathrm{pH} 7$ foi utilizada como água de diluição e o controle. Na Figura 15 são mostradas as placas já com as sementes sem a solução (canto superior direito) e com solução (canto inferior esquerdo). 
Figura 15 - Disposição das sementes nas placas de Petri.

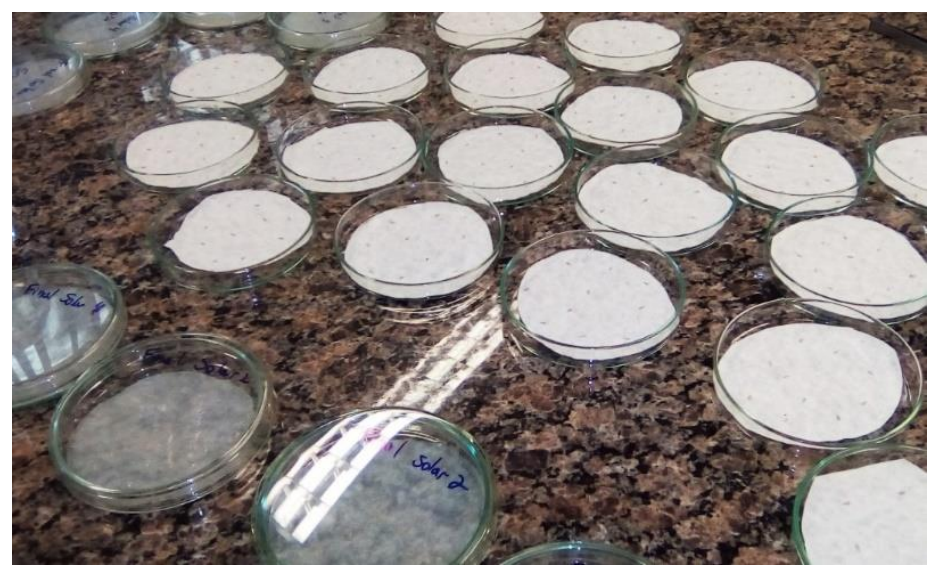

Fonte: Autoria própria.

Após todas as sementes terem sido colocadas, as placas foram cobertas com filme PVC e papel alumínio e incubadas por $120 \mathrm{~h}$ no escuro, a $24 \pm 1^{\circ} \mathrm{C}$. Ao final do período, mediu-se o comprimento do hipocótilo das sementes germinadas, que é a seção entre a radícula e o cotilédone da plântula, como mostrado na Figura 16.

Figura 16 - Segmentos da semente germinada de Lactuca sativa.

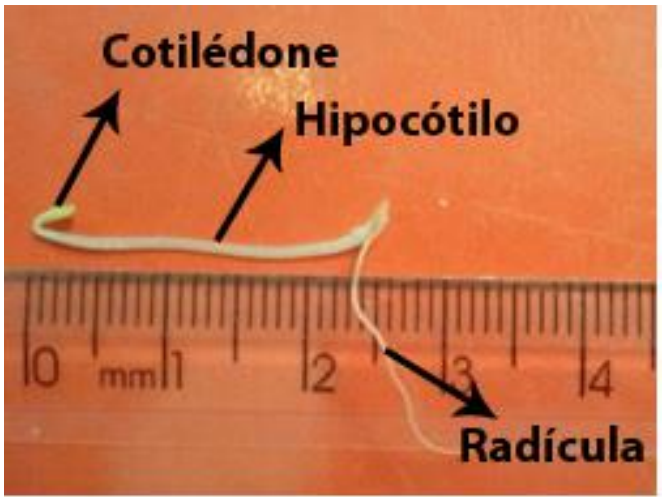

Fonte: Adaptação do Procedimento Operacional Padrão do LDTamb.

As sementes não germinadas foram contabilizadas para o cálculo do Índice de Germinação (IG) de cada amostra através da Equação 30, onde $\mathrm{G}_{\mathrm{A}}$ é o número de sementes que germinaram, $\mathrm{L}_{\mathrm{A}}$ é o comprimento dos hipocótilos nas amostras, $\mathrm{G}_{\mathrm{C}}$ é o número de sementes que germinaram no controle e $\mathrm{L}_{C}$ é o comprimento dos hipocótilos no controle.

$$
\operatorname{IG}(\%)=\frac{\left(\mathrm{G}_{\mathrm{A}} \times \mathrm{L}_{\mathrm{A}}\right)}{\left(\mathrm{G}_{\mathrm{C}} \times \mathrm{L}_{\mathrm{C}}\right)} \times 100
$$




\subsection{Ensaio de atividade antimicrobiana com Escherichia coli}

Para os testes de atividade antimicrobiana, utilizou-se uma cepa de Escherichia coli ATCC 25922 cultivada em meio de cultura Brain Heart Infusion (BHI).

Preparou-se uma suspensão de E.coli com tampão fosfato de sódio (PBS) correspondente à $10^{6}$ UFC (Unidades Formadoras de Colônias) $\mathrm{mL}^{-1}$, em que a densidade ótica em $590 \mathrm{~nm}$ foi igual a 0,324 . Esta suspensão foi depositada em placas de 72 poços, nas quais foram divididas em três grupos diferentes:

- Grupo 1 (controle): $100 \mu \mathrm{L}$ da suspensão de E. coli $+100 \mu \mathrm{L}$ de meio de cultura BHI;

- Grupo 2 (amostra inicial): $100 \mu \mathrm{L}$ da suspensão de $E$. coli $+50 \mu \mathrm{L}$ de meio de cultura $\mathrm{BHI}+50 \mu \mathrm{L}$ da amostra inicial;

- Grupo 3 (amostra final): $100 \mu \mathrm{L}$ da suspensão de E. coli $+50 \mu \mathrm{L}$ de meio de cultura $\mathrm{BHI}+50 \mu \mathrm{L}$ da amostra final.

Todos os experimentos foram feitos em triplicata.

Ao final, a viabilidade das bactérias foi avaliada pelo teste das microgotas. Retirouse uma alíquota de $100 \mu \mathrm{L}$ de cada poço e realizou-se uma diluição seriada de $10^{-1}$ a $10^{-5}$. Em seguida, foram retiradas quatro alíquotas de $15 \mu \mathrm{L}$ de cada diluição e foram depositadas em placas de ágar BHI e incubadas na estufa a $37{ }^{\circ} \mathrm{C}$ por 18 horas sem agitação.

Ao final, a quantificação foi feita pela contagem apenas das placas que continham de 5 a 50 UFC por microgota, para se tornar uma contagem viável. A quantidade de $E$. coli presente na amostra foi então determinada pela média do número de colônias multiplicada pelo fator de diluição, ou seja, pela quantidade média de UFC por mililitro de solução. 


\section{Resultados e Discussão}

\subsection{Planejamento Experimental Inicial}

Os resultados da degradação para o metilparabeno (MP) e propilparabeno (PP) do primeiro planejamento experimental estão listados na Tabela 9. Para cada experimento, os valores de porcentagem de degradação foram obtidos por meio da razão entre as áreas iniciais e finais dos cromatogramas, normalizando-se este resultado dividindo-se pelo valor da Irradiância Total, como mostrado na Equação 31.

Tabela 9 - Resultados normalizados do planejamento inicial $2^{3}$ com duplicatas.

\begin{tabular}{|c|c|c|c|c|c|c|}
\hline Ensaio & $\begin{array}{c}\mathbf{H}_{2} \mathbf{O}_{2} \\
\left(\mu \mathrm{g} \mathrm{L}^{-1}\right)\end{array}$ & $\begin{array}{c}\mathrm{Fe}^{3+} \\
\left(\mu \mathrm{g} \mathrm{L^{-1 }}\right)\end{array}$ & $\begin{array}{c}\text { Vazão } \\
\left(\mathbf{L} \text { min }^{-1}\right)\end{array}$ & 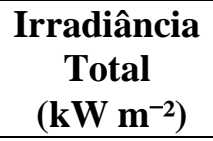 & $\begin{array}{c}\text { Degradação } \\
\text { MP } \\
\left(\% \mathbf{m}^{2} \mathbf{k W}^{-1}\right)\end{array}$ & $\begin{array}{c}\text { Degradação } \\
\text { PP } \\
\left(\% \mathbf{m}^{2} \mathbf{k W}^{-1}\right)\end{array}$ \\
\hline 1 & 650 & 60 & 1,0 & 2,56 & 31,0 & 33,7 \\
\hline 2 & 550 & 50 & 1,0 & 2,37 & 26,0 & 27,5 \\
\hline 3 & 550 & 60 & 0,5 & 2,66 & 24,9 & 26,8 \\
\hline 4 & 650 & 50 & 1,0 & 2,32 & 31,4 & 34,2 \\
\hline 5 & 550 & 50 & 0,5 & 3,41 & 19,5 & 22,6 \\
\hline 6 & 650 & 60 & 1,0 & 2,27 & 33,4 & 36,9 \\
\hline 7 & 650 & 60 & 0,5 & 2,36 & 30,0 & 34,4 \\
\hline 8 & 550 & 50 & 1,0 & 2,59 & 25,2 & 28,2 \\
\hline 9 & 550 & 60 & 1,0 & 2,55 & 25,7 & 27,2 \\
\hline 10 & 650 & 50 & 0,5 & 2,65 & 26,3 & 28,4 \\
\hline 11 & 550 & 60 & 1,0 & 3,10 & 22,7 & 23,8 \\
\hline 12 & 550 & 60 & 0,5 & 2,44 & 25,5 & 27,6 \\
\hline 13 & 650 & 50 & 0,5 & 1,88 & 27,2 & 30,0 \\
\hline 14 & 650 & 50 & 1,0 & 1,72 & 28,8 & 31,7 \\
\hline 15 & 550 & 50 & 0,5 & 2,29 & 17,2 & 19,5 \\
\hline 16 & 650 & 60 & 0,5 & 2,48 & 27,9 & 31,5 \\
\hline
\end{tabular}

$\%$ Degradação $($ normalizada $)=\frac{100-\left(\frac{A .100}{A_{0}}\right)}{\text { Irradiância Total }}$

Os experimentos que apresentaram as melhores degradações foram os de número 1, 4, 6 e 7, destacados em negrito na Tabela 9. A pior porcentagem de degradação correspondeu ao experimento número 15, com 39,3 e 44,6\% (não normalizados) para o MP 
e o PP, respectivamente. Já a melhor porcentagem de degradação foi a do experimento número 1, com 79,3 e 86,3\% (não normalizados), também respectivamente. A porcentagem média de degradação para o MP foi de 65,4\% e para o PP foi de 71,9\% em $30 \mathrm{~min}$ de experimento, uma boa degradação para o planejamento inicial, o que indica que os níveis ensaiados foram bem escolhidos.

Pode-se inferir da Tabela 9, aproximadamente, que as maiores porcentagens de degradação corresponderam aos experimentos nos níveis superiores do planejamento, enquanto as piores degradações se deram nos níveis inferiores. Este fato fica mais evidente observando-se os gráficos de Pareto e os gráficos de superfície de resposta, das Figuras 17 e 18 , respectivamente.

Observa-se nos gráficos de Pareto que, na faixa estudada (95\% de confiança), todos os fatores foram estatisticamente significativos, para ambos os compostos. O mais significativo foi a concentração de peróxido de hidrogênio, que apresentou quase o dobro do efeito observado das outras variáveis. E, tanto para o MP quanto para o PP, os parâmetros apresentaram efeito positivo, o que indica que um aumento no valor absoluto dessas variáveis implicaria em maiores degradações no experimento. Por serem três fatores, os gráficos de superfície são mostrados em pares na Figura 18, com o terceiro fator fixado em seu valor central.

Observa-se, nas Figuras 18a-d, que um aumento nas concentrações de ferro(III) e de peróxido de hidrogênio implica em um aumento na porcentagem de degradação, para ambos os compostos, sendo que a inclinação da superfície ao longo do eixo da concentração de peróxido é mais acentuada, o que indica que o efeito deste fator foi mais importante. Nas Figuras 18e-f, a inclinação da superfície de resposta já não é tão acentuada, sendo quase paralela ao plano X-Y, o que indica que, embora haja influência, os demais efeitos não são tão significativos como o da concentração de peróxido de hidrogênio, em concordância com o que se observou nos gráficos de Pareto (Figura 17). 
Figura 17 - Gráficos de Pareto para (a) metilparabeno e (b) propilparabeno.

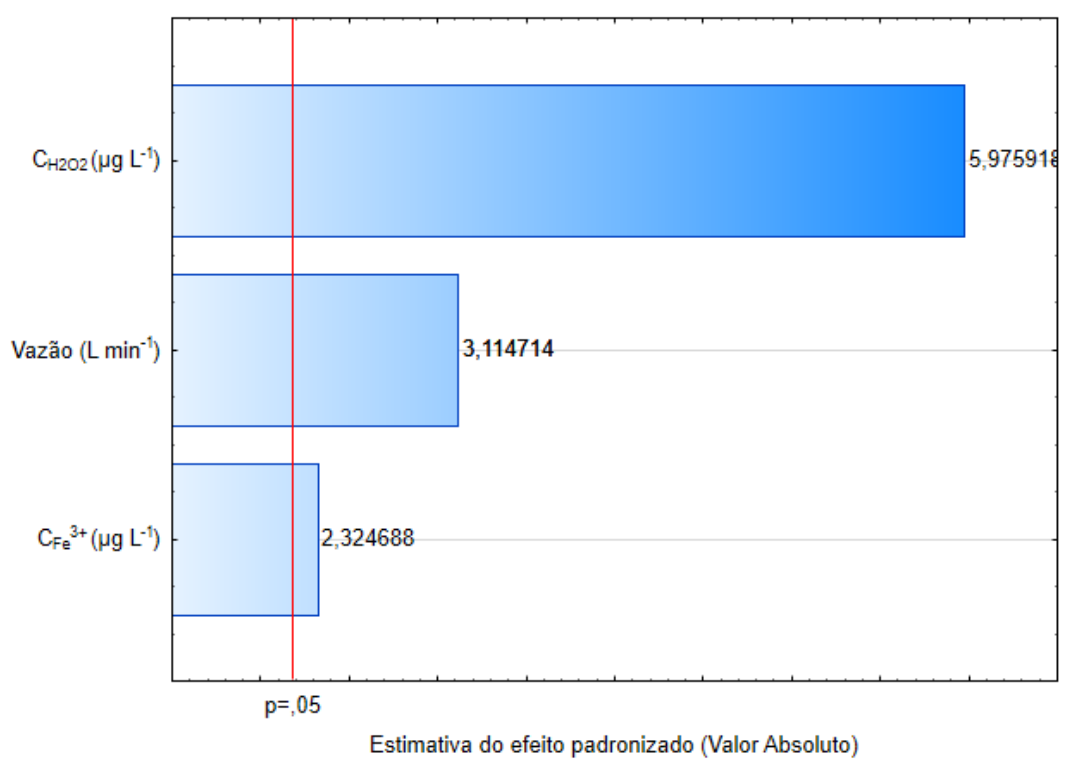

(a)

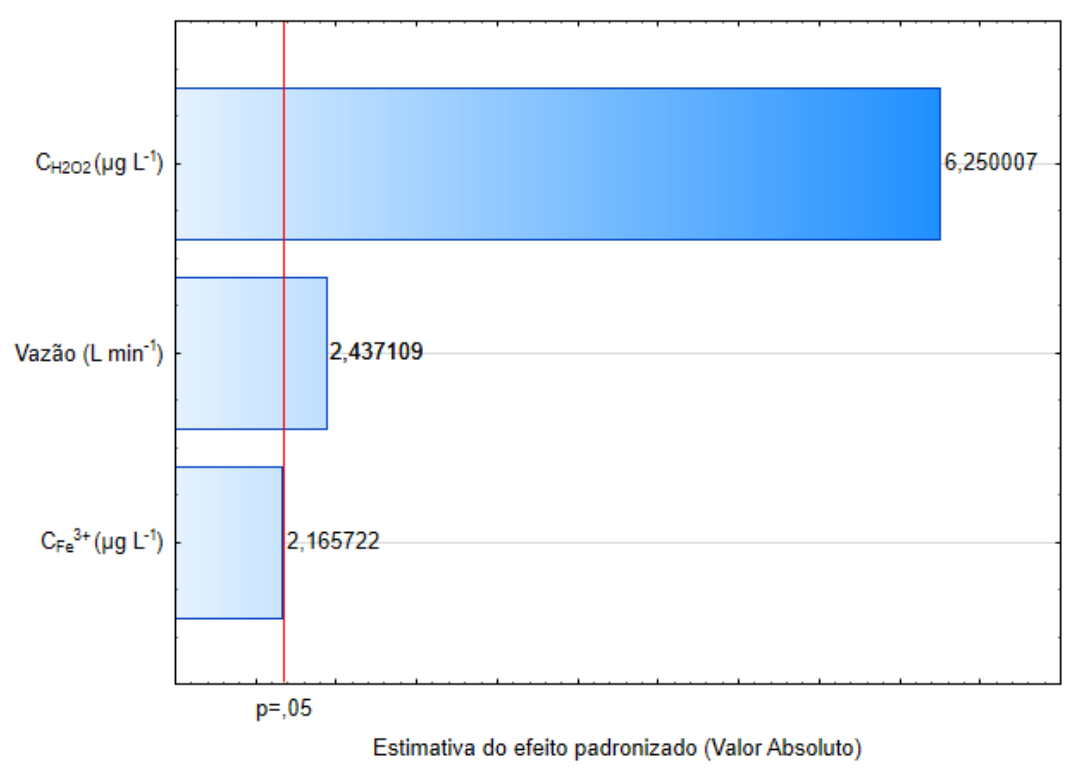

(b) 
Figura 18 - Gráficos da superfície de resposta para (a, c, e) metilparabeno e (b, c, f) propilparabeno.

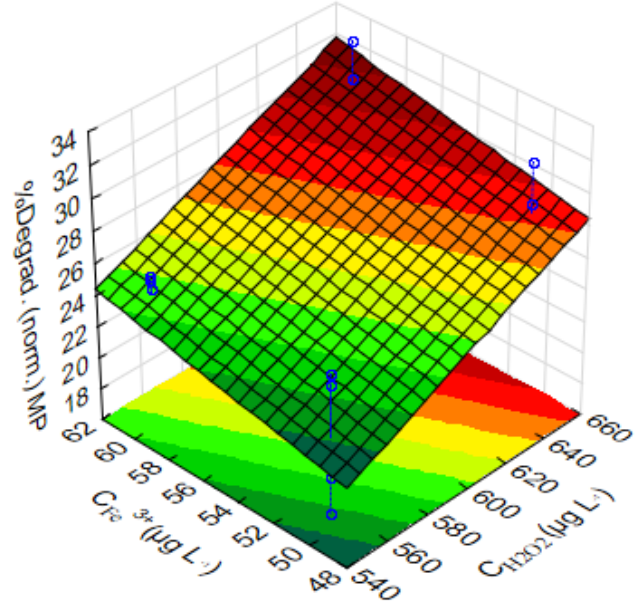

(a)

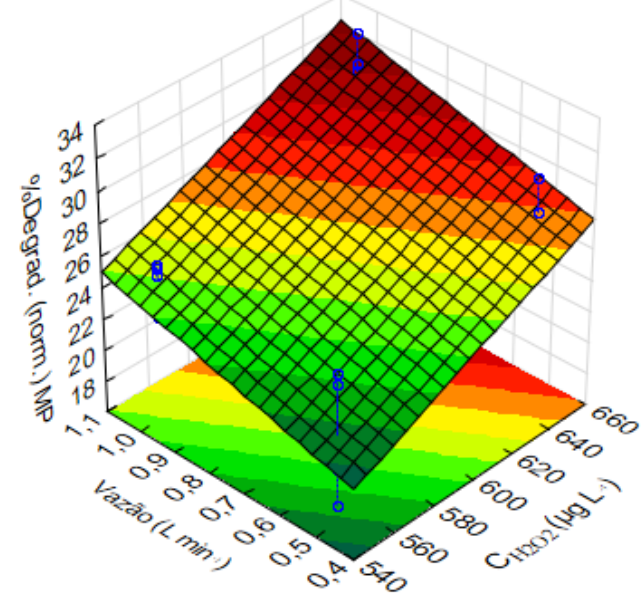

(c)

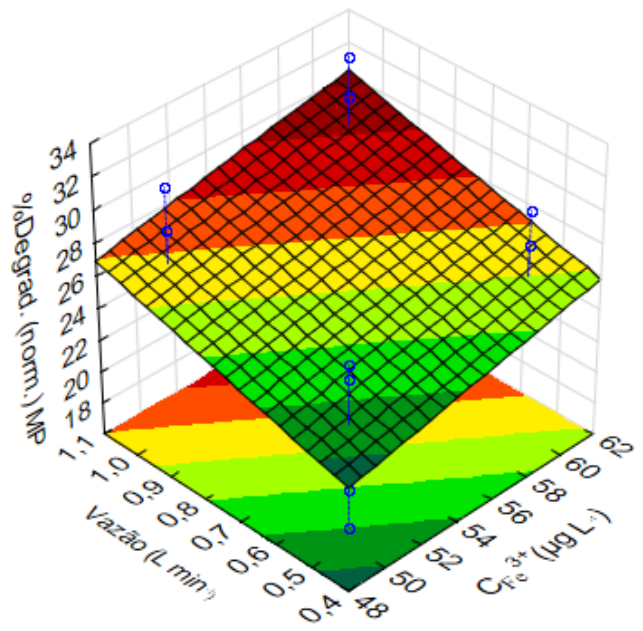

(e)

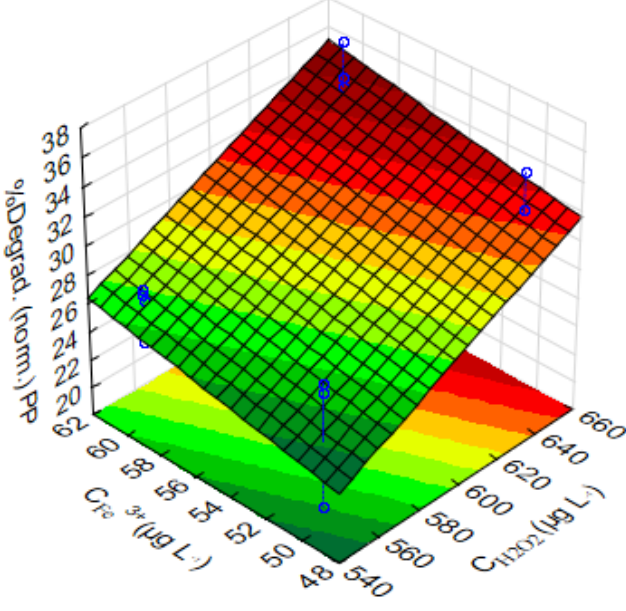

(b)

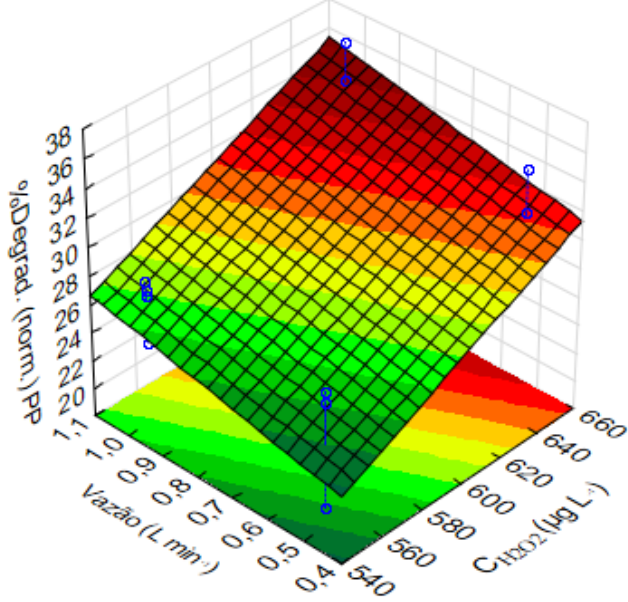

(d)

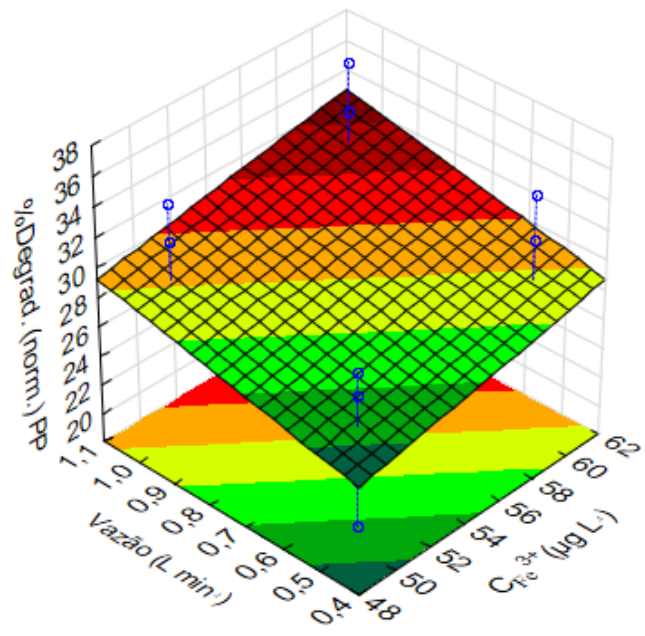

(f) 
Como a degradação é feita em uma etapa só (os dois compostos na mesma solução) e sabendo-se que as respostas foram bastante similares para o MP e o PP, optou-se por realizar o cálculo dos efeitos novamente, em conjunto, multiplicando os resultados da degradação normalizada do MP e do PP e submetendo este produto a uma nova análise. Esse novo resultado indica o caminho no qual se obtém uma maior degradação tanto do MP quanto do PP. Os gráficos de Pareto e de superfície de resposta foram novamente obtidos para essa nova variável-resposta são mostrados nas Figuras 19 e 20, respectivamente.

Figura 19 - Gráfico de Pareto para a variável-resposta MP×PP.

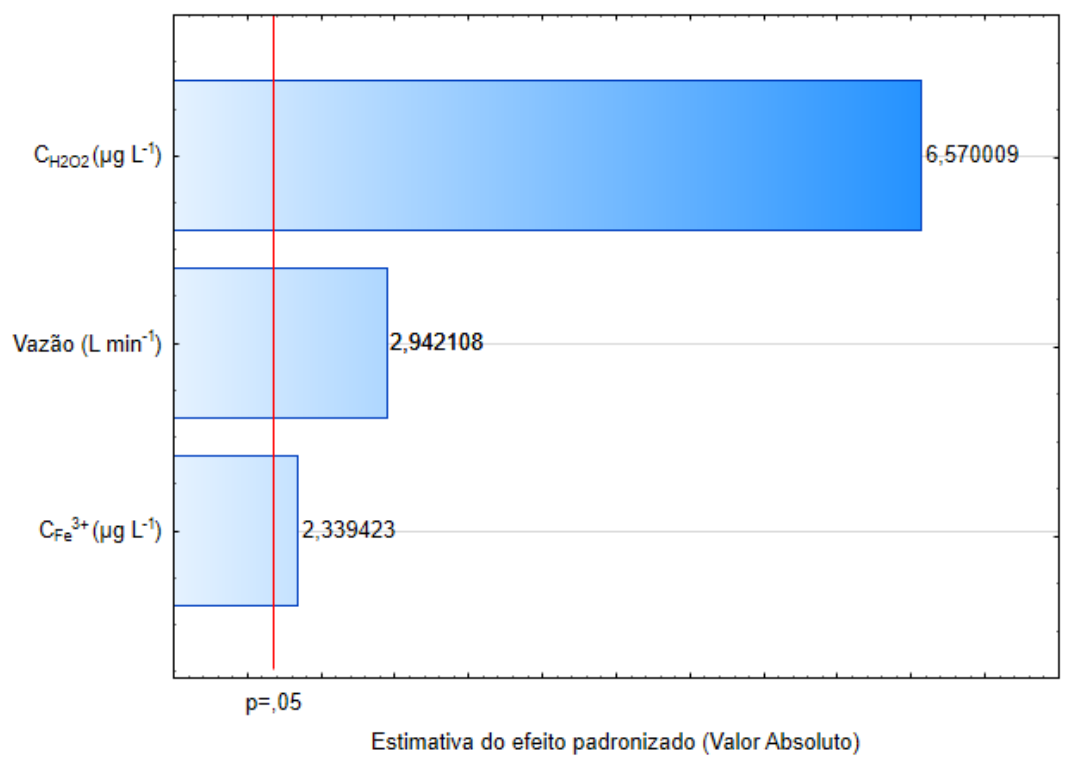


Figura 20 - Gráficos de superfície de resposta para a variável-resposta $\mathrm{MP} \times \mathrm{PP}$.

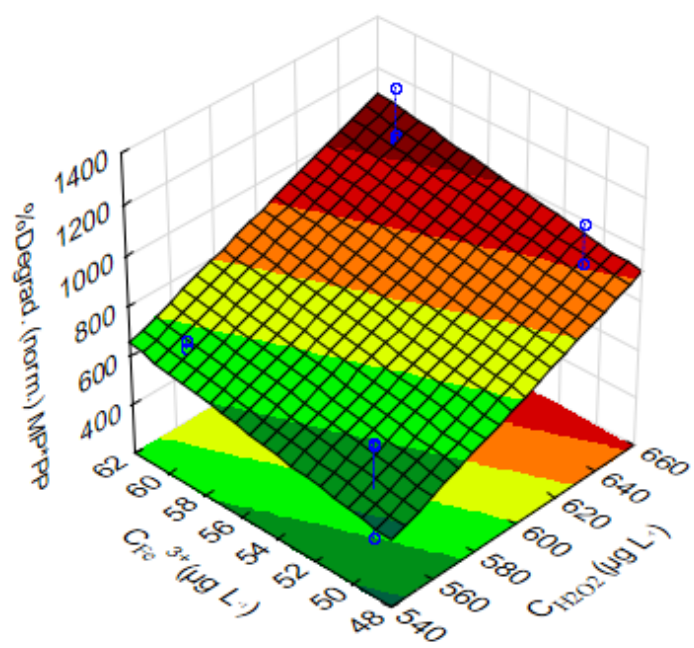

(a)

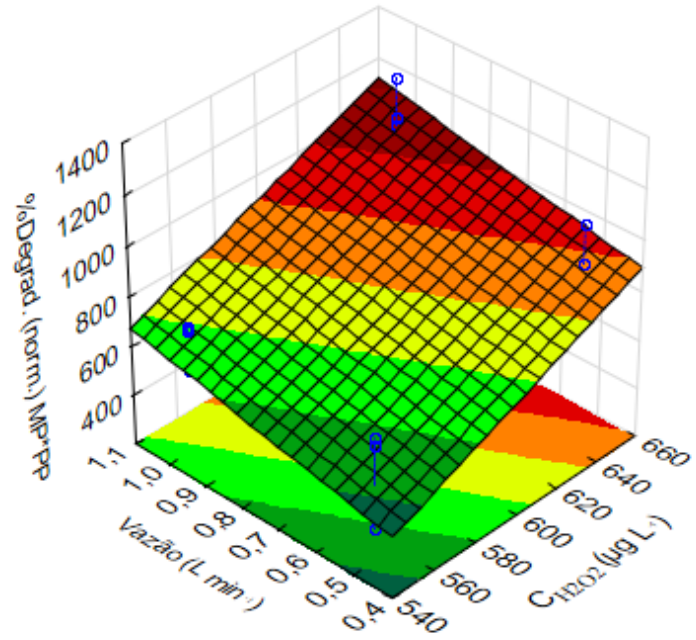

(b)

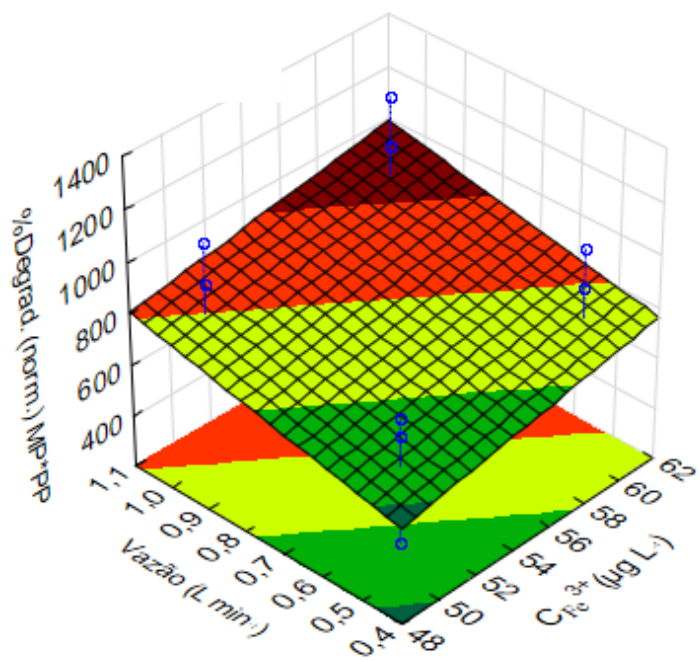

(c) 
Como esperado, o comportamento dessa nova variável-resposta foi muito semelhante ao dos dois compostos separadamente. Sendo assim, utilizou-se o produto MP*PP no cálculo dos passos do Caminho de Máxima Inclinação, na continuação da Metodologia de Superfícies de Respostas.

Antes de se prosseguir com o método, porém, estimou-se o erro experimental, mostrado na Tabela 10. Utilizaram-se as Equações 32 e 33, nas quais vé o número de graus de liberdade e $n$ é o número de ensaios idênticos (BARROS NETO; SCARMINIO; BRUNS, 2007). Tendo sido obtido um erro experimental considerado aceitável $(<5 \%)$, deu-se continuidade ao planejamento.

$$
\begin{gathered}
\text { Variância conjunta }=s^{2}=\frac{s_{1}^{2} v_{1}+s_{2}^{2} v_{2}+\cdots+s_{n}^{2} v_{n}}{v_{1}+v_{2}+\cdots+v_{n}} \\
\text { Erro Experimental }(\%)=\sqrt{\frac{s^{2}}{2}}
\end{gathered}
$$

Tabela 10 - Erro experimental do planejamento preliminar.

\begin{tabular}{ccc}
\hline $\begin{array}{c}\text { Experimentos } \\
\text { (duplicatas) }\end{array}$ & \multicolumn{2}{c}{ Variâncias Amostrais } \\
\cline { 2 - 3 } 1 e 6 & MP & PP \\
\hline 2 e 8 & 0,38 & 5,12 \\
\hline 3 e 12 & 0,180 & 0,245 \\
\hline 4 e 14 & 3,38 & 0,320 \\
\hline 5 e 15 & 2,65 & 3,13 \\
\hline 7 e 16 & 2,21 & 4,81 \\
\hline 9 e 11 & 4,50 & 5,21 \\
\hline 10 e 13 & 0,405 & 1,28 \\
\hline Erro Experimental (\%) & $\mathbf{1 , 4}$ & $\mathbf{1 , 8}$ \\
\hline
\end{tabular}




\subsection{Caminho de Máxima Inclinação (CMI)}

Sabendo-se que o fator mais significativo, na faixa estudada do planejamento preliminar, foi a concentração de peróxido de hidrogênio, como mostrado pelo Gráfico de Pareto (Figura 20), ele foi tomado como base para o cálculo do CMI.

Para o cálculo dos "passos", mostrados na Tabela 11, utilizou-se a Equação 34. Os valores dos coeficientes foram obtidos do modelo sem interações (Equação 35), na qual $x_{1}, x_{2}$ e $x_{3}$ são os fatores codificados e $b_{1}, b_{2}$ e $b_{3}$ são os respectivos coeficientes do modelo.

$$
\begin{gathered}
\Delta x_{2,3}=\frac{b_{2,3}}{241,3} \times \Delta x_{1} \\
\hat{y}=713,4+241,3 x_{1}+75,2 x_{2}+71,8 x_{3}
\end{gathered}
$$

\begin{tabular}{|c|c|c|c|c|c|c|}
\hline Passo & $\begin{array}{c}\Delta \mathbf{x}_{1} \\
\left(\mathbf{H}_{2} \mathbf{O}_{2}\right)\end{array}$ & $\begin{array}{c}\Delta \mathbf{x}_{\mathbf{2}} \\
\left(\mathbf{F e}^{3+}\right)\end{array}$ & $\begin{array}{c}\Delta \mathbf{x}_{\mathbf{3}} \\
\text { (Vazão) }\end{array}$ & $\begin{array}{c}\mathbf{H}_{2} \mathbf{O}_{2} \\
\left(\mu \mathrm{g} \mathrm{L}^{-1}\right)\end{array}$ & $\begin{array}{c}\mathbf{F e}^{3+} \\
\left(\mu \mathrm{g} \mathrm{L}^{-1}\right)\end{array}$ & $\begin{array}{c}\text { Vazão } \\
\left(\mathrm{L} \mathrm{min}^{-1}\right)\end{array}$ \\
\hline Centro & 0 & 0 & 0 & 600 & 55 & 0,75 \\
\hline Centro + $\Delta$ & 1 & 0,312 & 0,298 & 650 & 58 & 0,80 \\
\hline Centro $+2 \Delta$ & 2 & 0,623 & 0,596 & 700 & 61 & 0,90 \\
\hline 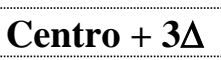 & 3 & 0,935 & 0,893 & 750 & 64 & 0,95 \\
\hline Centro $+4 \Delta$ & 4 & 1,246 & 1,191 & 800 & 67 & 1,05 \\
\hline Centro $+5 \Delta$ & 5 & 1,558 & 1,489 & 850 & 71 & 1,10 \\
\hline
\end{tabular}

Tabela 11 - Cálculo dos valores codificados para CMI.

Estabelecidos os valores, prosseguiu-se com a realização dos experimentos e os resultados são mostrados na Tabela 12 .

\begin{tabular}{|c|c|c|c|c|c|c|}
\hline \multirow[b]{2}{*}{ Passo } & \multirow{2}{*}{$\begin{array}{c}\mathrm{H}_{2} \mathrm{O}_{2} \\
\left(\mu \mathrm{g} \mathrm{L}^{-1}\right)\end{array}$} & \multirow{2}{*}{$\begin{array}{c}\mathrm{Fe}^{3+} \\
\left(\mu \mathrm{g} \mathbf{L}^{-1}\right)\end{array}$} & \multirow{2}{*}{$\begin{array}{c}\text { Vazão } \\
\left(\text { L } \text { min }^{-1}\right)\end{array}$} & \multirow{2}{*}{ 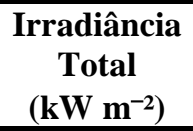 } & \multicolumn{2}{|c|}{ Degradação Normalizada (\%) } \\
\hline & & & & & MP & PP \\
\hline Centro & 600 & 55 & 0,75 & 1,39 & 24,0 & 30,3 \\
\hline Centro $+\Delta$ & 650 & 58 & 0,80 & 2,46 & 29,1 & 31,1 \\
\hline 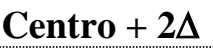 & 700 & 61 & 0,90 & 2,55 & 30,1 & 32,1 \\
\hline Centro $+3 \Delta$ & 750 & 64 & 0,95 & 1,73 & 35,2 & 39,9 \\
\hline Centro $+4 \Delta$ & 800 & 67 & 1,05 & 1,95 & 32,0 & 37,5 \\
\hline Centro $+5 \Delta$ & 850 & 71 & 1,10 & 2,15 & 27,7 & 31,9 \\
\hline
\end{tabular}

Tabela 12 - Resultados dos experimentos do CMI. 
$\mathrm{O}$ quarto experimento (Centro $+3 \Delta$ ) foi o que apresentou a maior degradação, destacado em negrito na Tabela 12. Como esperado, os experimentos apresentaram um aumento na degradação até um determinado valor, e desse ponto em diante, o rendimento apresentou uma relativa queda de eficiência. Na Figura 21, tem-se o gráfico dos experimentos do CMI, o que facilita a visualização do ponto a partir do qual o rendimento dos experimentos começa a diminuir.

Figura 21 - Resultados do CMI: - metilparabeno e $\bullet$ propilparabeno.

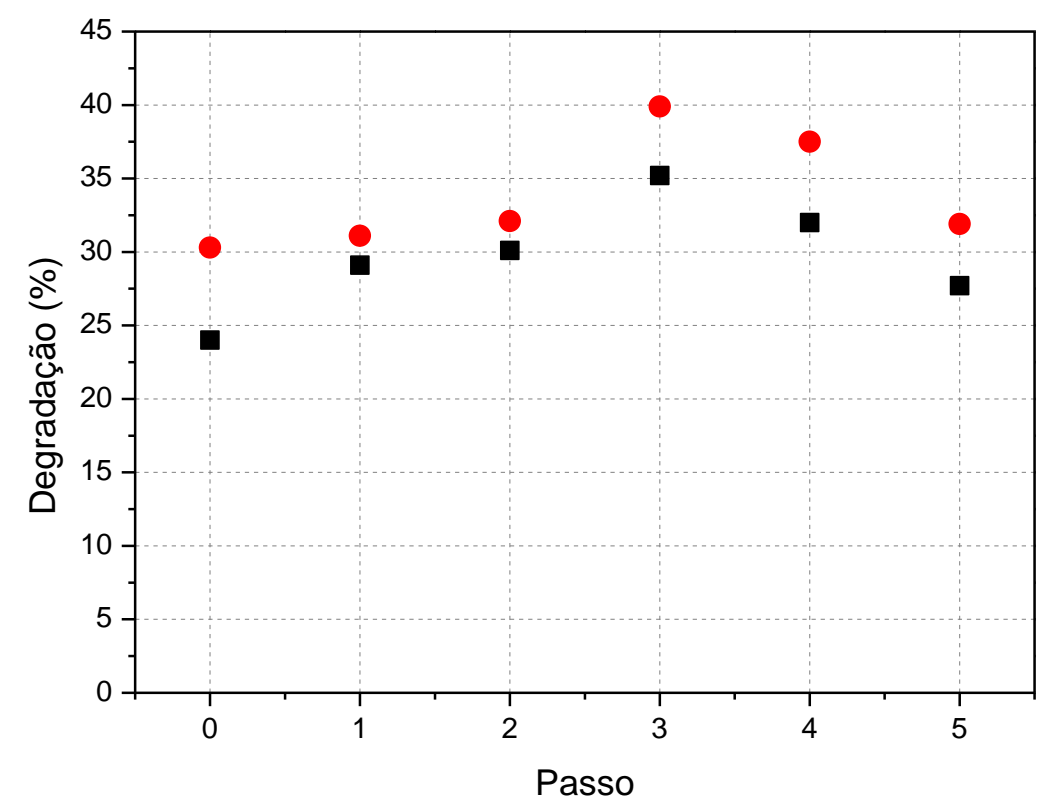

Este comportamento é esperado porque se houver excesso de peróxido de hidrogênio, os radicais hidroxila serão por ele sequestrados, diminuindo a eficiência do processo (NEYENS; BAEYENS, 2003). Dos outros fatores, a vazão é importante, pois está relacionada tanto com o tempo de irradiação do volume circulante no reator quanto com a mistura dos reagentes. Logo, ao longo do CMI, atingiu-se uma região ótima.

Utilizou-se, então, as condições experimentais do terceiro passo como o ponto central de um planejamento composto central (CCD), com o objetivo de se determinar o ponto ótimo para a degradação. 


\subsection{Planejamento Composto Central}

Este planejamento foi inicialmente feito apenas com a parcela fatorial $\left(2^{3}\right)$ e com três repetições no ponto central, totalizando onze experimentos, para se testar se a superfície de resposta poderia ser descrita por uma função linear. Os valores são mostrados na Tabela 13. Os onze experimentos foram feitoss aleatoriamente e os resultados são mostrados na Tabela 14.

Tabela 13 - Níveis do planejamento composto central.

\begin{tabular}{cccc}
\hline \multirow{2}{*}{ Fatores } & \multicolumn{3}{c}{ Níveis } \\
\cline { 2 - 4 } & $\begin{array}{c}\text { Inferior } \\
\mathbf{( - 1 )}\end{array}$ & $\begin{array}{c}\text { Central } \\
\mathbf{( 0 )}\end{array}$ & $\begin{array}{c}\text { Superior } \\
(+\mathbf{1})\end{array}$ \\
\hline $\mathrm{H}_{2} \mathrm{O}_{2}\left(\mu \mathrm{g} \mathrm{L}^{-1}\right)$ & 700 & 750 & 800 \\
$\mathrm{Fe}^{3+}\left(\mu \mathrm{g} \mathrm{L}^{-1}\right)$ & 59 & 64 & 69 \\
\hline $\mathrm{Vazão}\left(\mathrm{L} \mathrm{min}^{-1}\right)$ & 0,70 & 0,95 & 1,20 \\
\hline
\end{tabular}

Tabela 14 - Resultados do planejamento composto central (parcela fatorial).

\begin{tabular}{|c|c|c|c|c|c|c|}
\hline \multirow{2}{*}{ Ensaio } & \multirow{2}{*}{$\begin{array}{c}\mathbf{H}_{2} \mathbf{O}_{2} \\
\left(\mu \mathrm{g} \mathrm{L}^{-1}\right)\end{array}$} & \multirow{2}{*}{$\begin{array}{c}\mathbf{F e}^{3+} \\
\left(\mu \mathrm{g} \mathrm{L^{-1 }}\right)\end{array}$} & \multirow{2}{*}{$\begin{array}{c}\text { Vazão } \\
\left(\mathbf{L} \text { min }^{-1}\right)\end{array}$} & \multirow{2}{*}{ 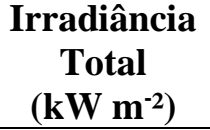 } & \multicolumn{2}{|c|}{ Degradação Normalizada (\%) } \\
\hline & & & & & MP & $\mathbf{P P}$ \\
\hline 1 & 800 & 59 & 1,2 & 1,26 & 29,9 & 29,7 \\
\hline 2 & 800 & 59 & 0,70 & 1,19 & 33,5 & 34,6 \\
\hline 3 & 750 & 64 & 0,95 & 2,02 & 36,1 & 37,8 \\
\hline 4 & 800 & 69 & 1,2 & 1,93 & 32,7 & 34,0 \\
\hline 5 & 700 & 69 & 1,2 & 1,07 & 29,4 & 28,8 \\
\hline 6 & 700 & 69 & 0,70 & 1,74 & 26,2 & 27,8 \\
\hline 7 & 700 & 59 & 1,2 & 1,35 & 27,5 & 25,2 \\
\hline 8 & 800 & 69 & 0,70 & 1,49 & 32,6 & 34,0 \\
\hline 9 & 750 & 64 & 0,95 & 1,82 & $\mathbf{3 5 , 4}$ & $\mathbf{3 8 , 4}$ \\
\hline 10 & 700 & 59 & 0,70 & 1,78 & 28,2 & 31,2 \\
\hline 11 & 750 & 64 & 0,95 & 2,30 & 39,6 & 40,1 \\
\hline
\end{tabular}

Analisando-se estatisticamente os resultados, através da regressão linear dos dados, o coeficiente de determinação $\left(\mathrm{R}^{2}\right)$ dos modelos gerados foram de 0,23 ou $23 \%$ para o metilparabeno e de 0,27 ou $27 \%$ para o propilparabeno. Os valores baixos de $\mathrm{R}^{2}$ para os modelos obtidos indicam de imediato que o modelo linear não se ajusta completamente aos dados e não consegue explicar todas as variações sem se considerar os efeitos quadráticos e as interações. Este fato fica comprovado pelos Gráficos de Pareto (Figura 22), 
na qual testa-se (além dos fatores significativos) se as interações de segunda ordem (curvatura) são significativas.

Figura 22 - Gráficos de Pareto do CCD (parcela fatorial) para: (a) metilparabeno e (b) propilparabeno.

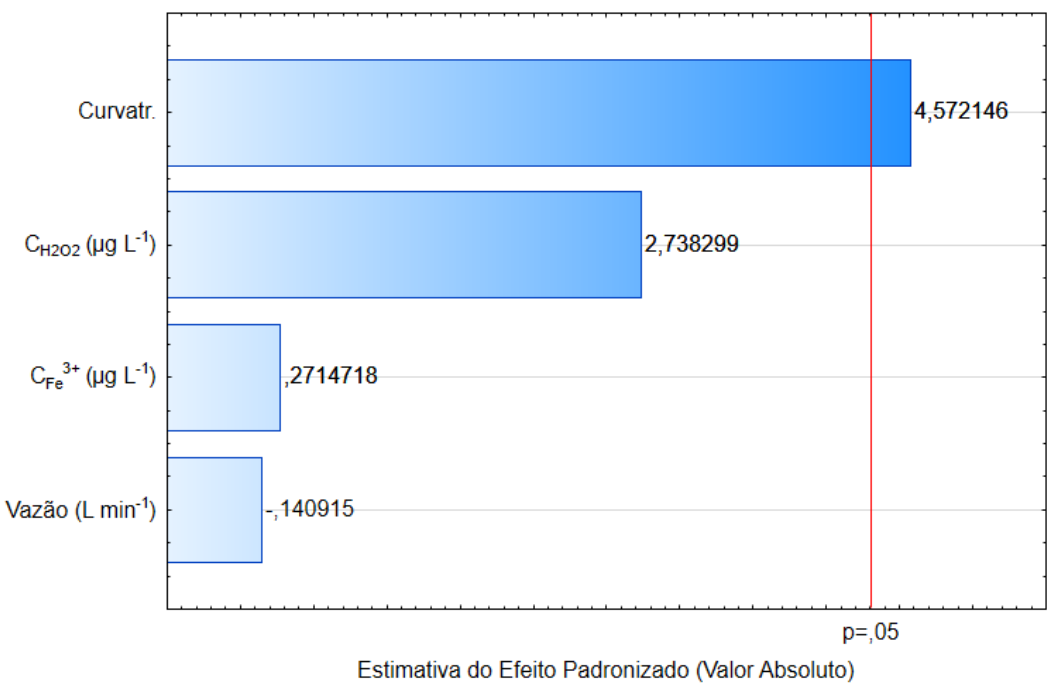

(a)

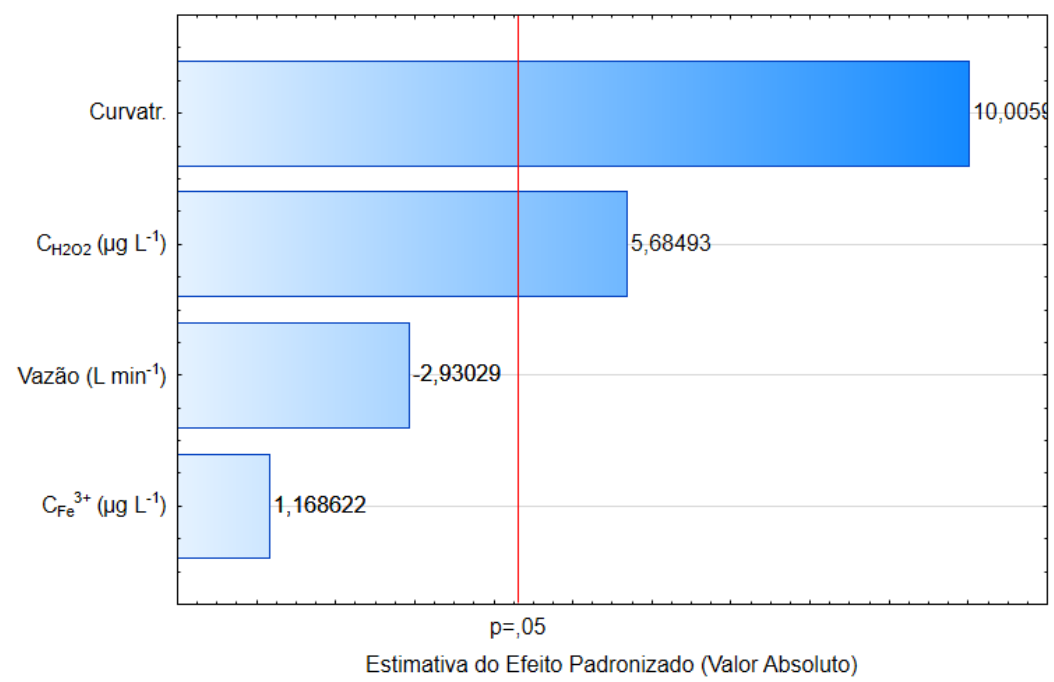

(b)

Por meio da Figura 22 pode-se inferir que, tanto para o MP quanto para o PP, a curvatura foi significativa, indicando que o modelo linear não era suficiente para explicar todas as interações. Sabendo disso, ampliou-se o planejamento fatorial com a parcela axial (gerando-se o CCD) a fim de se aumentar o número de graus de liberdade e modelar a curvatura da região ótima. Os pontos axiais e os respectivos resultados são mostrados na Tabela 15. 
Tabela 15 - Resultado do planejamento composto central (parcela axial).

\begin{tabular}{|c|c|c|c|c|c|c|}
\hline \multirow{2}{*}{ Ensaio } & \multirow{2}{*}{$\begin{array}{c}\mathrm{H}_{2} \mathrm{O}_{2} \\
\left(\mu \mathrm{g} \mathrm{L^{-1 }}\right)\end{array}$} & \multirow{2}{*}{$\begin{array}{c}\mathrm{Fe}^{3+} \\
\left(\mu \mathrm{g} \mathrm{L}^{-1}\right)\end{array}$} & \multirow{2}{*}{$\begin{array}{c}\text { Vazão } \\
\left(\mathbf{L} \text { min }^{-1}\right)\end{array}$} & \multirow{2}{*}{$\begin{array}{c}\text { Irradiância } \\
\text { Total } \\
\left(\mathbf{k W ~ m}^{-2}\right)\end{array}$} & \multicolumn{2}{|c|}{ Degradação Normalizada (\%) } \\
\hline & & & & & MP & $\mathbf{P P}$ \\
\hline 1 & 666 & 64 & 0,95 & 1,96 & 24,2 & 27,8 \\
\hline 2 & 750 & 56 & 0,95 & 2,02 & 35,2 & 36,1 \\
\hline 3 & 750 & 64 & 0,55 & 1,88 & 31,1 & 30,8 \\
\hline 4 & 834 & 64 & 0,95 & 1,92 & 34,6 & 37,1 \\
\hline 5 & 750 & 72 & 0,95 & 2,15 & 37,3 & 37,6 \\
\hline 6 & 750 & 64 & 1,35 & 1,85 & 29,5 & 29,1 \\
\hline
\end{tabular}

Com todos os experimentos prontos, foi realizada uma análise do conjunto total de dados (parcela fatorial e axial) do planejamento composto central. Novamente, foram utilizados o produto $\mathrm{MP} \times \mathrm{PP}$ como a variável-resposta. O modelo empírico final é mostrado na Equação 36, onde $x_{1}, x_{2}$ e $x_{3}$ são os fatores codificados correspondentes à concentração de peróxido de hidrogênio, à concentração de ferro(III) e à vazão, respectivamente.

$$
\begin{gathered}
\hat{y}=1445,6+157,2 x_{1}-190,3 x_{1}^{2}+29,3 x_{2}-63,2 x_{2}^{2}-36,6 x_{3} \\
-215,3 x_{3}{ }^{2}+21,5 x_{1} x_{2}-25,4 x_{1} x_{3}+72,0 x_{2} x_{3}
\end{gathered}
$$

Na Figura 23 são mostradas as superfícies de resposta e seus respectivos gráficos de contorno de cada superfície. Os pontos em azul são os pontos do planejamento composto central realizados.

Pode-se observar que, nas Figuras 23a e 23b, a região de ótimo - vermelha escura - é mais evidente do que na Figura 23c, onde há um grande "platô", indicando que, para esses fatores (concentração de ferro(III) e vazão), os níveis na faixa estudada não foram tão significativos para o resultado do experimento.

Por meio do Gráfico de Pareto, na Figura 24, fica mais clara esta afirmação, pois apenas a concentração de peróxido de hidrogênio (linear) foi significativa, com efeito positivo, enquanto que a vazão (quadrática) e a concentração de peróxido de hidrogênio (quadrática) tiveram efeitos negativos e significativos. 
Figura 23 - Gráficos de superfície de resposta e de contorno para a variável-resposta MP× PP obtidos a partir do planejamento composto central.
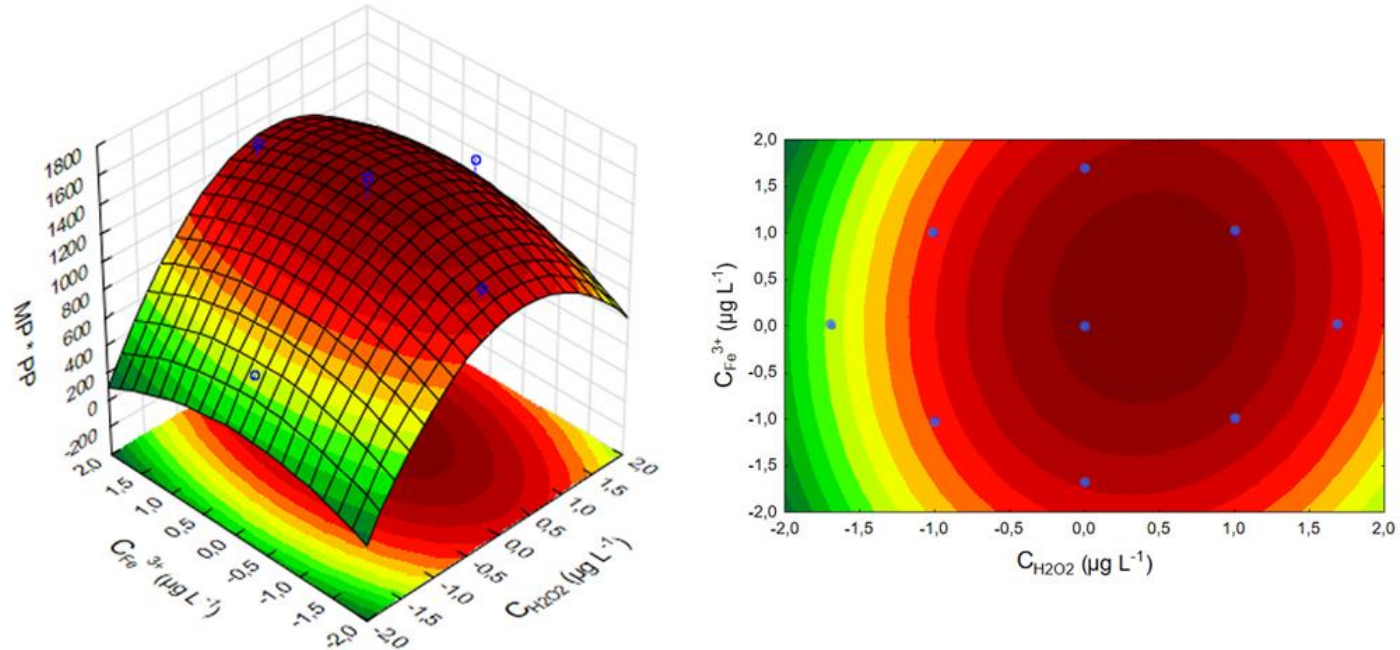

(a)
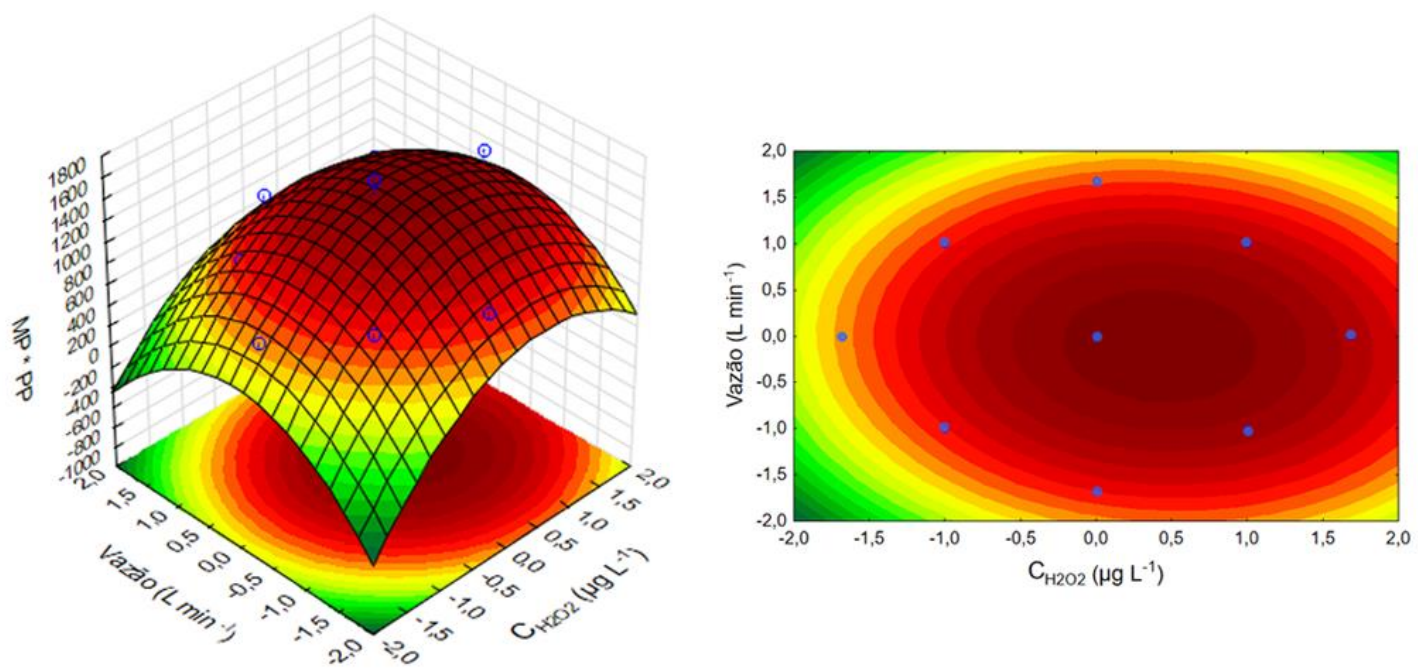

(b)
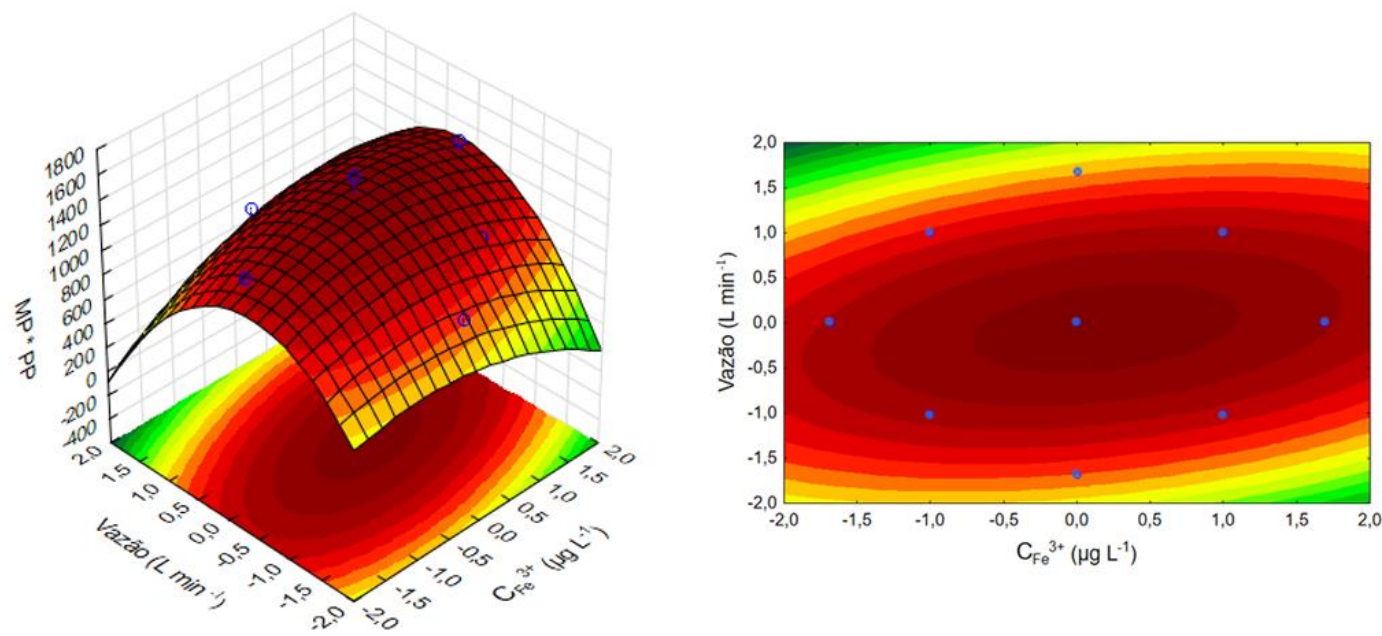

(c) 
Figura 24 - Gráfico de Pareto para MP*PP do planejamento composto central (completo).

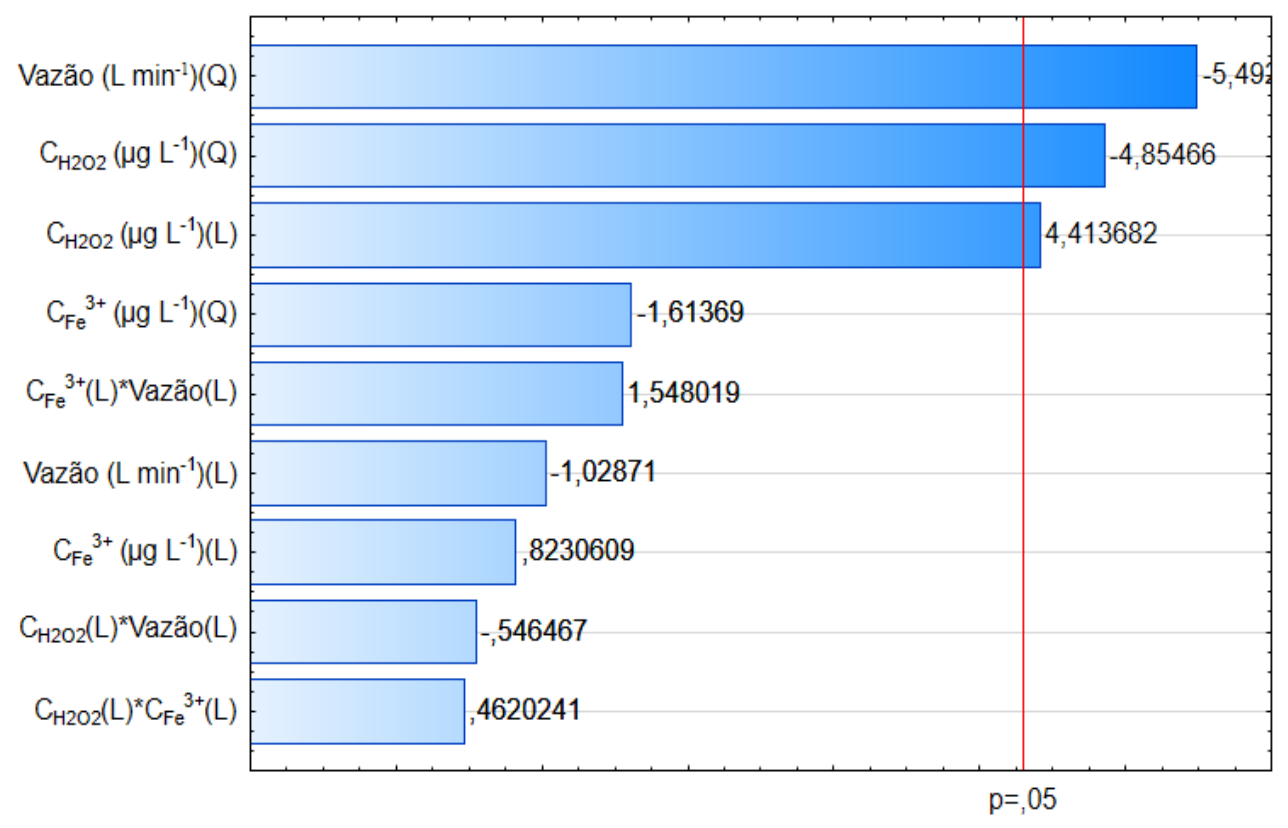

Estimativa do Efeito Padronizado (Valor Absoluto)

Na Tabela 16 é apresentada a ANOVA realizada para o modelo proposto. Aplicando-se o teste F com os valores da ANOVA, obtém-se que o valor calculado para $\mathrm{MQ}_{\mathrm{R}} / \mathrm{MQ}_{\mathrm{r}}=9,68$. Comparando-o com valor tabelado $\mathrm{F}_{9,7}=3,68$, percebe-se que $\mathrm{MQ}_{\mathrm{R}} / \mathrm{MQ}_{\mathrm{r}}>\mathrm{F}_{9,7}$, o que indica que não há falta de ajuste no modelo.

Tabela 16 - Tabela ANOVA para o modelo final.

\begin{tabular}{lccc}
\hline Fonte de variação & SQ & Graus de liberdade & MQ \\
\hline Regressão (R) & 115,1 & 9 & 12,78 \\
\hline Resíduo (r) & 9,24 & 7 & 1,32 \\
\hline Falta de Ajuste (faj) & 5,78 & 5 & 1,16 \\
\hline Erro Puro (ep) & 3,46 & 2 & 1,73 \\
\hline Total & 124,3 & 16 & \\
\hline $\mathrm{R}^{2}$ & 0,925 & & \\
\hline $\mathrm{R}^{2}$ máx. & 0,972 & & \\
\hline
\end{tabular}

Mesmo não havendo falta de ajuste, o coeficiente de determinação apresentou um valor relativamente baixo, embora satisfatório, devido aos desvios entre os valores previstos pelo modelo e os valores observados, ou seja, devido aos erros experimentais. Muito dos erros podem ser atribuídos à escala associada ao trabalho, como grandes volumes empregados no reator CPC (4,5 litros), concentrações pequenas dos compostos (microgramas por litro) e diversas etapas no processo, desde a degradação no reator até a 
análise no HPLC. Os desvios entre os valores observados e os valores previstos pelo modelo são mostrados na Figura 25.

Figura 25 - Dispersão residual dos pontos com relação ao previsto pelo modelo.

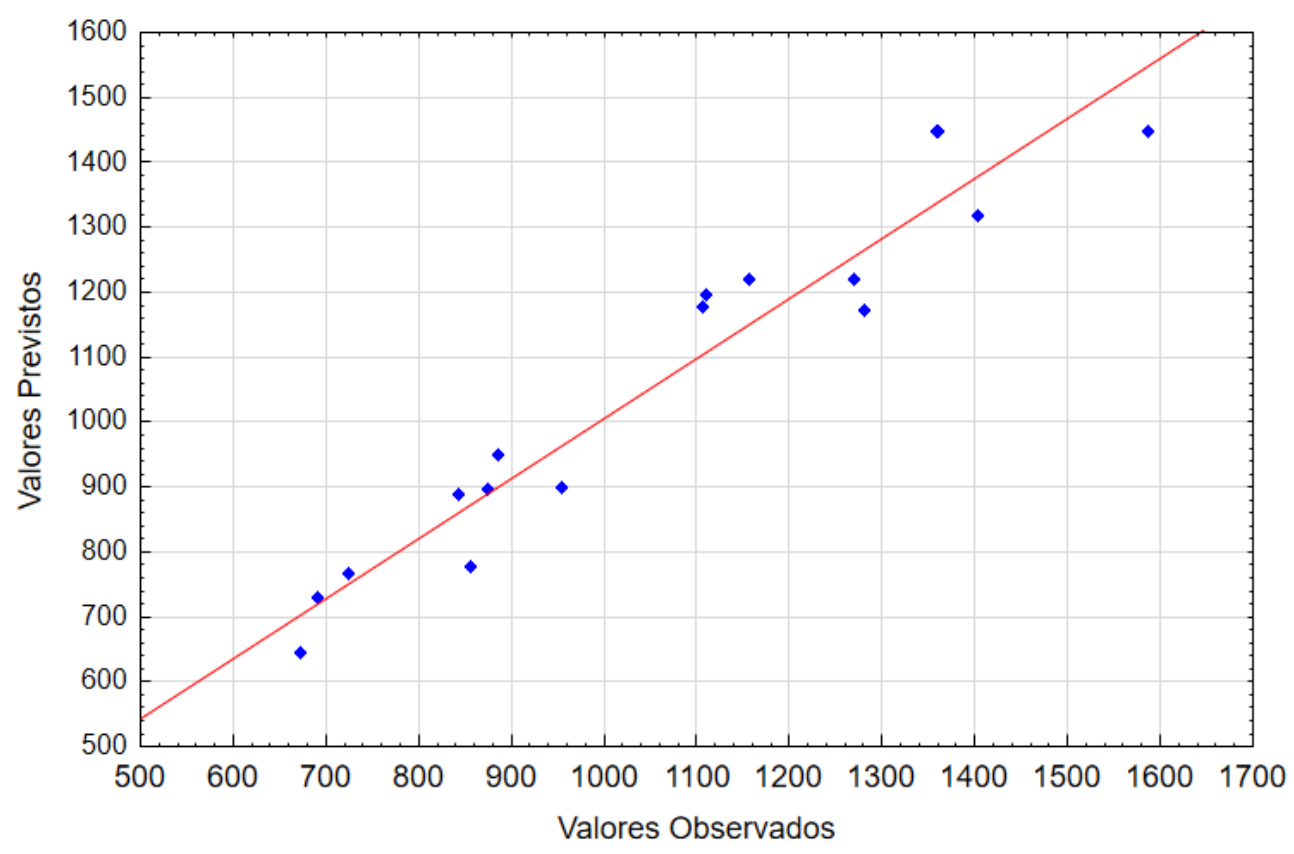

\subsection{Cinética de Degradação}

Uma vez que o modelo proposto foi satisfatório, determinou-se então seu ponto ótimo (máximo local), mostrado na Tabela 17. Com as condições ótimas de degradação estabelecidas, realizaram-se experimentos cinéticos, cujos resultados são mostrados na Figura 26.

Tabela 17 - Condições ótimas de degradação.

\begin{tabular}{cc}
\hline Fator & Máximo Local \\
\hline $\mathrm{C}_{\mathrm{H} 2 \mathrm{O} 2}\left(\mu \mathrm{g} \mathrm{L}^{-1}\right)$ & 771,6 \\
\hline $\mathrm{C}_{\mathrm{Fe}}{ }^{3+}\left(\mu \mathrm{g} \mathrm{L}^{-1}\right)$ & 65,3 \\
Vazão $\left(\mathrm{L} \mathrm{min}^{-1}\right)$ & 0,9 \\
\hline
\end{tabular}


Figura 26 - Cinética de degradação para: (a) metilparabeno e (b) propilparabeno. Experimentos realizados em triplicata.

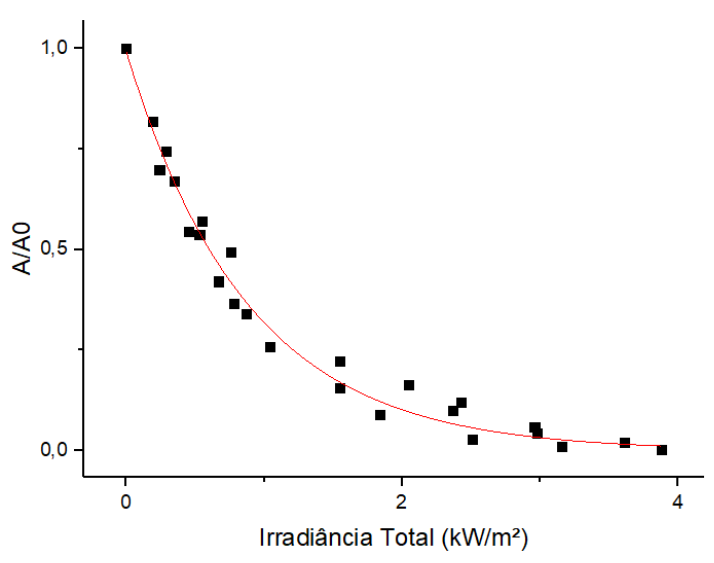

(a)

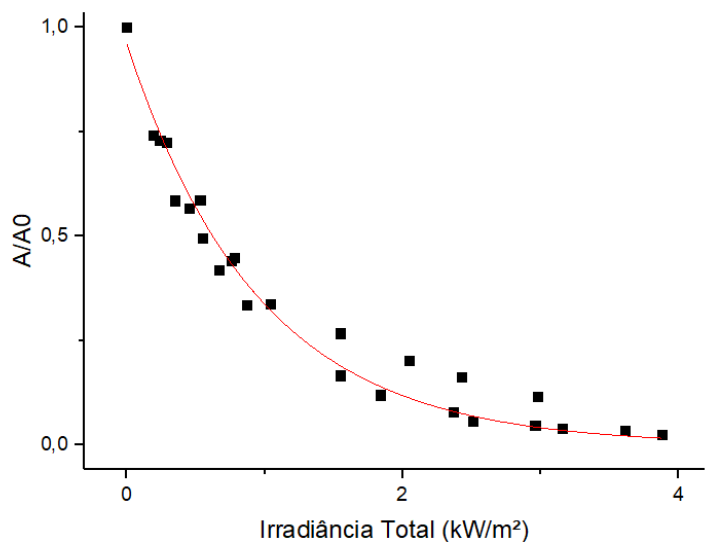

(b)

A Equação 37 representa a cinética de pseudo primeira ordem observada na Figura 27, na qual $A_{0}$ é a área cromatográfica inicial, $A$ é a área cromatográfica final, $k$ é a constante da taxa de degradação e $x$ é o valor da Irradiância Total.

$$
\frac{A}{A_{0}}=e^{-k x}
$$

Observa-se que os gráficos da Figura 27 foram traçados como a razão das áreas cromatográficas $\left(A / A_{0}\right)$ versus a Irradiância Total. Utilizou-se a Irradiância Total como fator nos cálculos da cinética neste caso (ao invés do tempo), pois as reações que ocorrem no processo foto-Fenton são dependentes de uma fonte luminosa. Como a irradiância solar não é um fator que se possa controlar, em tempos diferentes podem chegar valores diferentes de potência, o que influencia na degradação final e, consequentemente, na taxa da reação. Portanto, a constante de remoção e a cinética estão em função da Irradiância Total medida. Na Tabela 18 são mostradas as constantes de taxa e os respectivos coeficientes de determinação para o MP e o PP.

Tabela 18 - Constantes cinéticas e coeficientes de determinação.

\begin{tabular}{ccc}
\hline Composto & $\boldsymbol{k}\left(\mathbf{m}^{\mathbf{2}} \mathbf{k W} \mathbf{- 1}\right)$ & $\mathbf{R}^{\mathbf{2}}$ \\
\hline MP & $1,2 \pm 0,034$ & 0,987 \\
PP & $1,1 \pm 0,042$ & 0,979 \\
\hline
\end{tabular}


Observa-se que as taxas de remoção para o MP e PP são aproximadas. Isto é esperado, pois são compostos de uma mesma classe e possuem estruturas moleculares semelhantes, além do fato de que o radical hidroxila é pouco seletivo.

\subsection{Testes Biológicos}

O teste de fitotoxicidade com sementes de Lactuca sativa indicou que as amostras não apresentaram toxicidade. Todas as amostras, inicial (solução com $100 \mu \mathrm{g} \mathrm{L}^{-1}$ de parabenos) e a final (após o tratamento), não apresentaram diferenças significativas do controle (água mineral). Isto indica uma baixa fitotoxicidade, para ambos os compostos puros, metilparabeno e propilparabeno e para seus produtos da degradação, ou seja, não houve geração de toxicidade durante o tratamento.

Semelhantemente ao teste de fitotoxicidade, o teste de atividade antimicrobiana com o efluente do reator CPC também não apresentou qualquer diferença significativa em relação ao controle. A solução inicial não apresentou atividade antimicrobiana provavelmente devido à baixa concentração dos parabenos nela. Porém, o mais importante é a ausência de produtos de degradação com essa característica.

\subsection{Comparação com outros trabalhos da literatura}

Como mostrado pela Tabela 17, as condições ótimas de degradação foram: concentração de peróxido de hidrogênio $771,6 \mu \mathrm{g} \mathrm{L}^{-1}$, concentração de ferro(III) $65,3 \mu \mathrm{g} \mathrm{L}^{-1}$ e vazão $0,9 \mathrm{~L} \mathrm{~min}^{-1}$. O estudo cinético realizado neste ponto mostrou que a remoção é praticamente completa em 50 min de reação ou quando aproximadamente $3,9 \mathrm{~kW} \mathrm{~m}^{-2} \mathrm{de}$ potência total solar chegam ao reator CPC.

Na Tabela 19 são mostrados alguns trabalhos recentes da literatura. A primeira observação a ser feita é relacionada à concentração inicial dos poluentes. Tais trabalhos 
utilizaram concentrações muito maiores do que as ambientais. Ao contrário, nesta Dissertação, a concentração inicial era $0,100 \mathrm{mg} \mathrm{L}^{-1}$, compatível com a realidade das estações de tratamento.

Tabela 19 - Comparação dos resultados obtidos com outros da literatura.

\begin{tabular}{|c|c|c|c|c|c|c|c|}
\hline Estudo & Processo & $\begin{array}{c}\text { Fonte } \\
\text { luminosa }\end{array}$ & $\begin{array}{c}\text { [Parabenos }]_{0} \\
\left(\mathrm{mg} \mathrm{L}^{-1}\right)\end{array}$ & $\begin{array}{l}{\left[\mathrm{H}_{2} \mathrm{O}_{2}\right]} \\
\left(\mathrm{mg} \mathrm{L}^{-1}\right)\end{array}$ & $\begin{array}{c}\mathrm{Fe}] \\
\left(\mathrm{mg} \mathrm{L}^{-1}\right)\end{array}$ & $\begin{array}{c}\text { Tempo } \\
(\min )\end{array}$ & $\begin{array}{c}\text { Eficiência } \\
(\%)\end{array}$ \\
\hline $\begin{array}{c}\text { Lucas e Peres } \\
(2015)\end{array}$ & Foto-Fenton & $\begin{array}{l}\text { Lâmpada } \\
\text { UVC }\end{array}$ & $\begin{array}{l}180 \text { (metil) } \\
220 \text { (propil) }\end{array}$ & 200 & 21,7 & 180 & $\geq 63$ \\
\hline Güere (2014) & Foto-Fenton & $\begin{array}{l}\text { Lâmpada } \\
\text { UVC }\end{array}$ & $\begin{array}{c}100 \\
\text { (metil) }\end{array}$ & 52 & 4 & 30 & $>99$ \\
\hline $\begin{array}{l}\text { Domínguez et } \\
\text { al. (2014) }\end{array}$ & Fenton & - & $\begin{array}{l}20 \text { (metil, etil, } \\
\text { propil e butil) }\end{array}$ & 8,9 & 1,45 & 2.880 & $>93$ \\
\hline $\begin{array}{l}\text { Zúñiga-Bení- } \\
\text { tez (2015) }\end{array}$ & Foto-Fenton & $\begin{array}{c}\text { Lâmpada } \\
\text { de Xenô- } \\
\text { nio }\end{array}$ & $\begin{array}{c}1,00 \\
\text { (metil) }\end{array}$ & 155 & 21 & 120 & $>99$ \\
\hline $\begin{array}{l}\text { Velegraki et } \\
\text { al. (2014) }\end{array}$ & $\mathrm{TiO}_{2} / \mathrm{UV} / \mathrm{H}_{2} \mathrm{O}_{2}$ & $\begin{array}{c}\text { Lâmpada } \\
\text { de Xenô- } \\
\text { nio }\end{array}$ & $\begin{array}{c}1,00 \\
\text { (metil) }\end{array}$ & 3,8 & - & 45 & $>99$ \\
\hline $\begin{array}{c}\text { Araújo } \\
\text { (2017) }\end{array}$ & Foto-Fenton & $\begin{array}{c}\text { UVA e } \\
\text { UVB } \\
\text { (Solar) }\end{array}$ & $\begin{array}{c}\mathbf{0 , 1 0 0} \\
\text { (metil e propil) }\end{array}$ & 0,77 & 0,065 & $\mathbf{5 0}$ & $>99$ \\
\hline
\end{tabular}

Em segundo lugar, é comum aos trabalhos que empregaram processos Fenton, o uso de concentrações $\left(\mathrm{mg} \mathrm{L}^{-1}\right)$ bem maiores de peróxido de hidrogênio, comparando-se com as de ferro. Em média, com o processo foto-Fenton, utilizou-se dez vezes mais peróxido de hidrogênio. Isso normalmente é necessário para privilegiar a ocorrência da oxidação em detrimento da coagulação (CHENG et al., 2018; KANG et al., 2002).

Com exceção do trabalho de Lucas e Peres (2014), todos os demais foram otimizados. Fica clara a necessidade de tal procedimento em estudos de desempenho de uma determinada tecnologia de tratamento: enquanto a eficiência do trabalho citado foi de aproximadamente $63 \%$, as eficiências dos demais foram todas acima de $90 \%$ (de fato, quatro das cinco listadas foram acima de 99\%).

Fica clara a superioridade das tecnologias fotoquímicas (fotocatálise e foto-Fenton) sobre a térmica (Fenton). Embora, para o processo térmico, se tenha conseguido uma eficiência acima de $93 \%$, o tempo necessário para atingi-la é muito grande $(2.880$ $\min$ ou $48 \mathrm{~h}$ ). 
É impossível se fazer uma comparação justa entre os resultados obtidos nesta Dissertação e os demais. Primeiramente, isso ocorre devido à diferença entre as fontes luminosas utilizadas. Algumas eram lâmpadas monocromáticas (lâmpadas UVC), que não podem ser comparadas a uma fonte com espectro de emissão contínuo, como o Sol. Outras, embora apresentem um espectro de emissão contínuo que simula o do Sol (lâmpadas de Xe), têm uma emissão constante. Tal não acontece com a luz solar, que depende de vários fatores, tais como: latitude do local onde se encontra o reator, época do ano, grau de cobertura do céu etc.

Um segundo motivo é que o reator CPC foi operado no modo de batelada com reciclo, enquanto os demais estudos utilizaram sistemas reacionais de batelada simples (sem reciclo). Esse fato dá origem a uma menor quantidade de produtos de degradação e em menor concentração, quando comparado ao modo batelada sem reciclo (LEVENSPIEL, 1999).

A única maneira possível de se fazer tal comparação seria por meio da dose de energia recebida pelos sistemas reacionais, desde que todas as fontes tivessem espectros de emissão semelhantes e parcelas de luz direta e difusa também semelhantes, o que não é o caso.

Independentemente do já exposto, pode-se dizer, a grosso modo, que os resultados aqui obtidos são semelhantes aos de Güere (2014) e de Velegraki et al. (2014), com as vantagens de se usar uma fonte luminosa sem custo e se trabalhar com um sistema que não requer operações unitárias de separação sólido-líquido. 


\section{Conclusão}

Foi possível mostrar que o processo foto-Fenton solar, usando-se um reator CPC é eficiente para a remoção simultânea de metilparabeno e propilparabeno. Para se determinar a eficiência do processo, foi fundamental o uso da Metodologia de Superfície de Resposta como ferramenta de otimização.

Digno de nota é ter-se realizado o estudo de degradação com concentrações ambientais dos parabenos, simulando-se melhor a realidade das Estações de Tratamento de Água e de Esgoto.

Por se ter usado concentrações na faixa de $\mu \mathrm{g} \mathrm{L}^{-1}$, o desafio analítico foi significativo. O uso da DLLME (Microextração Líquido-Líquido Dispersiva) mostrou-se bastante adequado como técnica de pré-concentração e extração dos analitos para posterior análise.

Ambos os parabenos apresentaram a mesma taxa de degradação. Isso deve ter sido devido à semelhança estrutural entre os dois compostos e à baixa seletividade do radical hidroxila.

Talvez mais importante que a remoção dos parabenos, tenha sido a obtenção de produtos de degradação, do efluente do reator, biologicamente inativos. Os resultados tanto de fitotoxicidade (Lactuca sativa) quanto de atividade antimicrobiana (Escherichia coli) foram negativos. 


\section{Perspectivas Futuras}

- Identificar os intermediários de degradação do processo foto-Fenton solar;

- Realizar o estudo usando-se o ferrioxalato, de forma a se trabalhar com pH próximo à neutralidade;

- Estender a aplicação do reator para outros tipos de soluções, como para esgoto simulado ou até mesmo amostras reais, retiradas de ETE ou corpos d'água espalhados na região de São Carlos;

- Realizar um estudo ecotoxicológico com outros níveis tróficos e também de atividade estrogênica. 


\section{REFERÊNCIAS}

ANDERSEN, F. A. Final amended report on the safety assessment of methylparaben, ethylparaben, propylparaben, isopropylparaben, butylparaben, isobutylparaben, and benzylparaben as used in cosmetic products. International Journal of Toxicology. v. 27 Suppl.4, p. 1-82, 2008.

BARROS NETO, B.; SCARMINIO, I.; BRUNS, R. Como fazer experimentos: aplicações na ciência e na indústria. 3. ed. Campinas: Editora da UNICAMP, 2007. 480 p.

BERTOLETTI, E. Controle ecotoxicológico de efluentes líquidos no estado de São Paulo. 2. ed. São Paulo: CETESB, 2013. 42 p.

BEZERRA, M. A.; SANTELI, R. E.; OLIVEIRA, E. P.; VILLAR, L. S.; ESCALEIRA L. A. Response surface methodology (RMS) as a tool for optimization in analytical chemistry. Talanta, v. 76, n. 5, p. 965-977, 2008.

BIRD, R. E.; HULSTROM, R. L.; LEWIS, L. J. Terrestrial solar spectral data sets. Solar Energy, v. 30, n. 6, p. 563-573, 1983.

BLEDZKA, D.; GROMADZINSKA, J.; WASOWICZ, W. Parabens from environmental studies to human health. Environment International, v. 67, p. 27-42, 2014.

BRASIL, J. L.; VAGHETTI, J. C. P.; ROYER, B.; SANTOS, A. A.; SIMON, N. M.; PAVAN, S.A.; DIAS, S. L. P.; LIMA, E. C. Planejamento estatístico de experimentos como uma ferramenta para otimização das condições de biossorção de $\mathrm{Cu}$ (II) em batelada utilizando-se casca de nozes pecã como biossorvente. Química Nova, v. 30, n.3, p. 548-553, 2007.

CANOSA, P; RODRÍGUEZ, I.; RUBÍ, E.; BOLLAÍN, M. H.; CELA, R. Optimisation of a solid-phase microextraction method for the determination of parabens in water samples at the low ng per litre level. Journal of Chromatography A, v. 1124, p. 3-10, 2006.

CASTRO, Flávia Junqueira de. Avaliação ecotoxicológica dos percolados das colunas de cinzas de carvão e de solos com cinza de carvão utilizando Lactuca sativa e Daphnia similis como organismos teste. 106f. Dissertação (Mestrado em Ciências) - Instituto Nacional de Pesquisas Espaciais, São Paulo, 2013.

CHENG, Z; YANG, B.; CHEN, Q.; JI, W.; SHEN, Z. Characteristics and difference of oxidation and coagulation mechanisms for the removal of organic compounds by quantum parameter analysis. Chemical Engineering Journal, v. 332, p. 351-360, 2018.

DARBRE, P. D.; ALJARRAH, A.; MILLER, W. R.; COLDHAM, N. G.; SAUER, M. J.; POPE, G. S. Concentrations of parabens in human breast tumors. Journal of Applied Toxicology, v. 24, p. 25-32, 2004. 
DAUCHY, X.; HAMAN, C.; ROSIN, C.; MUNOZ, J. F. Occurrence, fate and behavior of parabens in aquatic environments: a review. Water Research, v. 68, n. 1, p.1-11, 2015 .

DEJAEGHER, B.; HEYDEN, Y. V. Experimental designs and their recent advances in set-up, data interpretation, and analytical applications. Journal of Pharmaceutical and Biomedical Analysis, v. 56, n. 2, p. 141-158, 2011.

DOMÍNGUEZ, J. R.; MUÑOZ, M. J.; PALO, P.; GONZÁLEZ, T.; PERES, J. A.; CUERDA-CORREA, E. M. Fenton advanced oxidation of emerging pollutants: parabens. International Journal of Energy and Environmental Engineering, v. 5, p. 2-3, 2014.

GALINARO, C. A.; PEREIRA, F. M.; VIEIRA, E.M. Determination of parabens in surface water from Mogi Guaçu river (São Paulo, Brazil) using dispersive liquid-liquid microextraction based on low density solvent and LC-DAD. Journal of the Brazilian Chemical Society, v. 26, n.11, p.2005-2013, 2015.

GAO, Y.; AN, T.; FANG, H.; JI, Y.; LI, G. Computational consideration on advanced oxidation degradation ofphenolic preservative, methylparaben, in water: mechanisms,kinetics, and toxicity assessments. Journal of Hazardous Materials, v. 278, p. 417-425, 2014.

GONZÁLEZ-MARIÑO, I.; QUINTANA, J. B.; RODRÍGUEZ, I.; CELA, R. Simultaneous determination of parabens, triclosan and triclocarban in water by liquid chromatography/electrospray ionisation tandem mass spectrometry. Rapid Communications in Mass Spectrometry, v. 23, p.1756-1766, 2009.

GONZÁLEZ-MARIÑO, I.; QUINTANA, J. B.; RODRÍGUEZ, I.; CELA, R. Evaluation of the occurrence and biodegradation of parabens and halogenated by-products in wastewater by accurate mass liquid chromatography quadrupole time-of-flight mass spectrometry (LC-QTOF-MS). Water Research, v. 45, p. 6770-6780, 2011.

GÜERE, Carlos Dante Gamarra. Estudo da degradação do metil parabeno utilizando processos Fenton, foto-Fenton e eltro-Fenton. 2014. 83 f. Dissertação (Mestrado em Físico-Química) - Instituto de Química de São Carlos, Universidade de São Paulo, São Carlos, 2014.

GMUREK, M.; ROSSI, A. F.; MARTINS, R. C.; QUINTA-FERREIRA, R. M.; LEDAKOWICZ, S. Photodegradation of single and mixture of parabéns - kinetic, byproducts identification and cost-efficiency analysis. Chemical Engineering Journal, v. 276, p. 303-314, 2015.

HODGSON, E. Introduction to toxicology. In: HODGSON, E. (Ed.). A textbook of modern toxicology. Hoboken: John Wiley \& Sons, 2004. v. 3, p. 3-12.

HUANG, C. P.; DONG, C.; TANG, Z. Advanced chemical oxidation: its present role and potential future in hazardous waste treatment. Waste Manage, v. 13, p. 361-377, 1993. 
INTERNATIONAL UNION OF PURE AND APPLIED CHEMISTRY (IUPAC). Compendium of chemical terminology: the gold book. 2. ed. 1997. p. 32.

Disponível em: < https://goldbook.iupac.org/pdf/goldbook.pdf>. Acesso em 10 nov. 2016.

JONKERS, N.; KOHLER, H. P.; DAMMSHÄUSER, A.; GIGER W. Mass flows of endocrine disruptors in the Glatt River during varying weather conditions. Environmental Pollution, v. 157, p. 714-723, 2009.

JONKERS, N.; SOUSA, A.; GALANTE-OLIVEIRA, S.; BARROSO, C. M.; KOHLER, H. P.; GIGER, W. Occurrence and sources of selected phenolic endocrine disruptors in Ria de Aveiro, Portugal. Environmental Science and Pollution Research, v. 17, p.834-843, 2010.

KANG, S.-Y.; LIAO, C.-H.; CHEN, M.-C. Pre-oxidation and coagulation of textile wastewater by the Fenton process. Chemosphere, v. 46, p. 923-928, 2002.

KOMMINENI, S.; ZOECKLER, J.; STOCKING, A.; LIANG, S.; FLORES, A.; KAVANAUGH, M. Advanced Oxidation Processes. In: MELIN, G. (Org.). Treatment technologies for removal of methyl tertiary butyl ether (MTBE) from drinking water: air stripping, advanced oxidation processes, granular activated carbon, synthetic resin sorbents. 2. ed. Fountain Valley: Center for Groundwater Restoration and Protection, National Water Research Institute, 2000. Cap. 3. p. 109-199. Disponível em: <http://www.nwriusa.org/pdfs/1999TreatmentTechnologiesReportFullversion.pdf>. Acesso em: 01 nov. 2015.

LEBLANC, G. A. Acute toxicity. In: HODGSON, E. (Ed.). A textbook of modern toxicology. Hoboken: John Wiley \& Sons, 2004. v. 3, p. 215-224.

LEBLANC, G. A. Basics of environmental toxicology. In: HODGSON, E. (Ed.). A textbook of modern toxicology. Hoboken: John Wiley \& Sons, 2004. v.3, p. 463-478.

LEE, H.B.; PEART, T.E.; SVOBODA, M.L. Determination of endocrine-disrupting phenols, acidic pharmaceuticals, and personal-care products in sewage by solid-phase extraction and gas chromatography-mass spectrometry. Journal of Chromatography A. v. 1094, p.122-129, 2005.

LEIDY, R. B. Toxicant analysis and quality assurance principles. In: HODGSON, E. (Ed.). A textbook of modern toxicology. Hoboken: John Wiley \& Sons, 2004. v.3, p. 23-29.

LEVENSPIEL, O. Chemical reaction engineering. 3. ed. Hoboken: John Wiley \& Sons, 1999. $688 \mathrm{p}$.

LORAINE, G. A.; PETTIGROVE, M. E. Seasonal variations in concentrations of pharmaceuticals and personal care products in drinking water and reclaimed wastewater in southern California. Environmental Science Technology, v. 40, p. 687-695, 2006.

LUCAS, M. S.; PERES, J. A. Decolorization of the azo dye reactive black by Fenton and photo-Fenton oxidation. Dye and Pigments, v. 71, p. 236-244, 2006. 
LUCAS, M. S.; PERES, J. A. Removal of emergin contaminants by Fenton and UVdriven advanced oxidation processes. Water, Air \& Soil Pollution, n. 8, v. 226, 2015.

MACHULEK, A.; QUINA, F. H.; GOZZI, F.; SILVA, O.; FRIENDRICH, L. C.; MORAES, J. E. F. Fundamental mechanistic studies of the photo-Fenton reaction for the degradation of organic pollutants. In: PUZYN, T. (Ed.). Organic pollutants ten years after the Stockholm convention - environmental and analytical update. Rijeka: Intech, 2012. Disponível em: <http://www.intechopen.com/books/organic-pollutants-ten-years-after-the-stockholm-convention-environmental-and-analytical-update/fundamental-mechanistic-studies-of-the-photo-fenton-reaction-for-the-degradationof-organic-pollutan>. Acesso em: 10 out. 2015.

MALATO, S.; FERNÁNDEZ-IBÁÑEZ, P.; MALDONADO, M. I.; BLANCO, J.; GERNJAK, W. Decontamination and disinfection of water by solar photocatalysis: recent overview and trends. Catalysis Today, v. 147, n. 1, p. 1-59, 2009.

MARTINS, L. M.; SILVA, C. E.; MOITA NETO, J. M.; LIMA, A. S.; MOREIRA, R. F. P. M. Aplicação de Fenton, foto-Fenton e UV/ $\mathrm{H}_{2} \mathrm{O}_{2}$ no tratamento de efluente têxtil sintético contendo o corante Preto Biozol UC. Engenharia Sanitária e Ambiental, v. 16, n. 3, p. 261-270, 2011.

MELO, S. A. S.; TROVÓ, A. G.; BAUTIZ, I. R.; NOGUEIRA, R. F. P. Degradação de fármacos residuais por processos oxidativos avançados. Quimica Nova, v. 32, n. 1, p. 188-197, 2009.

MOTA, André Luis Novais. Desenvolvimento de um sistema foto-oxidativo visando aplicação no tratamento de águas produzidas em campos de petróleo. 2010. $175 \mathrm{f}$. Tese (Doutorado em Engenharia Química) - Departamento de Engenharia Química, Universidade Federal do Rio Grande do Norte, Natal, 2010

NAGELKERKE, N. J. D. A note on a general definition of the coefficient of determination. Biometrika, v. 78, n. 3, p.691-692, 1991.

NEYENS, E.; BAEYENS, J. A review of classic Fenton's peroxidation as an advanced oxidation technique. Journal of Hazardous Materials, v. 98, n. 1-3, p. 33-50, 2003.

NOGUEIRA, R. F. P.; TROVÓ, A. G.; SILVA, M. R. A.; VILLA, R. D.; OLIVEIRA, M. C. Fundamentos e aplicações ambientais dos processos Fenton e foto-Fenton.

Química Nova, v. 30, n. 2, p. 400-408, 2007.

ORTEGA, M. C.; MORENO, M. T.; ORDOVÁS, J.; AGUADO, M. T. Behaviour of different horticultural species in phytotoxicity bioassays of bark substrates. Scientia Horti-culturae Turae, v. 66, n. 1-2, p. 125-132, 1996.

PAXEUS, N. Organic pollutants in the effluents of large wastewater treatment plants in Sweden. Water Research, v. 30, p.1115-1122, 1996.

PERES, J. A. S.; CARVALHO, L. H. M. de; BOAVENTURA, R. A. R.; COSTA, C. A. V. Characteristics of p-Hydroxybenzoic Acid Oxidation using Fenton's Reagent. Journal of Environmental Science and Health, Part A, n. 39, p. 2897-2913, 2004. 
PIAO, C.; CHEN, L.; WANG, Y. A review of the extraction and chromatographic determination methods for the analysis of parabens. Journal of Chromatography B, v. 969, p. 139-148, 2014.

PIGNATELLO, J. J.; OLIVEROS, E.; MACKAY, A. Advanced oxidation processes for organic contaminant destruction based on the Fenton reaction and related chemistry. Critical Reviews in Environmental Science and Technology, v. 36, n. 6, p. 1-84, 2006.

ROSSI, D.; BELTRAMI, M. Sediment ecological risk assessment: in situ and laboratory toxicity testing of Lake Orta sediments. Chemosphere, v, 37, n. 14-15, p.2885-2894, 1998.

ROUTLEDGE, E. J.; PARKER, J.; ODUM, J.; ASHBY, J.; SUMPTER, J. P. Some alkyl hydroxyl benzoate preservatives (parabens) are estrogenic. Toxicology of Applied Pharmacology, v. 153, p. 12-19, 1998.

SILVA, Andréia Souto da. Avaliação da secagem do bagaço de cajá usando planejamento fatorial composto central. 83 f. Dissertação (Mestrado em Pesquisa e Desenvolvimento de Tecnologias Regionais). Universidade Federal do Rio Grande do Norte, Natal, 2008.

SONI, M. G.; TAYLOR, S. L.; GREENBERG, N. A.; BURDOCK, G. A. Evaluation of the health aspects of methyl paraben: a review of the published literature. Food and Chemical Toxicology. v. 40, p. 1335-1373, 2002.

SONI, M. G.; CARABIN, I. G.; BURDOCK, G. A. Safety assessment of esters of $p$-hydroxybenzoic acid (parabens). Food and Chemical Toxicology. v. 43, n. 7, p. 9851015, 2005.

TEIXEIRA, C. P. A. B.; JARDIM, W. F. Processos oxidativos avançados: conceitos teóricos. Caderno Temático, v. 3, p.1-83, 2004.

TERASAKI, M.; TAKERMURA, Y.; MAKINO, M. Paraben-chlorinated derivatives in river waters. Environmental Chemistry Letters, v. 10, p. 401-406, 2012.

VALENTIM, A. C. S; DEZOTTI, M. Processos e técnicas para o controle ambiental de efluentes líquidos. Rio de Janeiro: E-papers, 2008. 360 p.

VanLOON, G. W.; DUFFY, S. J. Environmental Chemistry: a global perspective. 3. ed. London: Oxford University, 2010. 560 p.

VELEGRAKI, T.; HAPESHI, E.; FATTA-KASSINOS, D.; POULIOS, I. Solar-induced heterogeneous photocatalytic degradation of methyl-paraben. Applied Catalysis B: Environmental, v. 178, p. 2-11, 2015.

ZÚÑIGA-BENÍTEZ, H.; ARISTIZÁBAL-CIRO, C.; PEÑUELA, G. A. Photodegradation of the endocrine-disrupting chemicals benzophenone-3 and methyl-paraben using Fenton reagent: optimization of factors and mineralization/biodegradability studies, Journal of the Taiwan Institute of Chemical Engineers, v. 59, p.380-388, 2015. 